

\section{MATERIALS FOR MONOLITHIC INTEGRATION OF OPTICAL FUNCTIONS ON CMOS}

Balaji Rangarajan 
The graduation committee consists of:

\begin{tabular}{|c|c|c|}
\hline Chairman: & Prof. Dr. Ir. A.J. Mouthaan & University of Twente \\
\hline Secretary: & Prof. Dr. Ir. A.J. Mouthaan & University of Twente \\
\hline Promotor: & Prof. Dr. Jurriaan Schmitz & University of Twente \\
\hline Assistant & & \\
\hline promotor: & Dr. Alexey Y. Kovalgin & University of Twente \\
\hline Referee: & Dr. Kerstin Wörhoff & University of Twente \\
\hline Members: & Prof. Dr. Ir. W.M.M. Kessels & $\begin{array}{l}\text { Eindhoven University } \\
\text { of Technology }\end{array}$ \\
\hline & Prof. Dr. Han Gardeniers & University of Twente \\
\hline & Prof. Dr. D. J. Gravesteijn & $\begin{array}{l}\text { NXP semiconductors } \\
\text { and }\end{array}$ \\
\hline & & University of Twente \\
\hline
\end{tabular}

This project was funded by the Smart Mix Programme of the Netherlands Ministry of Economic Affairs and the Netherlands Ministry of Education, Culture and Science.

PhD Dissertation: University of Twente, Enschede, The Netherlands.

Title: Materials for Monolithic Integration of Optical functions on CMOS Author: Balaji Rangarajan

ISBN: 978-90-365-0720-2

DOI: $10.3990 / 1.9789036507202$

Cover (front and back): An artistic impression of grain orientation map obtained using electron backscatter diffraction for polycrystalline germanium-silicon.

Copyright (C) 2013 Balaji Rangarajan All rights reserved. No part of this publication may be reproduced, stored in a retrieval system, or transmitted, in any form or by any means, electronic, mechanical, photocopying, recording or otherwise, in whole or in part without the prior written permission of the copyright owner.

Printed in The Netherlands. 


\title{
MATERIALS FOR MONOLITHIC INTEGRATION OF OPTICAL FUNCTIONS ON CMOS
}

\author{
DISSERTATION
}

to obtain

the degree of doctor at the University of Twente, on the authority of the rector magnificus, prof. dr. H. Brinksma,

on account of the decision of the graduation committee, to be publicly defended

on Friday the $8^{\text {th }}$ of November 2013 at 14:45

by

Balaji Rangarajan

born on $27^{\text {th }}$ October 1984

in Tambaram, Tamilnadu, India. 
This dissertation is approved by Prof. Dr. Jurriaan Schmitz (promotor) and Dr. Alexey Y. Kovalgin (assistant promotor). 


\section{Contents}

1 Monolithic integration of optical functions on CMOS .............. 1

1.1 Trends in microelectronic technology ............................... 1

1.1.1 Low temperature processing................................ 4

1.2 Optical functionality on CMOS....................................... 5

1.2.1 Project overview.................................................. 6

1.3 Photodetectors.............................................................. 7

1.3.1 Controlling crystallinity ....................................... 9

1.4 Waveguides ................................................................ 10

1.5 Outline of this thesis.................................................... 12

References................................................................... 13

2 Material characterization techniques..................................... 17

2.1 Scanning electron microscopy .......................................... 18

2.2 Electron backscatter diffraction........................................ 19

2.3 Atomic force microscopy ................................................ 22

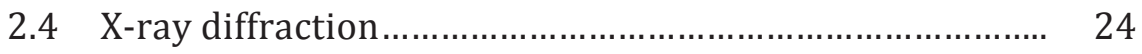

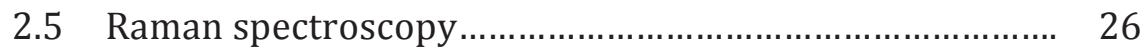

2.6 X-ray photoelectron spectroscopy................................... 27

2.7 Spectroscopic ellipsometry ............................................ 27

2.8 Fourier transform infrared spectroscopy …....................... 29

2.9 Prism coupling technique ............................................. 31

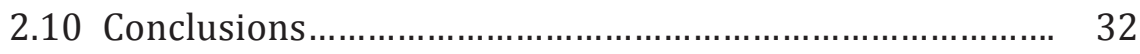

References................................................................... 32

3 Green laser crystallization and dopant activation of GeSi

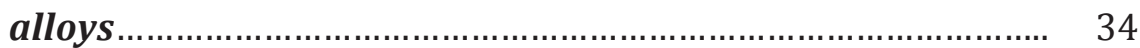

3.1 Waveguide integrated photodetector on CMOS................ 35

3.2 Deposition of GeSi films................................................ 36

3.3 Sample preparation and laser system............................. 37

3.4 Crystallization: Sequential super-lateral growth.............. 38

3.5 Control over location and density of grain boundaries.... 40

3.6 Optimization of laser process parameters........................ 40 
3.7 Material characterization and analysis............................ 42

3.7.1 Optimization of grain size and grain confinement 42

3.7.2 Grain orientation and residual stress.................. 47

3.7.3 Optical properties............................................. 52

3.8 Activation of ion-implanted dopants.............................. 56

3.9 Conclusions ................................................................ 57

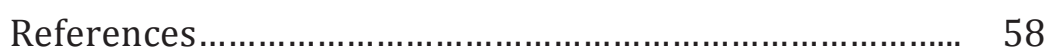

4 Low loss silicon oxynitride: Deposition and properties...... 60

4.1 Deposition system........................................................ 61

4.2 Precursor gases......................................................... 61

4.3 Experimental.......................................................... 62

4.4 Chemical modeling of plasma composition...................... 63

4.5 Understanding the influence of process parameters on $\mathrm{SiO}_{\mathrm{x}} \mathrm{N}_{\mathrm{y}}$ properties......................................................... 65

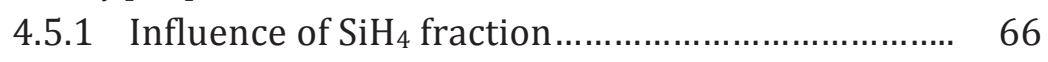

4.5.2 Influence of deposition pressure........................... 71

4.5.3 Influence of Ar-to- $\mathrm{N}_{2}$ ratio .................................... 74

4.6 Measurement of propagation losses................................ 76

4.7 FTIR analysis on Si-H and N-H bonds............................. 79

4.8 Testing CMOS compatibility on Timepix chips.................. 81

4.9 Conclusions............................................................. 82

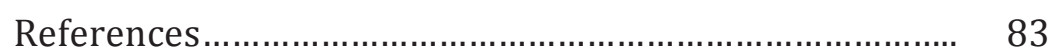

5 Conclusions and Recommendations..................................... 85

5.1 Conclusions.............................................................. 85

5.1.1 Germanium-Silicon (GeSi) ................................. 85

5.1.2 Silicon Oxynitride (SiON) .................................... 86

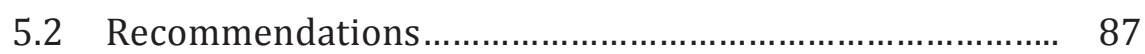

5.2.1 Germanium-Silicon (GeSi) ............................... 87

5.2.2 Silicon Oxynitride (SiON) .................................. 88

5.2.3 Fabrication of photodetectors and waveguides 88 and their integration

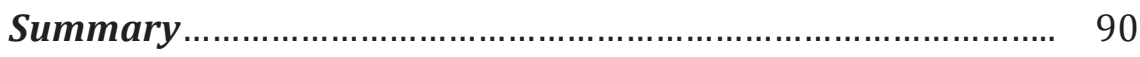

Samenvatting ................................................................. 93

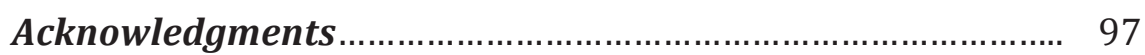




\section{Chapter 1}

\section{Monolithic integration of optical functions on CMOS}

\subsection{Trends in microelectronic technology}

Continued miniaturization of microelectronic systems has brought many advantages such as increase in the processing power and smaller footprint. Most importantly it has brought down the cost per function as shown in Fig. 1.1 improving the economic value of the microchip. This is a direct result of the tremendous advancements made in the semiconductor manufacturing industry and follows the prediction made by G. E. Moore in [1].

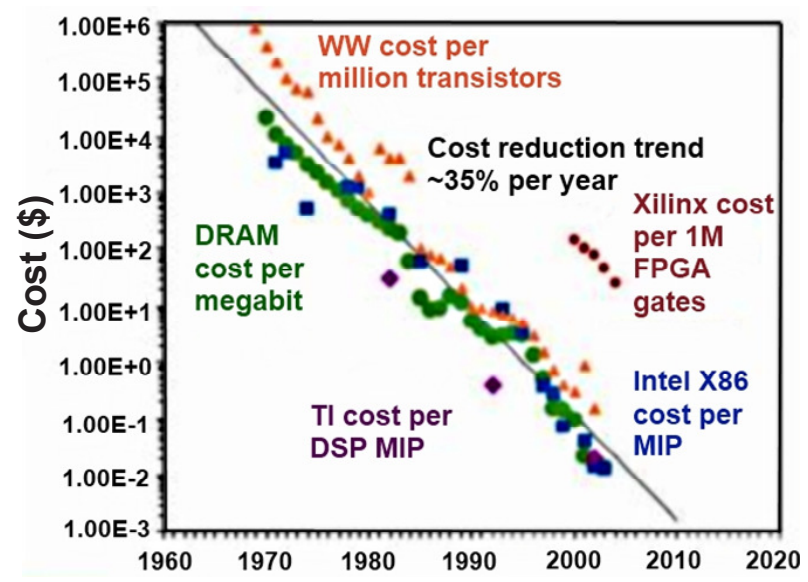

Fig 1.1: Reduction in cost per function due to miniaturization. FPGA: field-programmable gate array, DSP: digital signal processor, MIP: million instructions per second (Source of the image: www.intel.com)

Materials for Monolithic Integration of Optical Functions on CMOS 
Such advancements in technology (with Intel and Samsung at the forefront) include the introduction of new materials. For instance, in the period 1970-2005 the silicon dioxide gate dielectric in a fieldeffect transistor has been aggressively scaled down to sub-1 nm thickness [2], at which point excessive tunneling leakage prohibited further scaling. In order to solve this problem the industry turned towards dielectrics with a higher relative dielectric constant, or high$\mathrm{k}$ dielectrics, in particular hafnium based oxides [3]. However use of high-k dielectrics along with poly-silicon gate electrode brought other issues. It resulted in Fermi level pinning and degraded channel mobility [4]. This was eventually remedied by replacing the polysilicon gate electrode by metal alloys.

But even after going through such major advancements in technology the process of miniaturization in complementary metaloxide-semiconductor (CMOS), dynamic random access memory (DRAM) and flash technologies is coming to an end around the year 2018, as forecast by the International Technology Roadmap for Semiconductors [5]. Therefore it becomes necessary to look for other technologies and methodologies to further advance microelectronics.

To this end, many scientists are proposing novel devices such as gate-all-around transistors [6], nano-electromechanical field-effect transistors (FETs) [7] and tunnel FETs [8] as well as exploring new channel materials such as graphene. At the time of writing this thesis, graphene (a single atomic layer of graphite) is popularly touted as the next revolutionary material that can disrupt the semiconductor industry, with its supreme electronic and mechanical properties [9]. Other recent works exploring different materials include: transistors made of single layer molybdenite $\left(\mathrm{MoS}_{2}\right)$ [10] and transistors made of indium-gallium-arsenide [11] possibly combined with germaniumchannel transistors into high-performance CMOS [12].

Besides the search for better materials and novel devices, one can further improve a CMOS chip by adding new functionalities to it. Examples of such functionalities include sensing and actuating (both physical and chemical), energy harvesting, and optical data processing and communication.

The addition of new functionalities can be achieved either by monolithic or heterogeneous integration. The monolithic approach involves integrating all the components on a single substrate 
(normally silicon). This approach requires the fabrication processes of all components to be compatible. On the other hand heterogeneous integration involves the formation of different components on different chips and subsequently integrating them using techniques such as wafer bonding and through silicon via interconnections for $3 \mathrm{D}$ stacking. The latter integration approach relaxes the compatibility requirements considerably.

CMOS post-processing is an example of monolithic integration. New components are fabricated on top of a completed, but unpackaged CMOS chip. A wide variety of new functionalities has been stacked on CMOS in this manner, such as micro-electromechanical system (MEMS) based thermal micro-sensors [13] and solar cells for energy harvesting [14].

The digital micromirror device (DMD) [15] is a well-known commercialized example. Fig. 1.2 shows the configuration of two DMD pixels. Each pixel consists of an aluminum mirror (16 x $16 \mu \mathrm{m}^{2}$ ) held by yoke and hinges to modulate light for projecting images on screen. These micromirrors are monolithically fabricated on top of a static random access memory (SRAM) CMOS chip. The aluminum mirrors are controlled electrostatically by bits stored in the SRAM cells.

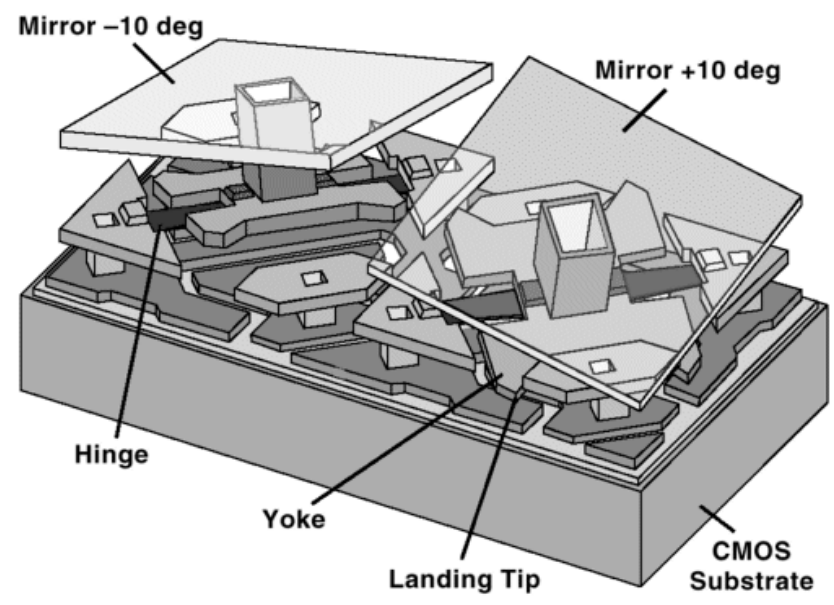

Fig 1.2: Diagram depicting two DMD pixels (Original source: reference [6], Copyright (C)1998 IEEE).

Review articles on adding functionalities on CMOS using postMaterials for Monolithic Integration of Optical Functions on CMOS 
processing can be found in reference [16, 17]. There are certain advantages to the post-processing approach. First, adding new functionalities does not require additional lateral space as it is done in the third dimension (vertical stacking). Second, this can be achieved with the current technology skill set without requiring any major disruptions and can therefore be done with low additional cost. Third, the CMOS manufacturing itself is not changed, hence the approach can exploit the standard technology and design infrastructure.

\subsubsection{Low temperature processing}

However, when post-processing a CMOS chip, we must keep it intact. A cross-section of a conventional CMOS chip is presented in Fig. 1.3. A fully processed CMOS chip contains metal lines made of aluminum or copper for interconnection. The presence of these metals particularly limits the temperature that can be applied during post-processing of CMOS chips. Typically the processing temperature is not allowed to exceed $450{ }^{\circ} \mathrm{C}$ for a few hours at most to avoid interconnect damage (see [16] and references therein). Therefore post-processing can only be done at relatively low temperatures compared to the manufacturing process of CMOS chips prior to metallization (which may go up to $1150{ }^{\circ} \mathrm{C}$ ).

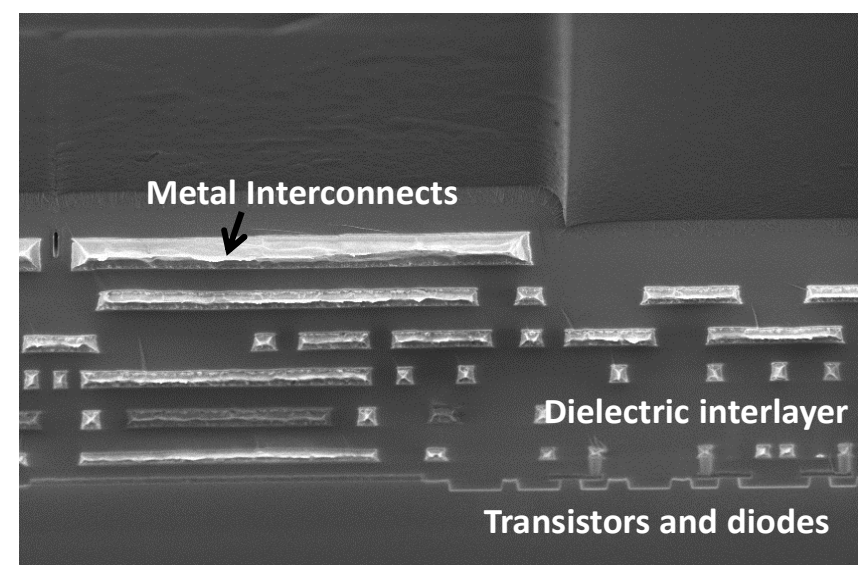

Fig 1.3: A cross-section of a CMOS chip showing its various components taken using Scanning Electron Microscope.

After post-processing, the CMOS chip is turned into a smart microsystem. To achieve competitive system performance, good quality materials are needed; the exact criteria defining the quality

Materials for Monolithic Integration of Optical Functions on CMOS 
will depend on the required systems or devices based on the application. Generally high temperature deposition techniques produce high quality films. As the deposition temperature is brought down to meet the CMOS post-processing requirement, the quality of materials is usually compromised. To reach good system specifications it is often necessary to improve the current low temperature processes such as plasma enhanced chemical vapor deposition to deliver materials with a comparable quality to those fabricated at high temperature.

\subsection{Optical functionality on CMOS}

In this thesis we focus on adding optical functionalities on CMOS. There is a wide variety of applications that can benefit from this approach. Some of the commercialized examples include (i) optical projection systems such as DMD (see section 1.1) and liquidcrystal-on-silicon [18], (ii) optical imaging systems such as CMOS active pixel sensors [19] found in digital still cameras and infrared micro-bolometer image sensors [20], and (iii) microdisplays based on organic light emitting diodes [21].

Additionally, new interesting applications are being pursued using optical waveguide sensing (on the basis of changes in the refractive index in proximity to the waveguide surface caused by external elements) for labs-on-chip. Examples include biosensors based on optical waveguide light-mode spectroscopy [22], optofluidic systems consisting of arrays of 1D photonic crystal resonators [23] and silicon photonic micro-ring resonators [24]. Apart from biosensing, in-situ monitoring of volatile compounds can also be performed using photonic micro-cantilevers (based on silicon nitride waveguides) [25].

Another important application is the (digital) data transport over optical interconnects. Such interconnects provide faster communication in comparison to their electrical counterparts [26]. This may come at the expense of higher energy usage: a proper design is important to keep the overall energy low, typically below $100 \mathrm{fJ} / \mathrm{bit}$ [27]. This amount is only weakly dependent of the crossed distance (contrary to electrical alternatives), making optical interconnects especially attractive for data communication over larger distances. On the other hand, optical interconnects have the benefit of galvanic isolation between different sections of the chip. Galvanic 
isolation is required in several applications, for instance in some medical instruments and advanced smart power electronics (that integrates CMOS and high voltage transistors), for safety and interference reasons.

\subsubsection{Project overview}

The work presented in this thesis was part of a project called MEMPHIS (Merging Electronics and Micro \& Nano Photonics in Integrated Systems - http://www.smartmix-memphis.nl/) funded by the Smart Mix Programme of the Netherlands Ministry of Economic Affairs and the Netherlands Ministry of Education, Culture and Science. The project was carried out by a consortium consisting of approx. 10 universities and 20 companies working along with approx. $30 \mathrm{PhD}$ students.

Part of this project's aim was to create complete optoelectronic building blocks for optical data transfer as shown in Fig. 1.4. Three basic blocks are studied in the project: light source, waveguide and photodetector. Work was initiated to make bright silicon-based light emitters and explore (low-temperature processed) materials for waveguides and photodetectors. The (CMOS process compatible) silicon-based light emitters produce light around $1150 \mathrm{~nm}$ wavelength and are pursued by other researchers from our group. For more details please refer to $[28,29]$.

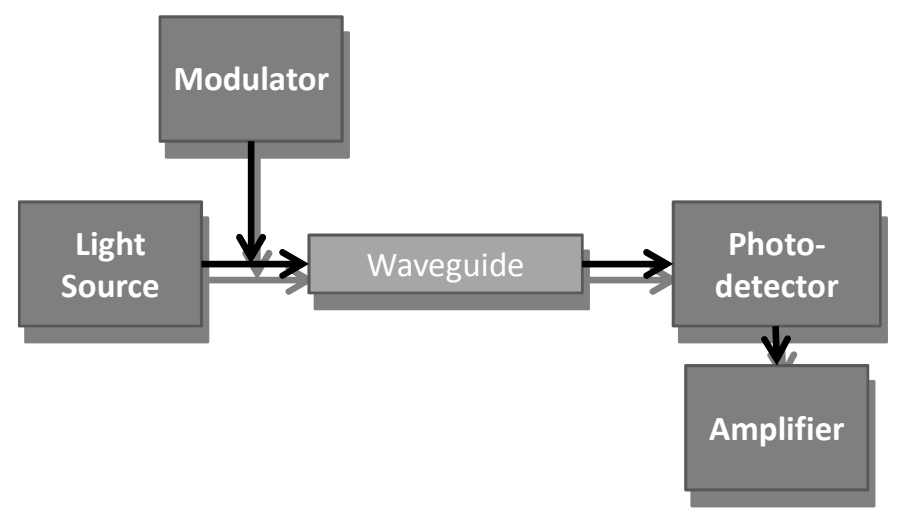

Fig 1.4: A block diagram of an optical interconnect. This thesis explores materials for waveguides and photodetectors compatible with CMOS post-processing. 
The work in this thesis involved the selection and optimization of materials and (low temperature) processes to realize waveguides and photodetectors on top of CMOS.

In much of the work presented in this thesis, we did not limit ourselves to $1150 \mathrm{~nm}$ wavelength (as produced by the silicon-based light emitters). We rather considered a wide spectrum of wavelengths ranging from visible to $1800 \mathrm{~nm}$ and aimed to work with materials which promise good properties in this range. This broadens the range of possible applications for the studied materials.

\subsection{Photodetectors}

The specific case of $1150 \mathrm{~nm}$ light detection was however our starting point. The corresponding photons (with energy of $1.08 \mathrm{eV}$ ) should be effectively absorbed by the material to generate electronhole pairs. This criterion rules out silicon. Effective production of electron-hole pairs can only occur if the energy of the photons is at least slightly larger than the band gap of the material. Silicon has a band gap of $1.12 \mathrm{eV}$ [30].

Therefore a material is needed with a band gap of $0.9 \mathrm{eV}$ or lower. III-V based compound semiconductors such as $\operatorname{InN}(0.7 \mathrm{eV})$ or InAs $(0.36 \mathrm{eV})$ [31] can easily fit the bill. However one has to keep in mind that such materials need to be compatible with the manufacturing constraints, which is not the case for III-V compound semiconductors. CMOS post-processing rules out epitaxy as well as high-temperature depositions. Considering the above two facts germanium, with a band gap of $0.67 \mathrm{eV}$ [30], can be a better choice. Germanium-based infrared photodetectors have been thoroughly discussed in the literature [32-34]. To be noted, to achieve high sensitivity, germanium photodetectors are normally made of epitaxial (mono-crystalline) germanium films grown at high temperatures. On top of an integrated circuit, we must work with amorphous or polycrystalline material instead.

Besides pure germanium, germanium-silicon (GeSi) alloys were also considered. The band gap of this alloy linearly decreases from $1.12 \mathrm{eV}(\mathrm{Si})$ to $0.67 \mathrm{eV}(\mathrm{Ge})$ with increasing germanium fraction [35]. Hence by varying the Ge to Si ratio one can cover a wide spectral range from visible to $1800 \mathrm{~nm}$ which satisfies our broader interests. GeSi alloys unlike pure Ge thus provide flexibility 
in tuning the responsivity of the photodetector for different wavelengths (see Fig. 1.6 for details). Therefore GeSi was chosen over pure Ge.

In order to determine the best $\mathrm{Ge}$ to $\mathrm{Si}$ ratio to enable a sensitive detection at $1150 \mathrm{~nm}$, Silvaco-Atlas code [36] was used to simulate $\mathrm{Ge}_{\mathrm{x}} \mathrm{Si}_{1-\mathrm{x}}$-based $\mathrm{p}$-i-n photodiodes in reverse bias $(-1 \mathrm{~V})$ (see Fig. 1.5). The fraction $x$ was varied between 0 and 1 . In the simulation the GeSi compounds were assumed mono-crystalline and unstrained. The doping concentrations of $\mathrm{p}$ - and n-type dopants were $10^{19} \mathrm{~cm}^{-3}$. The intrinsic region was uniformly irradiated with light with the angle of incidence perpendicular to the surface. The values of the refractive index and extinction coefficient for individual compositions were taken from literature [35].

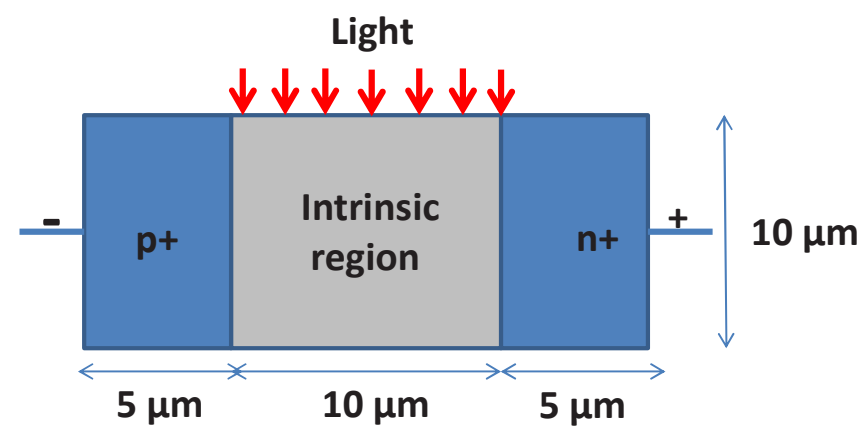

Fig 1.5: $\mathrm{Ge}_{X} \mathrm{Si}_{1-\mathrm{x}}$-based p-i-n photodiode in reverse bias (simulated using Silvaco-Atlas code). The doping concentrations of $p$ - and n-type dopants are $10^{19} \mathrm{~cm}^{-3}$. The $\mathrm{Ge}_{X} \mathrm{Si}_{1-x}$ were assumed mono-crystalline and unstrained.

The resultant trend is depicted in Fig. 1.6; the obtained values are similar to those reported in literature [37].Our simulations show that $\mathrm{Ge}_{0.85} \mathrm{Si}_{0.15}$ provides the highest responsivity at $1150 \mathrm{~nm}$ (Fig. 1.6), $0.1 \mathrm{AW}^{-1}$ higher than pure Ge.

Therefore $\mathrm{Ge}_{0.85} \mathrm{Si}_{0.15}$ was chosen for further experiments. As stated earlier, changing the composition of the GeSi material would enable tuning of peak responsivity for different wavelengths such as for $1550 \mathrm{~nm}$. We presume that a process developed for producing good quality $\mathrm{Ge}_{0.85} \mathrm{Si}_{0.15}$ films can be readily generalized to other compositions of the same material through fine-tuning of the process parameters.

Materials for Monolithic Integration of Optical Functions on CMOS 


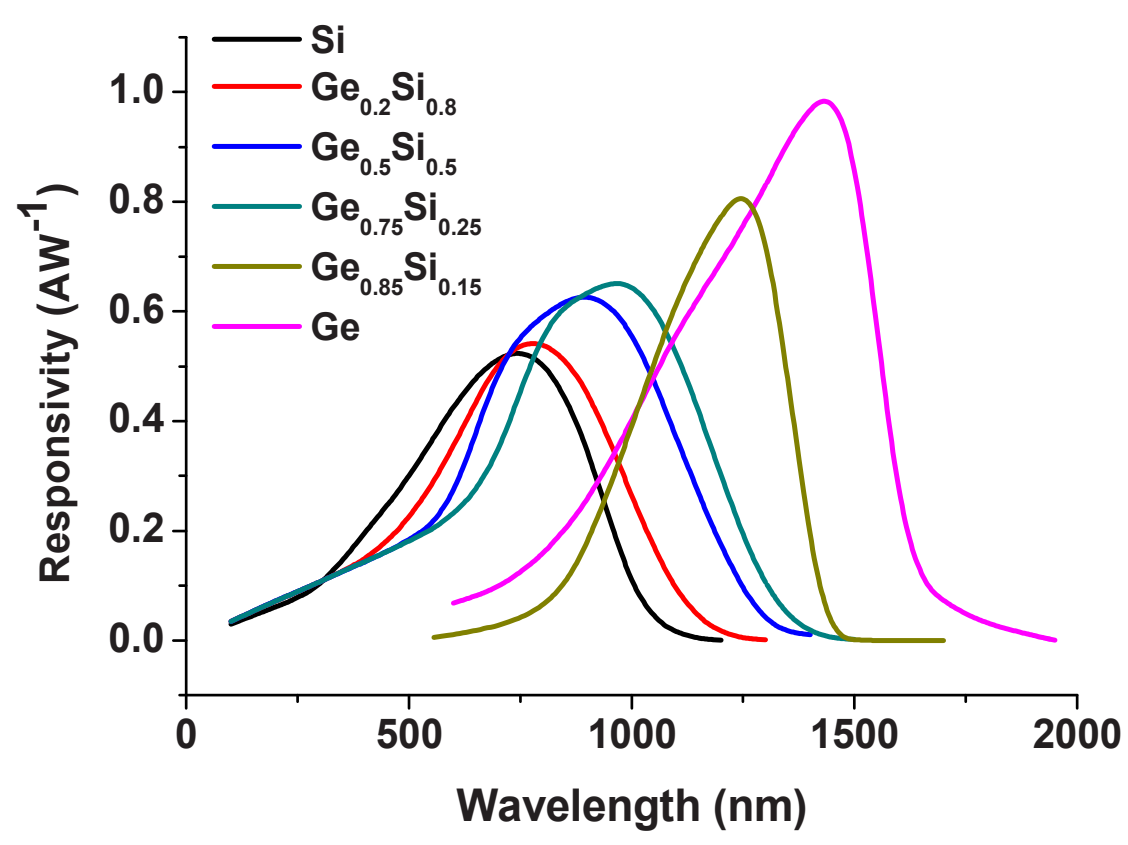

Fig 1.6: Responsivity as a function of wavelength for different compositions of $\mathrm{Ge}_{\mathrm{X}} \mathrm{Si}_{1-\mathrm{x}}$-based $\mathrm{p}$-i-n photodiodes (simulated using Silvaco-Atlas code).

To note, GeSi is a well-explored material. It has been proposed and applied in a variety of planar technologies, such as heterojunction bipolar transistors [38], strained MOS transistors [39], and even integrated photodetectors [40-42]. In recent years, polycrystalline GeSi (also denoted as $\mathrm{SiGe}$ ) is also utilized in CMOS post-processing. The material combines a low deposition temperature (around $400-450{ }^{\circ} \mathrm{C}$ ) with good mechanical and electrical properties, and it can be selectively etched. Hence it finds application as reflecting material [43], sacrificial layer [44], semiconductor [45] or conductor (when highly doped) [46] in above-CMOS microsystems as well as in RF MEMS [47, 48]. In our group GeSi has been studied since the 1990s for application in CMOS and MEMS devices [49].

\subsubsection{Controlling crystallinity}

For electronic devices such as photodiodes and thin film transistors, the material's crystallinity is of key importance. Due to 
thermal budget constraints mono-crystalline materials cannot be used in CMOS post-processing. Low temperature deposited amorphous materials can be used as an alternative. However amorphous semiconductors exhibit considerable non-idealities (such as an illdefined band gap and poor stability over time).

Poly-crystalline material can be a better alternative but it also has a drawback. In general, the grain boundaries in this material deteriorate the semiconductor behavior, for instance hindering carrier transport and providing recombination centers. When the device size comes in the same range as the crystal grain dimensions, a large device-to-device variability can occur due to the randomness in grain boundary positions [50, 51]. This causes current-voltage characteristics of similar devices fabricated on the same wafer to differ substantially. Several groups therefore study the possibilities to control the location and density of grain boundaries; in particular using the laser crystallization technique [52-56].

In this work pulsed-laser crystallization was chosen for $\mathrm{Ge}_{0.85} \mathrm{Si}_{0.15}$ films. This is used to control the grain size and its position. Relatively short laser pulses with relatively long repetition time lead to local film melting followed by film re-crystallization, while maintaining the substrate at a low temperature by avoiding sustained heating.

The majority of studies on laser crystallization of $\mathrm{Si}, \mathrm{GeSi}$ and Ge films utilize an excimer (ultraviolet) laser (e.g. [52, 57-59]). Because of the high absorption of ultraviolet light in Ge and high- $x$ $\mathrm{Ge}_{\mathrm{x}} \mathrm{Si}_{1-\mathrm{x}}$ films, such laser treatments lead to highly superficial heating of only the upper few nanometers. Apart from ultraviolet laser crystallization systems, tools with green lasers are also commercially available. A longer wavelength comes with a higher penetration depth, amounting to approx. $30-40 \mathrm{~nm}$ for green light, which significantly improves the crystallization of thicker films. In the study reported here, we employ a green pulsed laser, as a follow-up study of earlier work by I. Brunets et al. in our group on silicon crystallization.

\subsection{Waveguides}

Contrary to photodetectors, the most important criterion for a waveguide is its optical transparency. As mentioned previously, in

Materials for Monolithic Integration of Optical Functions on CMOS 
this work we chose to study a material that is not only transparent to light at $1150 \mathrm{~nm}$ wavelength but instead covers a wide spectrum of wavelengths ranging from visible to $1800 \mathrm{~nm}$. This broadens the scope of this material for other applications, including the telecommunication standard of $1550 \mathrm{~nm}$ wavelength as well as optical wavelength division multiplexing and lab-on-chip applications (they require visible wavelengths).

We consider silicon-based materials the most obvious candidates in view of their process compatibility with CMOS and $\mathrm{GeSi}$ photodetectors. Amorphous-silicon is excluded as it strongly absorbs light at visible wavelengths. The silicon-based materials meeting the transparency-range requirements are silicon dioxide, silicon nitride and silicon oxynitride. Silicon dioxide can also be excluded from this list due its low refractive index of 1.46 (at $632 \mathrm{~nm}$ wavelength). This is because a large refractive index contrast is needed between the waveguide core and its cladding layer (and further surroundings which on a CMOS chip is often silicon dioxide) for the better confinement of light.

Additionally when adding layers on top of CMOS, low mechanical stress is required for avoiding damage to the chip [16]. It has been shown in reference [60] that the mechanical stress in plasma enhanced chemical vapor deposited (PECVD) silicon oxynitride films can be lower compared to PECVD silicon nitride. Adding oxygen to the film produces less mechanical stress in comparison to oxygenfree silicon nitride.

Silicon oxynitride (or $\mathrm{SiON}$ ) can have variable refractive index, which can be tuned between $1.46\left(\mathrm{SiO}_{2}\right)$ and $2.02\left(\mathrm{Si}_{3} \mathrm{~N}_{4}\right)$ [60] (both values are for $632 \mathrm{~nm}$ wavelength). SiON with its wide transparency range (from visible to infrared wavelengths), low mechanical stress (which reduces the probability of damaging the CMOS chip) and tunable refractive index (which can be tuned to a value closer to $\mathrm{Si}_{3} \mathrm{~N}_{4}$ to reach better light confinement) was therefore chosen as the material for the waveguide.

In micro-fabrication, the deposition technologies for $\mathrm{SiON}$ are low pressure chemical vapor deposition (LPCVD) and PECVD. In both cases, a high temperature is required to obtain low optical losses: in LPCVD, the deposition temperature is typically $800{ }^{\circ} \mathrm{C}$ [61]. PECVD allows deposition well below $450{ }^{\circ} \mathrm{C}$; however, 
plasma-deposited films have a high hydrogen content in the form of $\mathrm{Si}-\mathrm{H}$ and $\mathrm{N}-\mathrm{H}$ bonds. Since these bonds cause high optical losses at wavelengths around $1500 \mathrm{~nm}$ [62], an annealing step at temperatures between $1000-1150{ }^{\circ} \mathrm{C}$ is applied for hydrogen removal [63-65]. Alternatively, for ultra-thin films $(\sim 10 \mathrm{~nm})$ plasma post-treatment at $300{ }^{\circ} \mathrm{C}$ was shown to reduce the hydrogen content [66].

In this work, we use inductively-coupled PECVD (ICPECVD) at $150{ }^{\circ} \mathrm{C}$ to deposit silicon oxynitride films. ICPECVD was chosen in combination with properly configured permanent magnets installed around reaction chamber to produce high density plasma. High density PECVD is known to provide better quality films compared to conventional PECVD. Similar work has been done by earlier researchers in our group such as producing low hydrogen content silicon nitride films [67] and high quality silicon oxide films [68] at room temperature using electron cyclotron resonance PECVD (ECRPECVD), another high density PECVD. This was later followed by deposition of high quality silicon dioxide at $150{ }^{\circ} \mathrm{C}$ using ICPECVD [69]. This layer was subsequently used as a gate dielectric in thin film transistors [70]. We apply the same ICPECVD equipment as used in $[69,70]$ for this work.

\subsection{Outline of this thesis}

The remainder of this thesis is composed as follows. In chapter 2, characterization techniques used for analyzing GeSi and SiON will be presented and their basic principles explained.

In chapter 3, crystallization of thin amorphous $\mathrm{Ge}_{0.85} \mathrm{Si}_{0.15}$ films using pulsed green laser will be discussed as well as the approaches to steer the grain growth process. Various methods for electrical activation of ion-implanted $\mathrm{p}$ - and n-type dopants in $\mathrm{Ge}_{0.85} \mathrm{Si}_{0.15}$ films will be compared.

In chapter 4, SiON films deposited using ICPECVD at $150{ }^{\circ} \mathrm{C}$ will be discussed focusing on the influence of the deposition parameters on the film properties. Optical propagation losses in the films will be measured and compared to the literature. We finally will demonstrate the survivability of a CMOS chip after deposition of the film on a chip's front surface.

Finally, conclusions will be presented and recommendations for 
future work will be given in chapter 5 .

\section{References}

1. G. E. Moore, Electronics 38, 114(1965).

2. R. Chau, J. Kavalieros, B. Roberds, R. Schenker, D. Lionberger, D. Barlage, B. Doyle, R. Arghavani, A. Murthy and G. Dewey, IEDM, 3.1.1 (2005).

3. M. T. Bohr, R. S. Chau, T. Ghani and K. Z. Mistry, IEEE Spectrum, 30 (2007).

4. R. Chau, S. Datta, M. Doczy, B. Doyle, J. Kavalieros and M. Metz, IEEE Electron Device Lett. 25, 408 (2004).

5. International Technology Roadmap for Semiconductors, www.itrs.net.

6. N. Singh, A. Agarwal, L.K. Bera, T.Y. Liow, R. Yang, S.C. Rustagi, C.H. Tung, R. Kumar, G.Q. Lo, N. Balasubramanian, and D.-L. Kwong, Electron Device Lett. 27, 383 (2006).

7. H. Kam, D. T. Lee, R. T. Howe, and T.-J. King, IEDM Technical Digest, 436 (2005).

8. P. F. Wang, K. Hilsenbeck, T. Nirschl, M. Oswald, C. Stepper, M. Weiss, D. Schmitt-Landsiedel, and W. Hansch, Solid State Electron. 48, 2281 (2004).

9. A. K. Geim and K. S. Novoselov, Nature Materials 6, 183(2007).

10. B. Radisavljevic, A. Radenovic, J. Brivio1, V. Giacometti and A. Kis, Nature Nanotech. 6, 147 (2011).

11. J. J. Gu, X. W. Wang, J. Shao, A. T. Neal, M. J. Manfra, R. G. Gordon and P. D. Ye, Device Research Conference, (2012).

12. M. Heyns, A. Alian, G. Brammertz, M. Caymax, Y.C. Chang, et al., IEDM, 13.1.1 (2011).

13. H. Baltes, O. Paul and O. Brand, Proc. IEEE 86, 1660 (1998).

14. J. Lu, A.Y. Kovalgin, K.H.M. van der Werf, R.E.I. Schropp, J. Schmitz, IEEE Trans. Electron Devices 58, 2014(2011).

15. P. F. Van Kessel, L. J. Hornbeck, R. E. Meier and M. R. Douglass, Proc. IEEE 86, 1687 (1998).

16. J. Schmitz, Nucl. Instr. Meth. A 576, 142(2007).

17. J. Schmitz, Future trends in microelectronics, (Wiley, 2013), p. 110-119.

18. LCoS special issue, Displays 23, 87 (2002).

19. E.R. Fossum, IEEE Trans. Electron Devices 44, 1689 (1997). 
20. B.E. Cole, R.E. Higashi, R.A. Wood, Proc. IEEE 86, 1679 (1998).

21. W.E. Howard, O.F. Prache, IBM J. Research and Development 45, 115 (2001).

22. A. Székács, N. Adányi, I. Székács, K. Majer-Baranyi and I. Szendrö, Appl. Opt. 48, B151 (2009).

23. S. Mandal and D. Erickson, Opt. Express 16, 1623 (2008).

24. A. L. Washburn, L. C. Gunn and R. C. Bailey, Anal. Chem. 81, 9499 (2009).

25. K. Misiakos, I. Raptis, A. Gerardino, H. Contopanagos, M. Kitsara, Lab Chip 9, 1261(2009).

26. M. R. Feldman, S. C. Esener, C. C. Guest, and S. H. Lee, Appl. Opt. 27, 1742 (1988).

27. D. A. B. Miller, Proc. of the IEEE 97, 1166 (2009).

28. G. Piccolo, A. Y. Kovalgin and J. Schmitz, Solid-state Electronics 74, 43 (2012).

29. V. P. Palackavalapil and R. J. E. Hueting, IEEE Trans. on Electron Devices 59, 26 (2012).

30. R. Braunstein, A.R. Moore, F. Herman, Phys. Rev. 109, 695 (1958).

31. http://www.ioffe.rssi.ru/SVA/NSM/Semicond/

32. G. Masini, S. Sahni, B. Analui, G. Capellini, J. Witzens, and C. Gunn, ECS Trans. 16, 601 (2008).

33. S. Assefa, S. Shank, W. Green, M. Khater, E. Kiewra, et al., IEDM, postdeadline session 33.8 (2012).

34. M. Rouvière, M. Halbwax, J. L. Cercus, E. Cassan, L. Vivien, D. Pasca, M. Heitzmann, J. M. Hartmann, D. Bouchier, S. Laval, Proc. of SPIE 5453, 142 (2004).

35. E. Kasper, Properties of Strained and Relaxed Silicon Germanium, (Inspec, 1995), p. 123-129.

36. Silvaco Atlas Manual, $\mathrm{http} / / / \mathrm{www}$. silvaco.com/products/device_simulation/atlas.htm 1

37. J. Wang and S. Lee, Sensors 11, 696 (2011).

38. A. Pruijmboom, C.E. Timmering, J. M. L. van Rooij-Mulder, D. J. Gravesteijn, W. B. de Boer, W. J. Kersten, J. W. Slotboom, C.J. Vriezema, R. de Kruif, Microelectronic Eng. 19, 427(1992).

39. S. Datta, J. Brask, G. Dewey, M. Doczy, B. Doyle, B. Jin, J. Kavalieros, M. Metz, A. Majumdar, M. Radosavljevic and R. Chau, IEEE BCTM 10.2, 194(2004).

40. J. Liu, D. Pan, S. Jongthammanurak, K. Wada, L. C. 
Kimerling, and J. Michel, Opt. Express 15, 623(2007).

41. A. Splett, T. Zinke, K. Petermann, E. Kasper, H. Kibbel, H.-J. Herzog and H. Presting, IEEE Photonics Technol. Lett. 6, 59(1994).

42. B. Jalali, A. F. J. Levi, F. Ross and E. A. Fitzgerald, Electronics Lett. 28, 269 (1992).

43. A. Witvrouw, L. Haspeslagh, O. V. Pedreira, J. De Coster, I. De Wolf, et al., J. Microelectromechanical systems 19, 202 (2010).

44. Y.K. Choi, T.J. King, and C. Hu, IEEE Trans. Electron Devices 49, 436 (2002).

45. G. Höck, E. Kohn, C. Rosenblad, H. von Känel, H.-J. Herzog and U. König, Appl. Phys. Lett. 76, 3920 (2000).

46. T.J. King, J. P. McVittie, K. C. Saraswat, and J. R. Pfiester, IEEE Trans. Electron Devices 41, 228 (1994).

47. S. A. Bhave, B. L. Bircumshaw, W. Z. Low, Y-S Kim, A. P. Pisano, T.J. King, and R. T. Howe, Solid-State Sens., Actuator and Microsystems Workshop, p. 34-37 (2002).

48. S. N. R. Kazmi, T. Aarnink, C. Salm, and J. Schmitz, IEEE Frequency Control Symposium, (2012).

49. A.Y. Kovalgin, J. Holleman, C. Salm, and P. Woerlee, Thin Film Transistor Technol. V: Proc. of the International Symposium 2000, 269 (2001).

50. J.G. Fossum and A. Ortiz-Conde, IEEE Trans. Electron Devices 30, 933 (1983).

51. A.K. Ghosh, C. Fishman, and T. Feng, J. Appl. Phys. 51, 446 (1980).

52. G.K Celler, J. Cryst. Growth 63, 429 (1983).

53. P. C. van der Wilt, B. D. van Dijk, G. J. Bertens, R. Ishihara, and C. I. M. Beenakker, Appl. Phys. Lett. 79, 1819 (2001).

54. C.-H. Kim, I.-H. Song, W.-J. Nam, and M.-K. Han, IEEE Electron Device Lett. 23, 315 (2002).

55. L. Mariucci, A. Pecora, R. Carluccio, and G. Fortunato, Thin Solid Films 383, 39 (2001).

56. T.-K. Chang, C.-W. Lin, C.-C. Tsai, J.-H. Lu, B.-T. Chen, and H.-C. Cheng, Electrochem. Solid-State Lett. 8, G14 (2005).

57. H. J. Kim and J. S. Im, Appl. Phys. Lett. 68, 1513 (1996).

58. S. Sedky, M. Gromova, T. Van der Donck, J-P. Celis, A. Witvrouw, Sens. Actuators, A 127, 316 (2006).

59. T. Sameshima, H. Watakabe, H. Kanno, T. Sadoh, M. Miyao, Thin Solid Films 487, 67 (2005).

60. C. M. M. Denisse, K. Z. Troost, J. B. Oude Elferink, F. H. P. 
M. Habraken, W. F. van der Weg and M. Hendriks, J. Appl. Phys. 60, 2536 (1986).

61. A. E. T. Kuiper, S. W. Koo, F. H. P. M. Habraken, and Y. Tamminga, J. Vac. Sci. Technol. B 1, 62 (1983).

62. J. Aarnio, P. Heimala, M. Del Giudice, and F. Bruno, Electron. Lett. 27, 2317 (1991).

63. F. Bruno, M. del Guidice, R. Recca, and F. Testa, App. Opt. 30, 4560 (1991).

64. A. Melloni, R. Costa, P. Monguzzi, and M. Martinelli, Opt. Lett. 28, 1567 (2003).

65. R. Germann, H. W. M. Salemink, R. Beyeler, G. L. Bona, F. Horst, I. Massarek, and B. J. Offrein, J. Electrochem. Soc. 147, 2237 (2000).

66. V. M. Kodach, J. Kalkman, D. J. Faber, and T. G. van Leeuwen, Biomed. Opt. Express 1, 176 (2010).

67. G. I. Isai, J. Holleman, H. Wallinga and P. H. Woerleeb, J. Electrochem. Soc. 151, C649 (2004).

68. A. Y. Kovalgin, G. Isai, J. Holleman and J. Schmitz, J. Electrochem. Soc. 155, G21 (2008).

69. A. Boogaard, A.Y. Kovalgin, I. Brunets, A.A.I. Aarnink, J. Holleman, R.A.M. Wolters and J. Schmitz, Surf. Coat. Tech. 201, 8976 (2007).

70. I. Brunets, J. Holleman, A.Y. Kovalgin, A. Boogaard, J. Schmitz, IEEE Trans. Electron Devices 56, 1637 (2009). 


\section{Chapter 2}

\section{Material Characterization Techniques}

This chapter summarizes the characterization techniques used in the later chapters. A scanning electron microscope was used for imaging the material. Crystallographic information was obtained using electron backscatter diffraction and $X$-ray diffraction. Atomic force microscopy was used for measuring surface roughness. Fourier transform infrared spectroscopy and Raman spectroscopy were used for the identification of different vibrational modes of group of atoms in the material. $X$-ray photoelectron spectroscopy was employed for the determination of elemental composition of the material. Spectroscopic ellipsometry was employed for the determination of refractive index and extinction coefficient. Finally, propagation losses were measured using prism coupling. 


\subsection{Scanning electron microscopy}

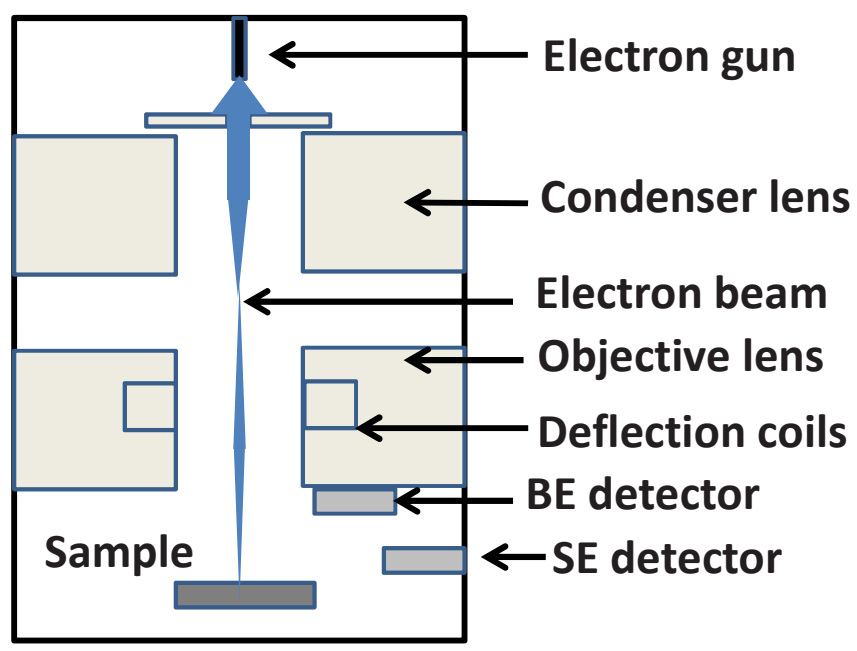

Fig 2.1: A schematic diagram of a scanning electron microscope.

Scanning electron microscopy (SEM) [1] is a very popular method and frequently used to produce images at micro- and nanoscale by scanning the samples using an electron beam in a vacuum chamber. The electrons are typically generated using a tungsten filament by the process of thermionic emission or by using a cold cathode field emission source in case of high resolution SEM.

The resulting beam of electrons is directed towards the sample using a set of condenser and objective lenses. Deflection coils are used to scan the sample surface. The energy of an electron beam can vary anywhere between a few $\mathrm{keV}$ to tens of $\mathrm{keV}$ depending on the imaging requirements.

When these high energy electrons impact the sample, they interact with the atoms in the volume of the sample leading to scattering and absorption. This results in the emission of secondary electrons (SE) along with some backscattered (BE) electrons. These electrons are captured by detectors and this information is then transferred to a computer program which constructs the image of the sample. A schematic diagram of a SEM setup is shown in Fig. 2.1.

Sample preparation for SEM can be very minimal. However

Materials for Monolithic Integration of Optical Functions on CMOS 
electrically insulating samples need to have conductive coating (or another discharging mechanism) in order to avoid charge build up as it can disrupt the imaging of the sample.

In this thesis a Zeiss-Merlin high resolution SEM was used to visualize the grains in germanium-silicon films using an in-lens detector (a SE detector placed in the electron column of the microscope instead of the usual position shown in Fig. 2.1). In-lens detectors are able to collect secondary electrons with extreme efficiency helping in producing better quality images.

In a polycrystalline material the electrons are backscattered differently based on the different grain orientations. This leads to different shades of grey in the resultant image, termed channeling contrast imaging [2]. This technique cannot be used to effectively distinguish different grains or obtain other kind of crystallographic information. For an in-depth analysis on the crystallinity of a material, electron back scatter diffraction (see section 2.2), another technique based on SEM, is usually preferred.

Additionally SEM was also used to obtain a cross-sectional view of germanium-silicon films and silicon oxynitride films deposited on top of CMOS (charge build up in this case was avoided by applying a conductive silver paint along one side of the chip). The cross-sectional view provided the necessary information about the thickness of the films as well as their surface roughness.

The lateral resolution of this system was approximately $10 \mathrm{~nm}$ with a probe current reaching up to $300 \mathrm{nA}$. The acceleration voltage can be varied from $20 \mathrm{~V}$ to $30 \mathrm{kV}$.

\subsection{Electron backscatter diffraction}

Electron backscatter diffraction (EBSD) [3] is a highly useful method that can be applied to derive crystallographic information of a (poly) crystalline material such as crystal orientation, grain sizes and grain boundaries.

An EBSD setup consists of a phosphorus screen, lens and a CCD camera (with a typical resolution of $640 \times 480$ pixels) and is attached to a SEM. The sample is loaded on to a stage in the SEM and the stage is angled at $70^{\circ}$ from the horizontal plane with the 
sample surface facing the phosphorous screen as shown in Fig. 2.2. This high angle is required for high contrast of the captured image. The probing distance in a sample can be up to 50 to $70 \mathrm{~nm}$.

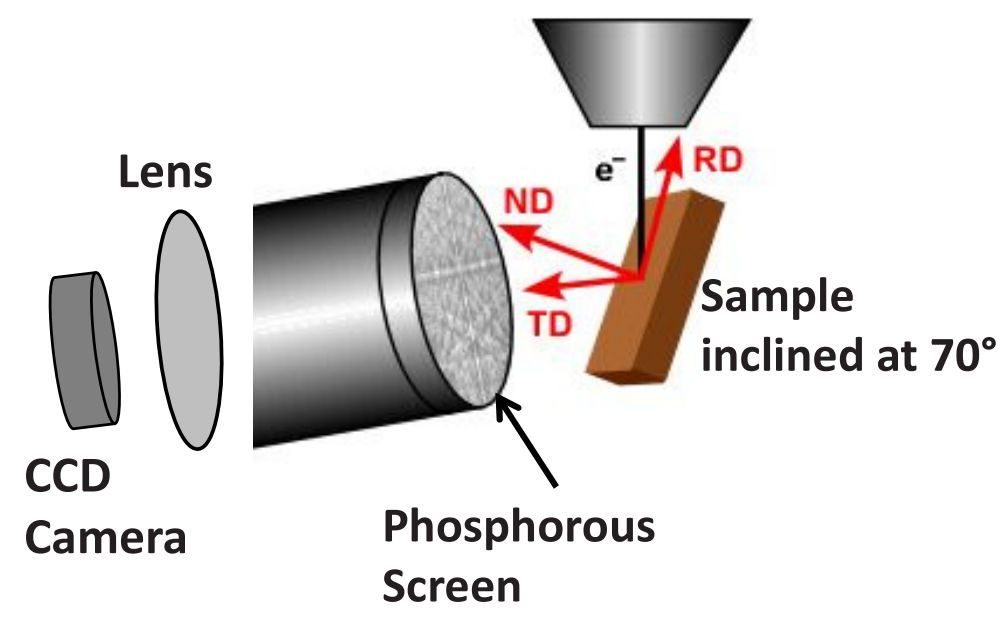

Fig 2.2: A schematic diagram of EBSD measurement. RD Rolling direction, TD - Transverse direction, ND - Normal direction.

One of the requirements for a successful measurement is to have low surface roughness (less than $3 \mathrm{~nm}$ RMS) to avoid degradation of the image quality. Surface polishing is therefore commonly employed in case of higher roughness.

When the electrons impinge on the sample, some electrons satisfying Bragg's condition are backscattered and escape the sample (see section 2.4). These electrons emanate as a pair of diffraction cones corresponding to each lattice plane and are intercepted by the phosphorus screen to create an image. The region formed between each individual pair of diffraction cones on the phosphorus screen is called a Kikuchi band [3] (see Fig. 2.3a depicting the formation of a single Kikuchi band). Since the diffraction cones have an extremely large angle the edges of the Kikuchi bands appear straight in the image. The width of the Kikuchi band is inversely proportional to the lattice spacing $d$. The image appearing in the phosphorus screen is then coupled to the CCD camera using the lens. An example of such a diffraction pattern with multiple Kikuchi bands is shown in Fig. 2.3b. Each of the Kikuchi bands can be referred back to a crystal 
plane which produced it and therefore can be categorized using Miller indices.

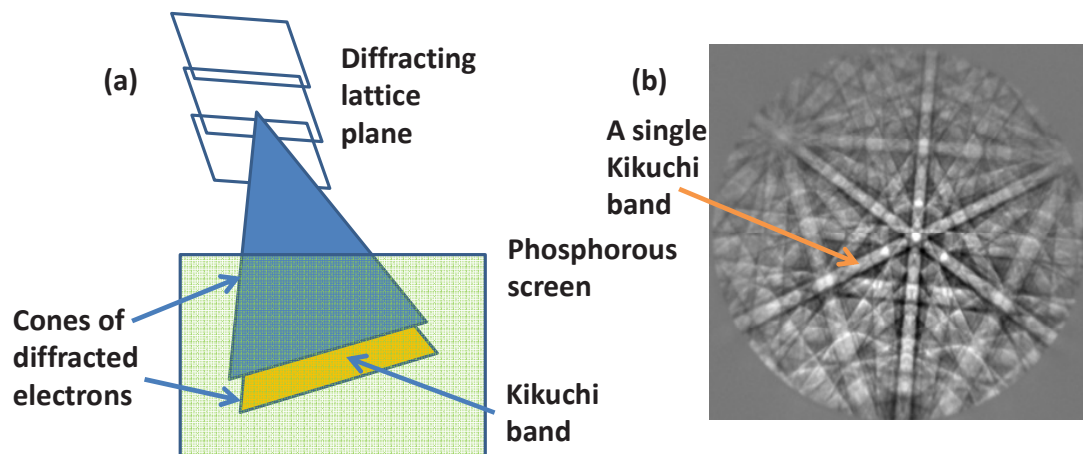

Fig 2.3: (a) A simple sketch showing the formation of a single Kikuchi band (b) An example of an electron backscatter diffraction pattern showing multiple Kikuchi bands representing different lattice planes.

In order to obtain a crystal orientation map, the sample can be scanned using a grid of points and fed to data analysis software. An example of such a map is shown in Fig. 2.4. In this image the crystal orientation is mapped using different colors and each color is allocated according to its position in the inverse pole figure (IPF) shown as an inset to the Fig. 2.4 (for example the red color indicates to (001) crystal face). The electrically-active grain boundaries are shown as dark blue lines and electrically-inactive twin boundaries (caused by symmetrical sharing of same lattice points by two different grains with $60^{\circ}$ misorientation) are represented as yellow lines. Statistical information such as the distribution of grain sizes can also be determined from data as visualized in Fig. 2.4. In addition $\alpha$ - the angle between a crystallographic plane and the sample surface (see Fig. 2.7), can also be determined using EBSD.

In this thesis EDAX's TEAM ${ }^{\mathrm{TM}}$ EBSD Analysis System which includes the OIM ${ }^{\mathrm{TM}}$ Data Analysis software was used to obtain the crystallographic information of germanium-silicon films such as crystal orientation, position of grains and grain boundaries as well as the distribution of grain sizes. 


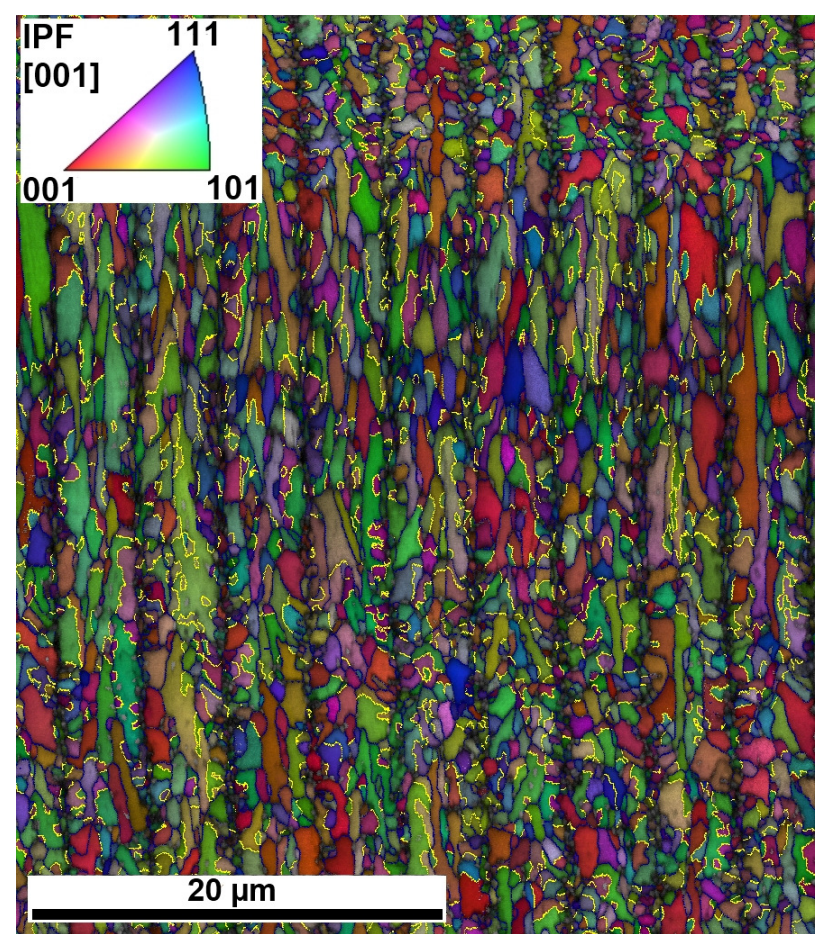

Fig 2.4: An example of a grain orientation map including the grain boundaries obtained using EBSD as seen along the normal direction (ND). The crystal orientation is mapped based on different colors and each color is allocated according to its position in the inverse pole figure (IPF) shown as an inset to the figure.

\subsection{Atomic force microscopy}

Atomic force microscopy (AFM) [4] is commonly used for studying the sample surface morphology. The scanning probe of an AFM consists of a cantilever which has an extremely sharp tip at the end. See Fig. 2.5 for a schematic sketch of an entire AFM setup. The radius of curvature of this tip is typically in the range of a few nanometers. This radius is commonly the determining factor in the lateral resolution of the AFM image. The lateral resolution of the system can reach up to $1 \mathrm{~nm}$ while the vertical resolution can go up to $0.1 \mathrm{~nm}$. The cantilever can be made of different materials depending on the mode of measurement and sample under study. The displacement of the tip is measured using a laser light that gets 
reflected from the top side of the cantilever to a set of photodetectors.

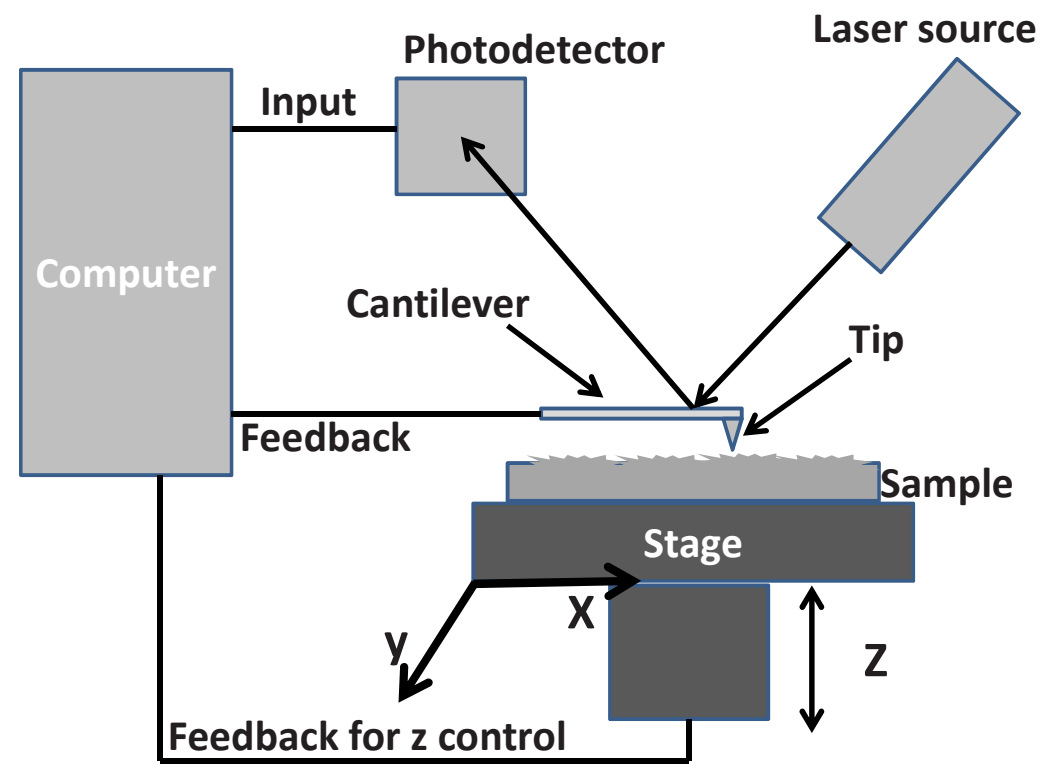

Fig 2.5: A schematic sketch of an atomic force microscope.

Three different modes of measurement are commonly employed for surface mapping. In contact mode the tip touches the sample surface and is then freely scanned across. The deflections of the tip are directly measured giving the required information. This measurement can also be done where the height of the tip is constantly adjusted to maintain a constant force using the feedback system. In this case the adjustment provides information about the sample surface.

Under non-contact mode the tip of the cantilever, oscillating at its resonant frequency, is brought close to the surface of the sample wherein forces (such as van der Waals forces) are exerted on the tip causing a change in its resonant condition. These changes are in turn detected and analyzed. Tapping mode is a kind of non-contact mode where the tip intermittently touches the sample. The advantage of this mode over the previous one is in getting better lateral resolution.

A Digital Instruments Dimension 3100 AFM was used under contact mode in this thesis for the measurement of the surface 
roughness of germanium silicon films.

\subsection{X-ray diffraction}

$\mathrm{X}$-ray diffraction (XRD) [5] is a very common technique that is used to obtain the crystallographic information of a (poly) crystalline material. This technique is based on the fact that a (poly) crystalline material contains many parallel crystallographic planes. When the samples are irradiated with X-rays, the irradiation interacts with the atoms in those crystallographic planes and is scattered back (with either constructive or destructive interference) as shown in Fig. 2.6, where $d$ is the distance between the crystallographic planes and $\theta$ is the angle of incidence with respect to the crystallographic planes.

Under Bragg's conditions as described by the following formula,

$2 d \sin \theta=n \lambda$,

where $n$ is a positive integer number indicating the given order, the scattered X-rays interfere constructively and are detected by the Xray detector giving a strong output signal. Otherwise destructive interference of the scattered X-rays prevails with a low output from the detector.

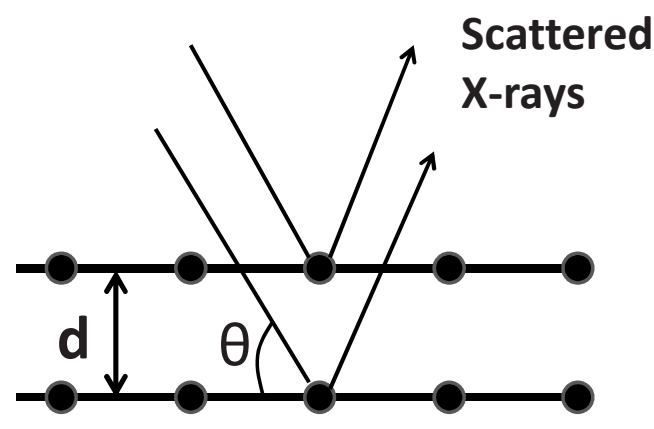

Fig 2.6: A schematic diagram showing Bragg diffraction.

Typically a $\theta-2 \theta$ scan is performed on the samples to analyze the crystallographic planes that are parallel to the surface (making $\omega=\theta$ with $\alpha=0$, where $\omega$ - incidence angle of the source to the sample surface and $\alpha$ - the angle between the crystallographic plane and the sample surface, see Fig. 2.7). In this case both the Xray source and the detector are aligned at $\theta$ to the sample surface and 
the sample is probed for various $\theta$. The result is plotted as detector counts versus $2 \theta$, a standard output for XRD. This plot can then be compared to a database and peaks appearing in the spectrum can be related to the various crystal faces present in the (poly) crystalline material such as (100), (111) or (311).

Polycrystalline materials also have crystallographic planes that are oriented at different angles $\alpha$ with respect to the sample surface (making $\omega \neq \theta$ ). In order to probe such planes grazing incidence angle XRD (GAXRD) can be performed using fixed low incidence angle $\omega$ typically ranging between $0.5^{\circ}$ to $5^{\circ}$ (see Fig. 2.7). The low incidence angle in GAXRD limits the X-ray penetration, so any angular dependence can also be used to resolve depth information.

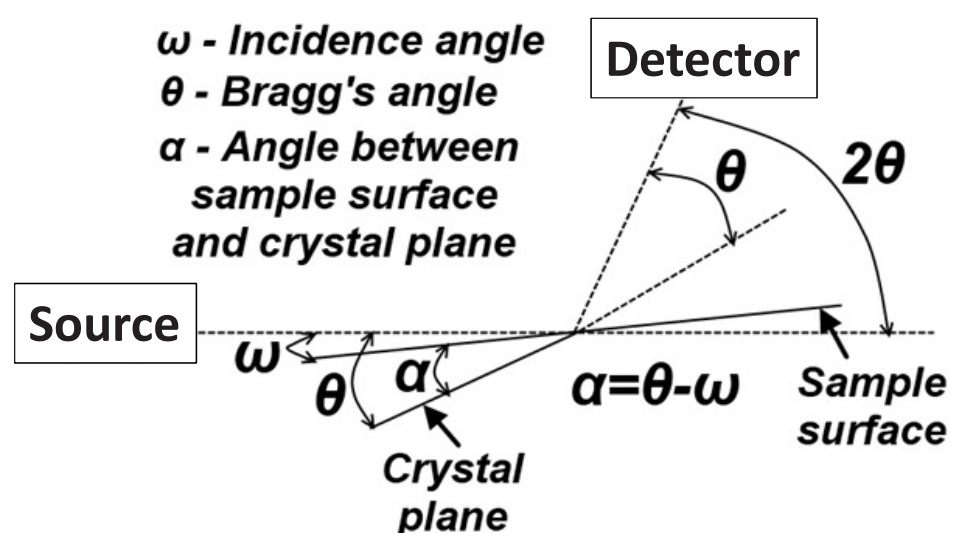

Fig 2.7: A schematic diagram showing GAXRD and different angles used in XRD.

Additionally strain in a particular crystallographic plane can be detected using XRD. Strain causes shift in the peak due to the change in $d$. From Eq 2.1 it can be noted that $d$ is inversely proportional to $\sin \theta$. Therefore a decrease in $d$ causes the peak to shift to higher $2 \theta$ whereas the opposite is observed for an increase in $d$.

In this thesis a Philips X'pert XRD II with a $2 \theta$ resolution of $0.02^{\circ}$ was used for determining the different crystal faces of the germanium-silicon films using both $\theta-2 \theta$ and GAXRD scan. Additionally the impact of laser crystallization on the strain in the GeSi layer was measured and quantified with this system. 


\subsection{Raman spectroscopy}

Raman spectroscopy [6] allows for observing vibrations of group of atoms ${ }^{1}$ in a material. This technique relies on the principle of Raman scattering i.e. the inelastic scattering of photons in a material (inelastic meaning that the energy of the photon changes during the scattering event). The vast majority of the photons scatter elastically ("Rayleigh scattering"). However some atoms may absorb the photon and fall back to an energy state that is either higher or lower than their original state. This causes the energy of the scattered photons to be either lower or higher than the incident ones, respectively. These two cases are called stokes an anti-stokes Raman scattering respectively. The anti-stokes Raman scattering is usually weaker than stokes Raman scattering.

Raman spectroscopy is challenging because the Rayleigh emission peak is much stronger than the nearby Raman peaks of interest. A variety of techniques is employed to isolate the shifted peaks. The resultant plot from this measurement contains Raman intensity (of scattered photons) for various atomic bonds as a function of wavenumber $(1 / \lambda)$.

For a material to be Raman-active, a change in polarizability should occur during vibration. This is different to infrared vibration where a net change in the permanent dipole moment is necessary. Hence FTIR and Raman spectroscopy can provide complementary information.

Raman spectroscopy is widely used for determining the strain in a material. Strain causes change in the inter-atomic distance and this in turn affects the vibrations. If the inter-atomic distance is reduced this causes the Raman peak to shift to lower wavenumbers. The opposite effect is seen if the inter-atomic distance is increased. This information can be used for determining the strain in a material.

In this thesis the Alpha300R confocal Raman microscope from Witech $\mathrm{GmbH}$ was used to observe the existence of strain in germanium-silicon films. The wavelength of the laser is $532 \mathrm{~nm}$. The resolution of the system is $0.8 \mathrm{~cm}^{-1}$.

\footnotetext{
${ }^{1}$ In this work we use the general term "group of atoms" to indicate molecules, molecular groups, and crystals. The more common term "molecular vibrations" is not always accurate in the context of the present work.
}

Materials for Monolithic Integration of Optical Functions on CMOS 


\subsection{X-ray photoelectron spectroscopy}

X-ray photoelectron spectroscopy (XPS) [7] is used for determining the elemental composition of the material. The principle behind this technique is simple. The material is irradiated with X-rays under high vacuum conditions and as a result electrons are emitted from the surface of the material. The kinetic energy and number of electrons emitted from the uppermost few $\mathrm{nm}$ of the material are monitored including their angular distribution. The binding energy is determined using the X-ray photon energy, electron kinetic energy and work function of the spectrometer. When the binding energy of the electrons is plotted against the number of detected electrons, this provides the XPS spectrum. The peaks appearing in the XPS spectra depend distinctively on the element and its electron configuration (i.e. its chemical bonding to other elements).

In order to acquire depth information of a sample, Ar sputtering is often performed in order to drill into the material in steps (the number of steps can be altered depending on the requirement) and analyze the sample at every step. The atomic concentration of an element can be determined by dividing the peak area with a relative sensitivity factor and normalize over all elements detected.

In this thesis a PHI Quantera SXM XPS (with Al Ka X-ray source producing a monochromatic beam at $1486.6 \mathrm{eV}$ with a minimum beam size of $9 \mu \mathrm{m}$ ) was used to determine the elemental composition of germanium-silicon and silicon oxynitride films. The accuracy of XPS is $\pm 10 \%$ of the measured atomic concentration.

\subsection{Spectroscopic ellipsometry}

Spectroscopic ellipsometry (SE) [8] is a popular method to determine the refractive index $n$ and extinction coefficient $k$ of thin material films. SE unlike a single wavelength ellipsometry uses a spectrum of wavelengths ranging from UV to mid-infrared for analysis. SE detects the changes in the polarization of the light in terms of amplitude ratio $\psi$ and phase difference $\Delta$ as the light gets reflected from the sample surface and reaches the detector. This information is used to determine the values of $n$ and $k$ as a function of wavelength. The schematic setup of SE is shown in Fig. 2.8. 


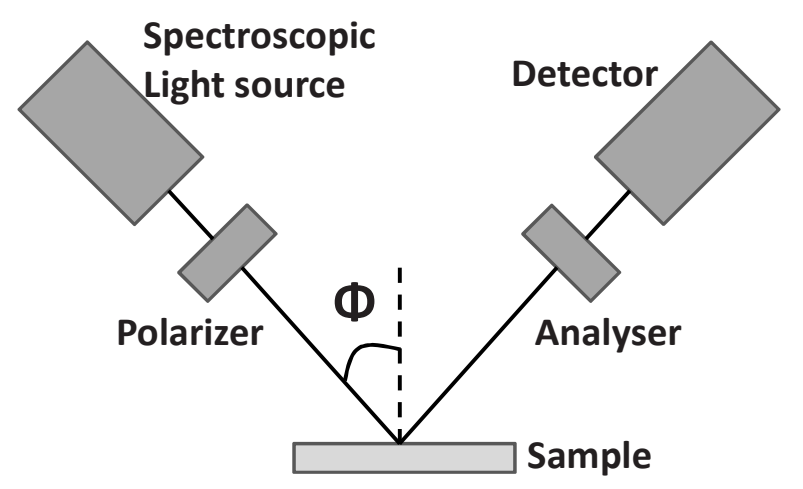

Fig 2.8: A schematic setup of spectroscopic ellipsometry

The Tauc-lorentz (TL) model developed by Jellison and Modine as described in [9] is commonly applied to analyze SE data for amorphous semiconductors and dielectrics. It is used in this thesis for the determination of $n$ and $k$. This is done by first fitting the generated $\psi$ and $\Delta$ values using the TL model to the values measured using SE. Upon a proper fit, the following four parameters are determined: the Tauc gap or optical band gap $E_{g}[8,9]$, the peak transition energy $E_{0}$, the broadening term $\mathrm{Br}$ and the transitionmatrix-element related parameter Amp. From these parameters the imaginary part $\varepsilon_{2}$ of the complex dielectric function is calculated using the following equation:

$$
\begin{array}{ll}
\varepsilon_{2}=\frac{A m p B r E_{0}\left(E-E_{g}\right)^{2}}{\left(E^{2}-E_{0}{ }^{2}\right)^{2}+B r^{2} E^{2}} \frac{1}{E} & E>E_{g} \\
\varepsilon_{2}=0 & E \leq E_{g}
\end{array}
$$

The real part $\varepsilon_{1}$ of the dielectric function is obtained by using Kramers-Kronig integration of $\varepsilon_{2}$. Conversion to $n$ and $k$ is then performed using the following equations:

$\varepsilon_{1}=n^{2}-k^{2}$

$\varepsilon_{2}=2 n k$

To note, the TL model only takes into account inter-band absorption in the material and does not include defect absorption, intra-band absorption or Urbach tail absorption [9]. (The Urbach tail is only caused by structural disorder in amorphous materials or 
thermal disorder in crystalline materials at high temperatures.) For GeSi films in our study inter-band absorptions are of high relevance as they can effectively create electron-hole pairs contributing to the photo-current in detectors.

According to the TL model the absorption is zero below $E_{g}$ (see Eq. 2.2). Inter-band absorption can only occur if the energy of a photon is above the electrical band gap of the material. Therefore $E_{g}$ as determined using this model can be interpreted as the electrical band gap itself. However for indirect band gap materials like GeSi the electrical band gap can be smaller than the calculated $E_{g}$ if the inter-band absorptions are considered to be a result of only direct band to band transitions (where crystal momentum is conserved).

For a (poly) crystalline material, in order to obtain a proper fit, two TL dispersions were used to accommodate two high energy interband peak transitions (i.e by using two values of $E_{0}$ ). As an example mono-crystalline silicon can have two peak transitions at $4.4 \mathrm{eV}$ and $3.4 \mathrm{eV}[10]$ in contrast to amorphous silicon which has a single broad peak in the spectrum [8]. It has been shown in $[11,12]$ that the TL model can also be used for polycrystalline materials.

In this work a Woollam M2000 SE with a spectral range of 245 to $1690 \mathrm{~nm}$ was used to determine $n$ and $k$ for germanium-silicon and silicon oxynitride films.

\subsection{Fourier transform infrared spectroscopy}

Fourier transform infrared spectroscopy (FTIR) [13] is performed to obtain an absorption spectrum for infrared wavelengths caused by vibrations of group of atoms (such as $\mathrm{Si}-\mathrm{N}, \mathrm{Si}-\mathrm{H}, \mathrm{Si}-\mathrm{H}_{2}$ etc.) in a material. An FTIR setup (sketched in Fig. 2.9) involves a broadband infrared light source; the light is passed via an interferometer (contains a combination of mirrors, one static and one moving) to the sample and then to the detector. At each position of the moving mirror, a different part of the infrared spectrum emerges from the interferometer. The light intensity is recorded for each position of the moving mirror by the computer program.

The raw data form the so-called interferogram. However, the interferogram does not directly provide the light intensity at each individual frequency (or wavelength $\lambda$ ), because at each mirror 
position, multiple frequencies pass through the interferometer. To extract the absorption as a function of frequency, or rather wavenumber $(1 / \lambda)$, the computer applies a Fourier transform to the interferogram. Every group of atoms can have different vibrational modes and each of them can cause different absorption peaks in the spectrum. Typical vibrational modes include stretching, bending, wagging and twisting. As with $\mathrm{XRD}$, the obtained spectrum can be compared to a library of known materials to relate absorption peaks to sample constituents.

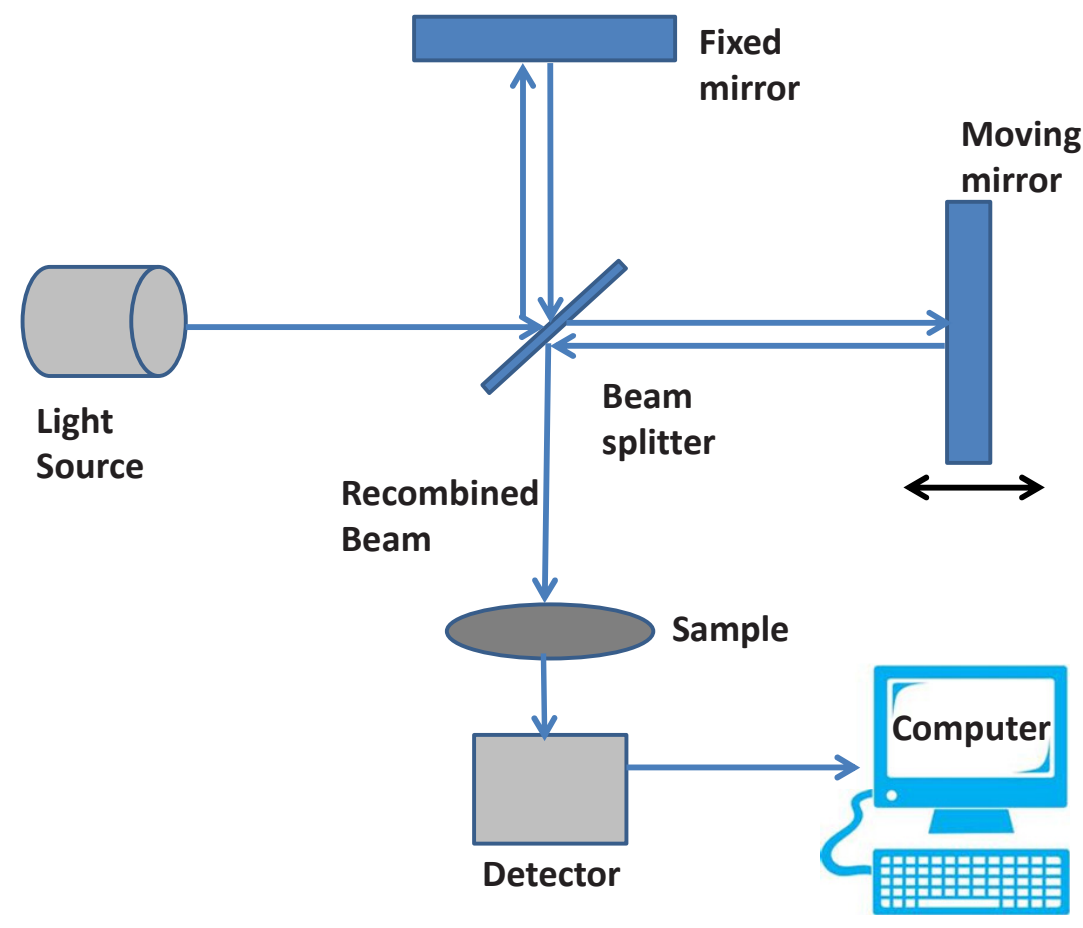

Fig 2.9: A simple sketch of an FTIR measurement setup.

In this thesis a Bruker Vertex 70 FTIR with a standard spectral range of $8000 \mathrm{~cm}^{-1}$ to $400 \mathrm{~cm}^{-1}$ and a spectral resolution of $0.4 \mathrm{~cm}^{-1}$ was used to determine the absorption of Si-N, Si-O-Si, Si-H, N-H and $\mathrm{O}-\mathrm{H}$ vibrational modes in $150 \mathrm{~nm}$ silicon oxynitride films. Determining the presence of $\mathrm{Si}-\mathrm{H}$ and $\mathrm{N}-\mathrm{H}$ bonds is crucial as the overtones of their vibrational modes cause optical losses around 1500 $\mathrm{nm}$ wavelength extending up to $1550 \mathrm{~nm}$. If the concentration of these bonds is lower than $1 \%$ of the entire measured volume, then 
their corresponding absorption peaks are not observable in the FTIR spectrum.

\subsection{Prism coupling technique}

The prism coupling technique [14] is commonly used to determine the propagation losses in a slab waveguide. Usually transverse-electric (TE) or transverse-magnetic (TM) polarized light (obtained using a polarizing filter) from a laser source is coupled into the slab waveguide using a (halved) prism. A slab waveguide is a simple waveguide structure with three layers such that the middle layer (or usually called as the core layer) has the highest refractive index. The other two layers are called cladding layers (in some cases the top cladding layer is air). The scattered light of the propagating fundamental TE mode or TM mode is captured by a digital camera. The losses are determined in $\mathrm{dB} / \mathrm{cm}$ by comparing the light intensity along the propagation direction in the captured images.

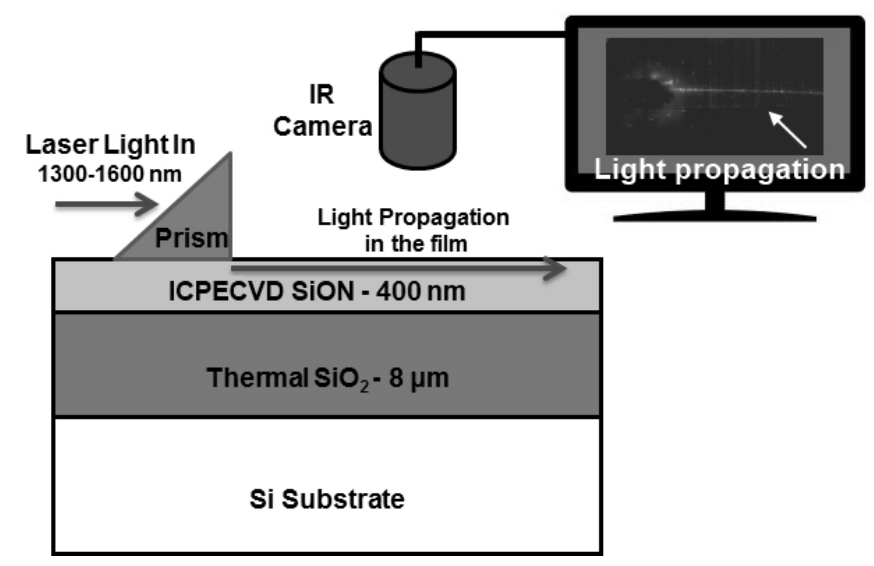

Fig 2.10: A schematic setup of prism coupling method using a halved prism.

Such a home-built system for our experiments is schematically shown in Fig. 2.10. In this thesis the prism coupling technique was used to determine the propagation losses in $400 \mathrm{~nm}$ thick silicon oxynitride waveguides at wavelengths in the range of 1300-1600 nm. The bottom cladding layer was $8 \mu \mathrm{m}$ thick thermally grown silicon dioxide (thick enough to avoid coupling of light to the silicon substrate) with a refractive index of 1.46 at $632 \mathrm{~nm}$ wavelength while 
the top layer was air. The scan length was $5 \mathrm{~cm}$ in all cases. The digital camera had $320 \times 240$ pixels and the captured images were analyzed using the imaging software ImageJ. Each measurement value reported in this thesis was obtained from multiple samples deposited under the same conditions yielding a statistical error close to $\pm 10 \%$.

\subsection{Conclusions}

All the material characterization techniques used in the upcoming chapters have been introduced with their basic principles explained. It aims to help the reader to relate the results obtained from these techniques with the physical or chemical properties of the material. All the characterization techniques have been used in their traditional mode of operation. Additional specific information can be found in the provided references.

\section{References}

1. L. Reimer, Scanning Electron Microscopy: Physics of Image Formation and Microanalysis, (Springer, 1998).

2. S. Canovic, T. Jonsson and M. Halvarsson, J. Physics: Conference Series 126, 012054 (2008).

3. A. J. Schwartz, Electron Backscatter Diffraction in Materials Science, (Springer, 2009).

4. P. Eaton and P. West, Atomic Force Microscopy, (OUP Oxford, 2010).

5. C. Suryanarayana and M. G. Norton, X-Ray Diffraction: A Practical Approach, (Springer, 1998).

6. I. R. Lewis, H. Edwards, Handbook of Raman Spectroscopy: From the Research Laboratory to the Process Line, (Taylor \& Francis, 2001).

7. P. van der Heide, X-ray Photoelectron Spectroscopy: An introduction to Principles and Practices, (John Wiley \& Sons, 2011).

8. H. Fujiwara, Spectroscopic ellipsometry: principles and applications, (John Wiley \& Sons, 2007).

9. G. E. Jellison and F. A. Modine, App. Phys. Lett. 69, 371 (1996).

10. J. R. Chelikowsky and M. L. Cohen, Phys. Rev. B 14, 556 (1976). 
11. Z. G. Hu, J. H. Ma, Z. M. Huang, Y. N. Wu, G. S. Wang, and J. H. Chu, Appl. Phys. Lett. 83, 3686 (2003).

12. Y. J. Cho, N. V. Nguyen, C. A. Richter, J. R. Ehrstein, B. H. Lee and J. C. Lee, Appl. Phys. Lett. 80, 1249 (2002).

13. B. C. Smith, Fundamentals of Fourier Transform Infrared Spectroscopy, (CRC Press, 2011).

14. R. Ulrich and R. Torge, App. Opt. 12, 2901 (1973). 


\section{Chapter 3}

\section{Green-Laser Crystallization and Dopant Activation of GeSi alloys}

This chapter focuses on the crystallization of thin amorphous GeSi films using a pulsed green laser. Preformed lines were employed during the crystallization process to steer the formation of large grains within specified boundaries. This originates from the notion that electronic devices fabricated on films with controlled location and density of grain boundaries can have less device-todevice variability. Further the electrical activation of ion-implanted $p$ - and n-type dopants in asdeposited polycrystalline GeSi films was studied using three different activation methods: furnace, rapid thermal and laser annealing. For reference the crystallization of implanted amorphous GeSi films was also explored. The samples were physically and electrically characterized to assess their applicability in above-CMOS process technologies.

This work was published in:

- B. Rangarajan, A.Y. Kovalgin, P. Oesterlin, R. de Kloe, I. Brunets and J. Schmitz, J. Solid State Sci. Technol. 1, P263 (2012). and presented at:

- 219th ECS meeting 2011, Montréal, QC, Canada (Oral presentation).

- 2011 MRS Spring Meeting \& Exhibit, San Francisco, California, US. (Poster). 


\subsection{Waveguide integrated photodetector on CMOS}

A schematic representation of a possible waveguide integrated p-i-n photodetector on CMOS is shown in Fig. 3.1. In this case the silicon oxynitride $(\mathrm{SiON})$ waveguide is placed on top of germanium silicon (GeSi) photodetector. Through evanescent coupling most of the light is coupled from the waveguide to the photodetector at the input port.

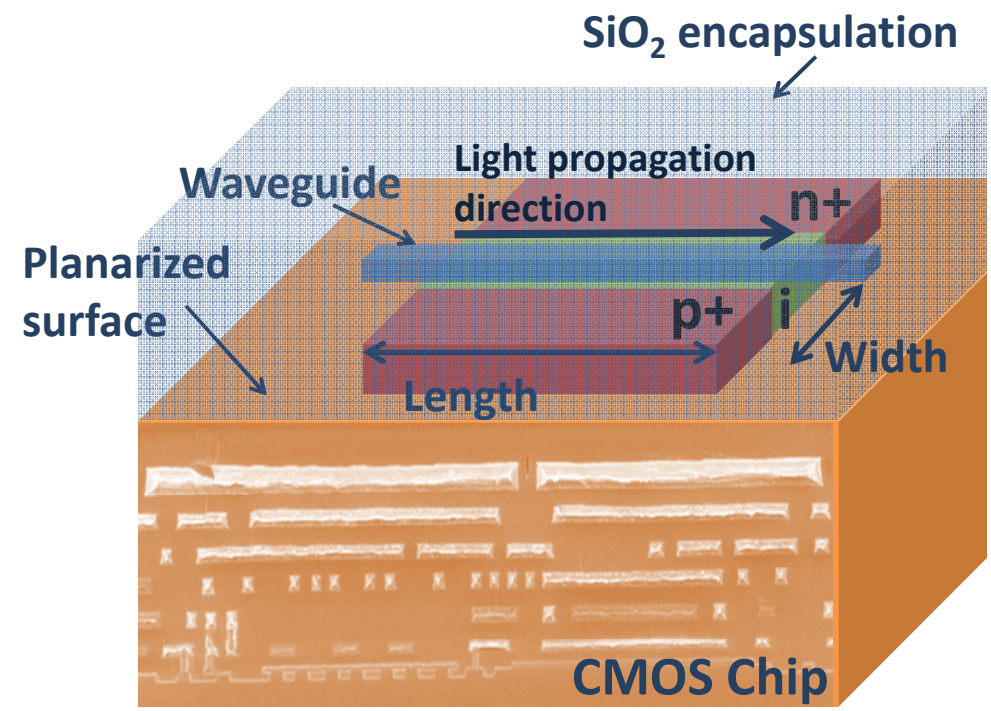

Figure 3.1: A schematic representation of a waveguide integrated p-i-n photodetector on CMOS. The top surface of the CMOS chip is planarized first using chemical mechanical polishing (CMP). GeSi photodetectors are then fabricated followed by $\mathrm{SiO}_{2}$ deposition. This surface is further polished using CMP for planarization as well as exposing the photodetector. SiON waveguides can then be fabricated on top of the photodetector along with a final encapsulation using $\mathrm{SiO}_{2}$. Contact holes are then made to access the p+ and $n+$ regions of the photodetector.

The light then propagates longitudinally along the length of the GeSi photodetector until it gets fully absorbed. The width of the

Materials for Monolithic Integration of Optical Functions on CMOS 
intrinsic region (which of course should be wider than the width of the waveguide) can be chosen for optimal photo-detection by applying simulations. The width influences the carrier collection efficiency and speed of the p-i-n photodetector. Considering that most photons travel longitudinally in $\mathrm{GeSi}$, the thickness requirement for the photodetector can be quite relaxed. This can be advantageous for this work as laser crystallization is very effective only for thin films (typically lower than $200 \mathrm{~nm}$ thickness).

Placing the waveguide on top of photodetector can have certain advantages. The top side of the laser crystallized film is likely to have better crystalline quality (i.e. with lesser defects) compared to the bottom side. This reduces recombination centers improving the photo-detection. Additionally the thickness of the waveguide and the photodetector can be designed independently based on their respective requirements.

As an alternative light can also be butt-coupled from a waveguide to a photodetector by placing them adjacent to each other. However, this requires that the thickness of the photodetector and the waveguide have to be matched which can constrain the flexibility in choosing the thickness of the GeSi film for crystallization.

\subsection{Deposition of GeSi films}

Low pressure chemical vapor deposition (LPCVD) was used to deposit $\mathrm{Ge}_{0.85} \mathrm{Si}_{0.15}$ films on 4-inch silicon wafers with 450 -nm wetoxide. The compositions of the deposited films were determined using X-ray photoelectron spectroscopy.

The LPCVD system used for this deposition is a horizontal hot wall system with resistive heaters and has a base pressure of $10^{-3}$ mbar. Amorphous- $\mathrm{Ge}_{0.85} \mathrm{Si}_{0.15}$ films were deposited at a temperature of $430{ }^{\circ} \mathrm{C}$ using $75 \mathrm{sccm} \mathrm{SiH}_{4}$ and $37 \mathrm{sccm} \mathrm{GeH}_{4}$ flow with a total pressure of 6 mbar for crystallization. The deposition rate in this case was $8 \mathrm{~nm} / \mathrm{min}$. With the same settings except a $0.2 \mathrm{mbar}$ total pressure, polycrystalline $\mathrm{Ge}_{0.85} \mathrm{Si}_{0.15}$ films were deposited on similarly wet-oxidized silicon wafers (with a deposition rate of $4 \mathrm{~nm} / \mathrm{min}$ ) as a reference as well as for dopant activation experiments. In either case the thickness uniformity across the wafer was within $\pm 10 \%$ of the final deposited thickness. 
Prior to each deposition, nucleation sites were created by depositing (in the same system) a few nanometers of amorphous $\mathrm{Si}$ at the same low temperature of $430{ }^{\circ} \mathrm{C}$ with a total pressure of $0.5 \mathrm{mbar}$ using $88 \mathrm{sccm} \mathrm{SiH}_{4}$ flow [1].

\subsection{Sample preparation and laser system}

Samples for crystallization were prepared by first depositing a $50 \mathrm{~nm}$ thick amorphous $\mathrm{Ge}_{0.85} \mathrm{Si}_{0.15}$ (a-GeSi) film using LPCVD on oxidized $\left(450 \mathrm{~nm} \mathrm{SiO}_{2}\right) \mathrm{Si}$ wafers. This film was patterned into approx. $900 \mathrm{~nm}$ wide lines with a pitch of $3 \mu \mathrm{m}$ using optical lithography and wet-etching. Hydrofluoric acid-nitric acid-acetic acid solution diluted with de-ionized water was used as the wet-etchant in this case. Subsequently, a $100 \mathrm{~nm}$ thick a-GeSi film was deposited (Fig. 3.2). The purpose of the thin GeSi lines under this film, the socalled preformed lines, will be explained in section 3.5.

For comparison, wafers without preformed lines were processed with otherwise identical fabrication steps i.e. wafer with a blanket a-GeSi layer.

The crystallization was performed at INNOVAVENT GmbH. Their laboratory system used a Yb:YAG thin disk green laser $(\lambda=515 \mathrm{~nm})$ with a pulse repetition rate of $10 \mathrm{kHz}$ and pulse duration of $285 \mathrm{~ns}$. Using an intricate optical system the laser beam was shaped into a Gaussian energy density profile along the $x$-axis of the laser beam (which is the scanning direction, see Fig. 3.2) with Full Width Half Maximum (FWHM) set at $15 \mu \mathrm{m}$. Along the $y$-axis, the beam was $2 \mathrm{~mm}$ wide with a uniform energy density profile. The samples were moved under this laser beam using a motorized wafer stage.

The laser pulse duration is $285 \mathrm{~ns}$, and the pulse interval is 100 $\mu \mathrm{s}$. With this relatively long cool-down time and the small illuminated area, the surface can cool down without a steep rise in substrate temperature. TFT-displays and thin-film solar panels on glass are commonly manufactured with this technique. 


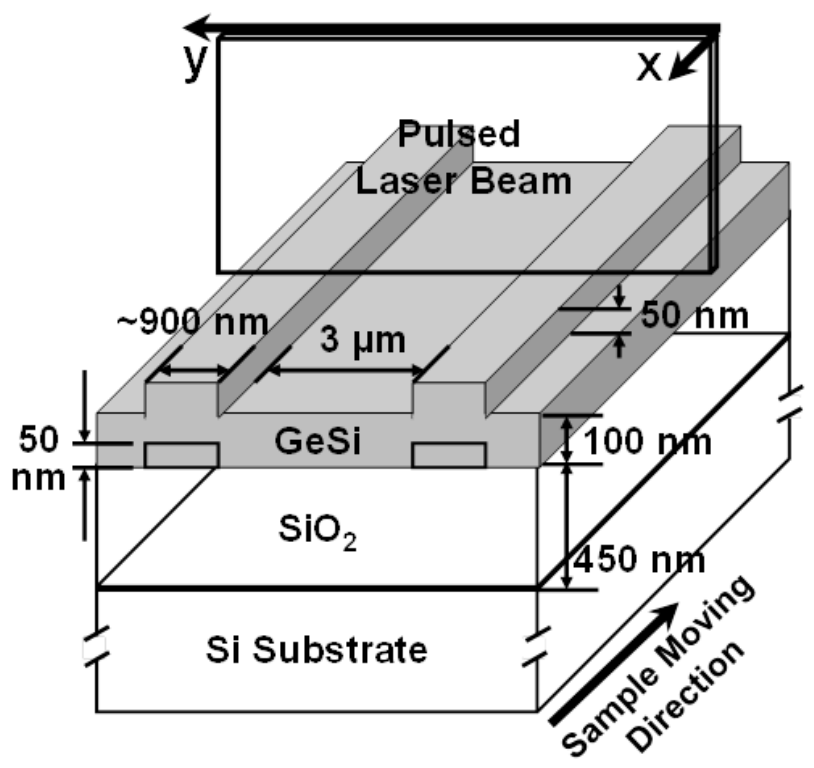

Figure 3.2: Overview of laser crystallization with preformed lines. The samples are moved unidirectionally under the laser beam along the $x$-axis. The preformed lines lie along the same axis.

\subsection{Crystallization: Sequential super-lateral growth}

The laser crystallization of GeSi (on oxide) as proposed in this chapter is based on the principle of super-lateral grain growth [3]. This entire process is shown schematically in Fig. 3.3. As per this principle, under irradiation of a single laser pulse, the crystallization begins from the edges of the irradiated region to its center creating elongated grains.

In order to obtain super-lateral grain growth, the laser conditions are needed to be optimized to create the so-called nearcomplete melting of the film [2]. With near-complete melting, small non-molten islands exist at the GeSi/oxide interface as shown in Fig. 3.3a.

Directly after each laser pulse, solidification begins at these non-molten pieces at the GeSi/oxide interface. To note, the laser beam has a Gaussian profile along the direction of super-lateral growth (i.e. along the x-axis, see Fig. 3.3b). This allows the laser 
energy to peak at the center and gradually decrease towards the edges. As a consequence the non-molten parts are mainly situated at the lateral edges and not in the center of the beam; the crystallization therefore starts at those edges. The two solidification fronts start moving from the edges of the irradiated region towards the center with the remaining GeSi laterally surrounding the irradiated region acting as a heat sink.

This ideal process is however affected by the spontaneous nucleation of the bulk super-cooled liquid at the center resulting in the formation of small grains sandwiched between the elongated grains (Fig. 3.3c) [3].

(a)
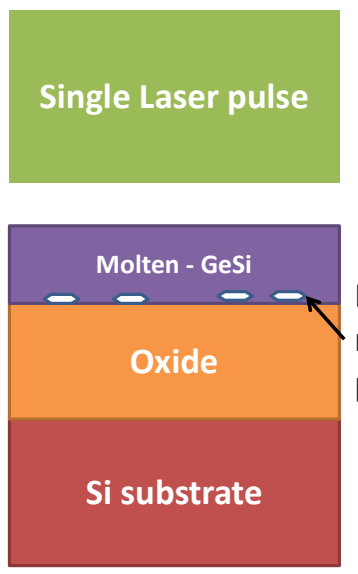

Sample

Cross-section
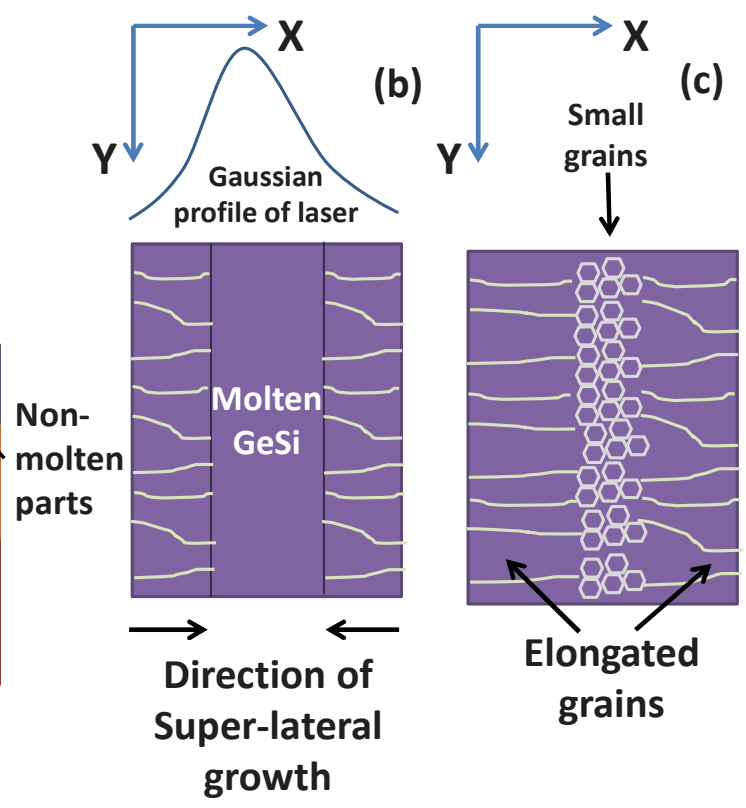

Fig 3.3: A schematic sketch showing (a) near-complete melting of GeSi as seen from cross-section where the existence of nonmolten islands is shown as white regions; (b) a top view of super-lateral growth during crystallization under a single laser pulse where the two solidification fronts start moving from the edges of the irradiated region towards the center; (c) a top view of the crystallized film with small grains sandwiched between elongated grains. The interruption of the super-lateral growth is caused by the spontaneous nucleation of the bulk super-cooled liquid at the center. 
To further continue with the lateral grain elongation, the next laser pulse is required to have a significant overlap with the previously irradiated region with a step size much smaller than the grain size. This allows the previously-formed elongated grains to act as seeds for the neighboring material. Ideally, this sequential superlateral growth will result in a gradual increase of the grain length after each pulse along the laser scanning direction [4].

\subsection{Control over location and density of grain boundaries}

For the purpose of steering the grain growth during the crystallization process, preformed lines were used. This controls the location and density of grain boundaries. As mentioned previously in section 1.3.1 grain boundaries are detrimental to the semiconductor device performance and their randomness can cause variability in the performance of similar devices fabricated on the same wafer.

Preformed lines create a periodic lateral thickness variation in the layer. The laser treatment is optimized for sequential super-lateral growth to occur only in between the preformed lines. On the lines themselves, partial melting however results in explosive recrystallization, leading to the formation of very small grains [5]. These lines obstruct any deviation in the length axis of the elongated grains by standing as a wall between two adjacent super-lateral growths. A pitch of $3 \mu \mathrm{m}$ was chosen for the preformed lines based on the previous experiments with the crystallization of amorphous $\mathrm{Si}$ films by I. Brunets et al. [6].

\subsection{Optimization of laser process parameters}

The process window to achieve the sequential super-lateral growth as described above was charted by varying pulse overlap, beam width, and energy per pulse. A large step size of $2 \mu \mathrm{m}$ of the laser beam (overlap of $95 \%$ with $40 \mu \mathrm{m}$ wide laser beam) resulted in discontinuity in the super lateral growth leading to a sequence of alternating small and large grains. A relatively high overlap of $98 \%$ was necessary to obtain micrometer-sized grains. A smaller overlap of $95 \%$ led to smaller grains due to the large step size. An even bigger overlap of $99 \%$ with much smaller step size resulted in dewetting (see Fig. 3.4), indicating excessive melting of the film possibly related to an insufficient cool-down time between laser pulses. 
By varying the laser-beam width, a FWHM of $15 \mu \mathrm{m}$ was found optimal to obtain micrometer-sized grains. Laser crystallization with a broader beam, having $40 \mu \mathrm{m}$ FWHM in the $x$-direction, led to small $100-200 \mathrm{~nm}$ grains. The insufficient steepness of this broader beam profile probably suppressed the super-lateral growth by enhancing spontaneous nucleation [3].

Considering the energy per pulse, at laser energy densities of $1.2-1.3 \mathrm{~J} / \mathrm{cm}^{2}$ per pulse, large grains (several micrometers long) were obtained. An increase of the laser energy density to $1.35 \mathrm{~J} / \mathrm{cm}^{2}$ resulted in partial de-wetting of the film whereas a decrease to $1.1 \mathrm{~J} / \mathrm{cm}^{2}$ led to the formation of small-sized grains of 200-300 nm.

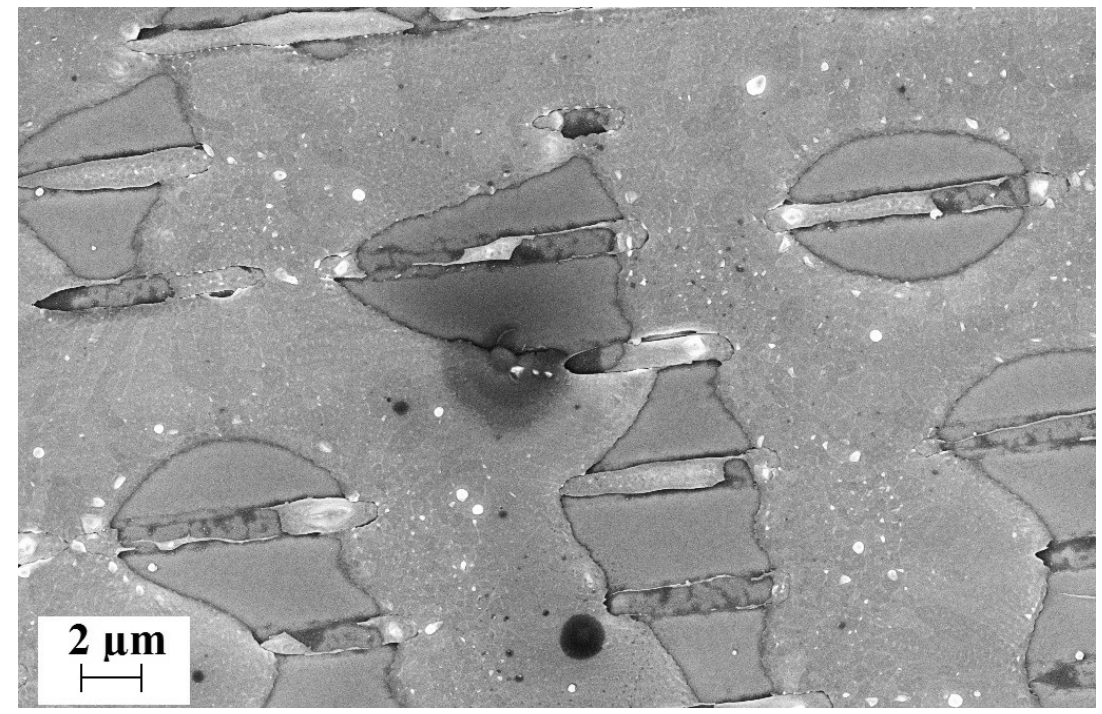

Figure 3.4: A SEM top view showing the result of using a bigger overlap of $99 \%$. Sections of the GeSi layer have opened up to reveal the oxide layer beneath it as a result of de-wetting caused by excessive melting of the film.

Encapsulation of the semiconductor by a thin $\mathrm{SiO}_{2}$ film was reported to improve the laser crystallization result in terms of process window and process control [8]. Our experiments to optimize crystallization while having a 20 -nm-thick $\mathrm{SiO}_{2}$ encapsulation, made by plasma enhanced chemical vapor deposition at $150{ }^{\circ} \mathrm{C}$, were however unsuccessful (the energy density per pulse was varied between 0.5 and $1 \mathrm{~J} / \mathrm{cm}^{2}$ ). The SEM image in Fig. 3.5 shows GeSi as 
bright regions with the appearance of bottom oxide represented by darker shades. The ablation of GeSi film could have been caused by the obstruction of hydrogen desorption by the encapsulating top oxide layer. It has been shown in literature that the ablation of silicon films (with high hydrogen content) can occur during crystallization due to explosive vaporization of hydrogen [8]. We did not see this issue for films with no encapsulation but an obstructing top layer could have triggered this effect.

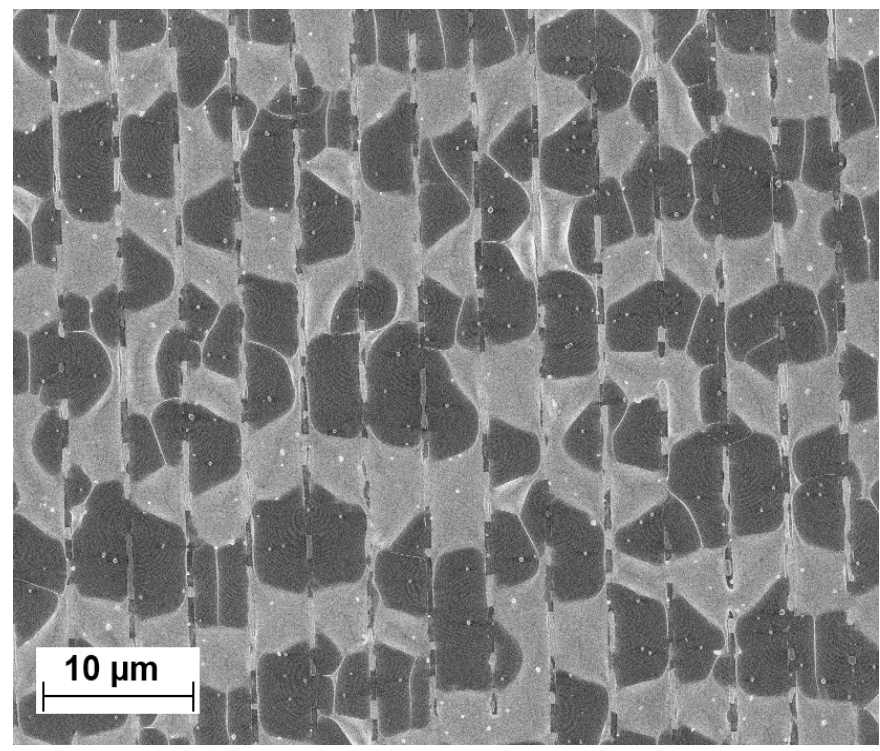

Figure 3.5: A SEM image showing that the use of $\mathrm{SiO}_{2}$ encapsulation during crystallization resulted in the ablation of GeSi films. This could be a result of the obstruction of hydrogen desorption by the encapsulating top oxide layer during crystallization process.

\subsection{Material characterization and analysis}

\subsubsection{Optimization of grain size and grain confinement}

EBSD measurements were performed on laser crystallized $\mathrm{Ge}_{0.85} \mathrm{Si}_{0.15}$ films (LC GeSi) with preformed lines, using a $98 \%$ overlap and a laser energy density of $1.2 \mathrm{Jcm}^{-2}$ per pulse. The result of the EBSD analysis is shown in Fig. 3.6 as a grain orientation map. The electrically active (i.e. affecting the current) grain boundaries are 
Chapter 3 - Green-Laser Crystallization and Dopant Activation of GeSi 43

Alloys

indicated with blue lines. Electrically inactive twin boundaries (caused by symmetrical sharing of same lattice points by two different grains with $60^{\circ}$ misorientation), indicated with yellow lines, amount to $12 \%$ of all grain boundaries.

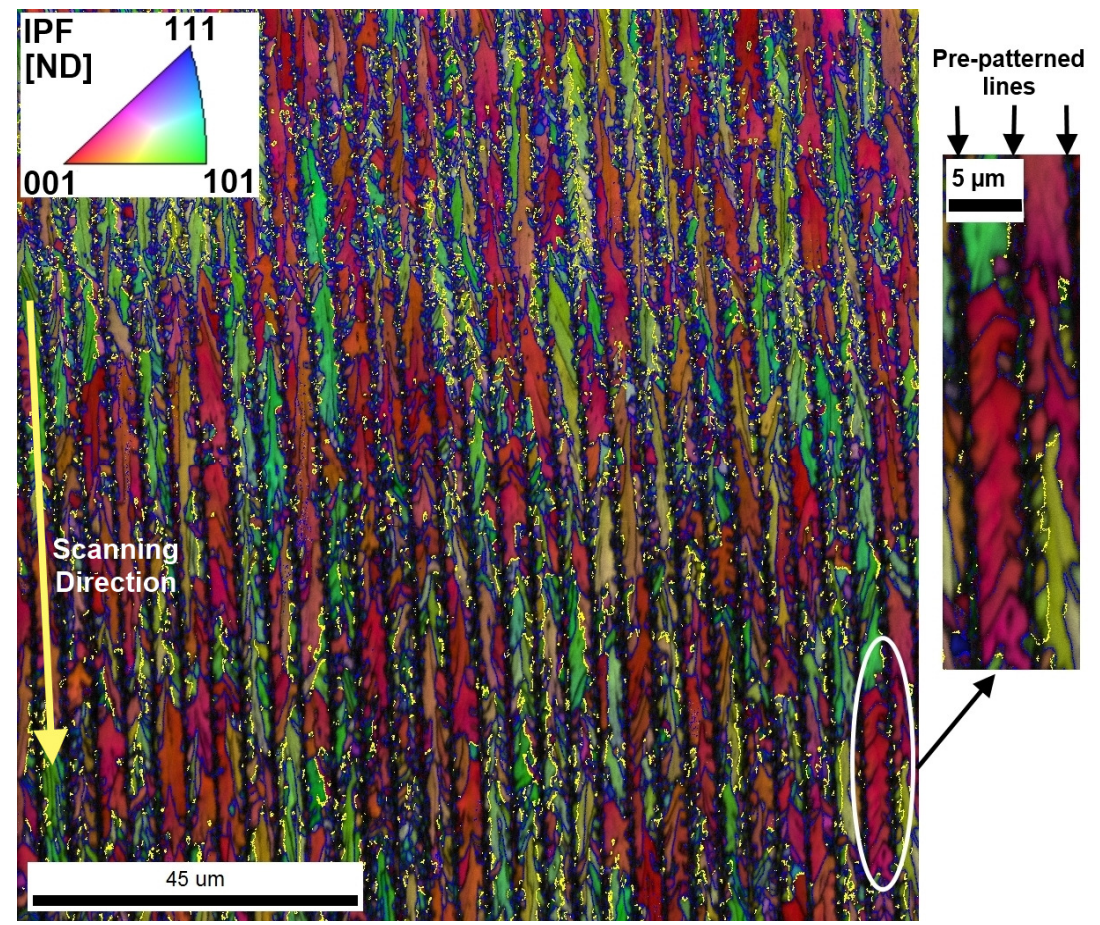

Figure 3.6: Grain orientation map obtained using EBSD for the optimized film. The size of the scanned area is $140 \times 140 \mu \mathrm{m}^{2}$. The crystal orientation is color-coded according to its position in the inverse pole figure (IPF) shown as an inset. The grain boundaries and twin boundaries are shown as blue and yellow lines, respectively. Elongated grains formed along the laser scanning direction are confined within the $3 \mu \mathrm{m}$ wide space by the preformed lines.

Approximately $30 \%$ of the $140 \times 140 \mu \mathrm{m}^{2}$ area is covered by grains with sizes in the range of (10-25) $\mathrm{x}(2-3) \mu \mathrm{m}^{2}$. In addition, in this $140 \times 140 \mu \mathrm{m}^{2}$ area (Fig. 3.5), 2-2.5 $\mu \mathrm{m}, 4-8 \mu \mathrm{m}$ and $25-35 \mu \mathrm{m}$ long grains occupy approx. $11 \%, 20 \%$ and $5 \%$ of the area, respectively (see the grain size statistics in Fig. 3.7). In total, $64 \%$ of measured area has grains longer than $2 \mu \mathrm{m}$, some reaching up to 
$50 \mu \mathrm{m}$. This is orders of magnitude larger than the layer thickness, a result of the sequential super-lateral growth. In the literature, crystal grains of up to approx. $2 \mu \mathrm{m}$ in length are reported in high- $x \mathrm{Ge}_{x} \mathrm{Si}_{1-x}$ films using a pulsed green laser so far [9].

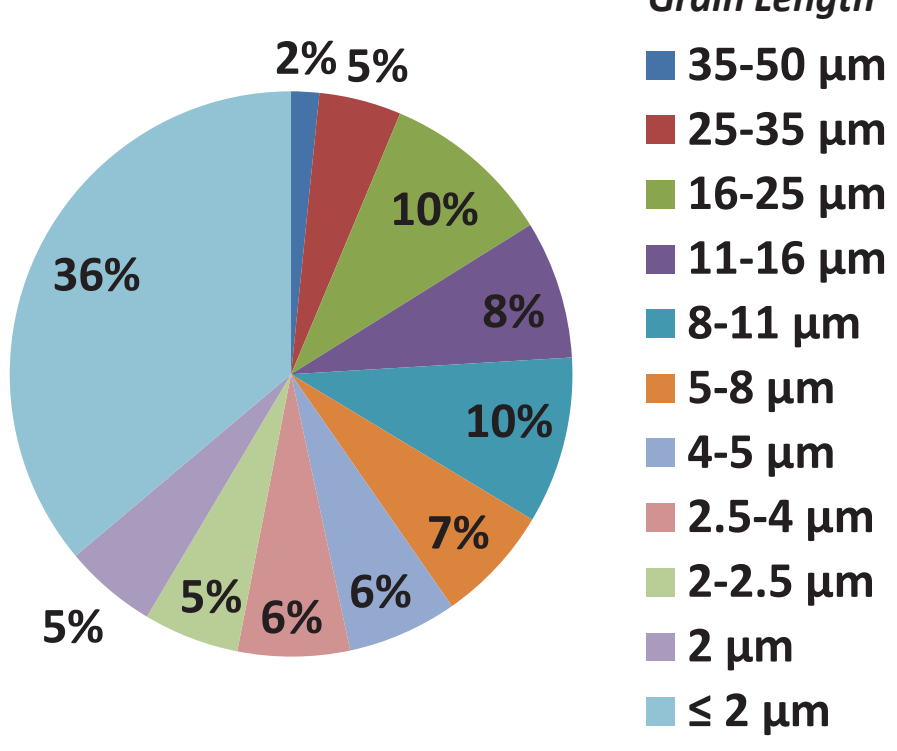

Figure 3.7: Grain size distribution from EBSD analysis of the scanned $140 \times 140 \mu^{2}$ area displayed in Fig. 3.6. In total, $64 \%$ of measured area has grains longer than $2 \mu \mathrm{m}$, some reaching up to $50 \mu \mathrm{m}$.

A top-view SEM image of the same sample shows similar structural features (Fig. 3.8). The contrast between grains seen here is most likely due to the different crystal orientations as indicated by EBSD.

The large grains are formed in between and confined by the preformed lines as shown in EBSD and SEM images (Figs. 3.6 and 3.8). For comparison, from Fig. 3.9 it can be seen that samples crystallized without preformed lines also have long grains but with more variety in the grain's length axis (as indicated by the dotted arrows). From these findings it can be concluded that preformed lines constrain the position and length axis of the grains within a defined space (here $3 \mu \mathrm{m}$ wide), which may lead to better-controlled characteristics of properly-placed devices as reported earlier for

Materials for Monolithic Integration of Optical Functions on CMOS 
silicon [7].

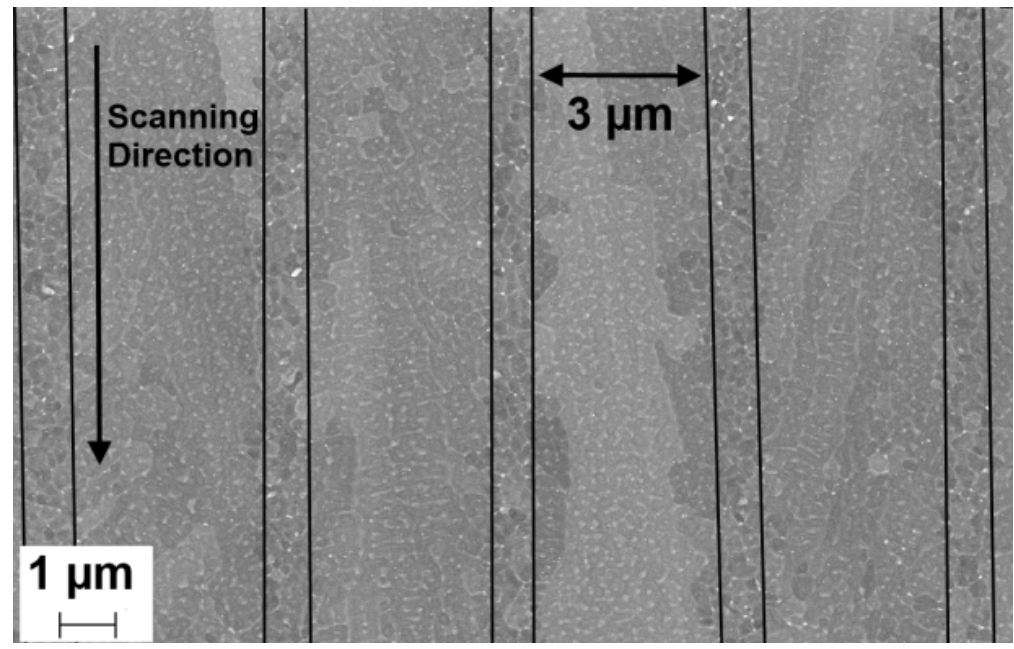

Figure 3.8: SEM top view of the LC GeSi film with preformed lines (the parallel lines indicate the position of the preformed lines). The large grains $\left((10-25) \times(2-3) \mu m^{2}\right)$ are confined within the $3 \mu \mathrm{m}$ wide space by the preformed lines during crystallization. The contrast between grains is most likely due to different crystal orientation as supported by the results from EBSD.

However the crystallization behavior is opposite to that observed in the earlier work on laser crystallization of a-Si films [6]. Namely in [6], it was observed that the grain centers are positioned on the lines and the grain boundaries are mostly located between the lines.

The two experiments are similar in the sense that the same equipment was used and the film thicknesses and line patterns are the same. However, the laser energy was higher for the GeSi treatments, and further, the two materials under study have significantly different material properties that play a role in the laser crystallization: most importantly reflection, absorption length for green light, specific heat, melting point, melting energy and heat conduction.

A thorough modeling of the laser anneal process may give a conclusive explanation for the different behavior. A qualitative explanation is the following: in the silicon case, only partial melting 
occurs where the lines remain solid and act as the starting point for nucleation. In the GeSi case, the material is likely to melt further, and the thinner regions may cool down faster than the thicker ones, leading to solidification to start in the thinner areas.

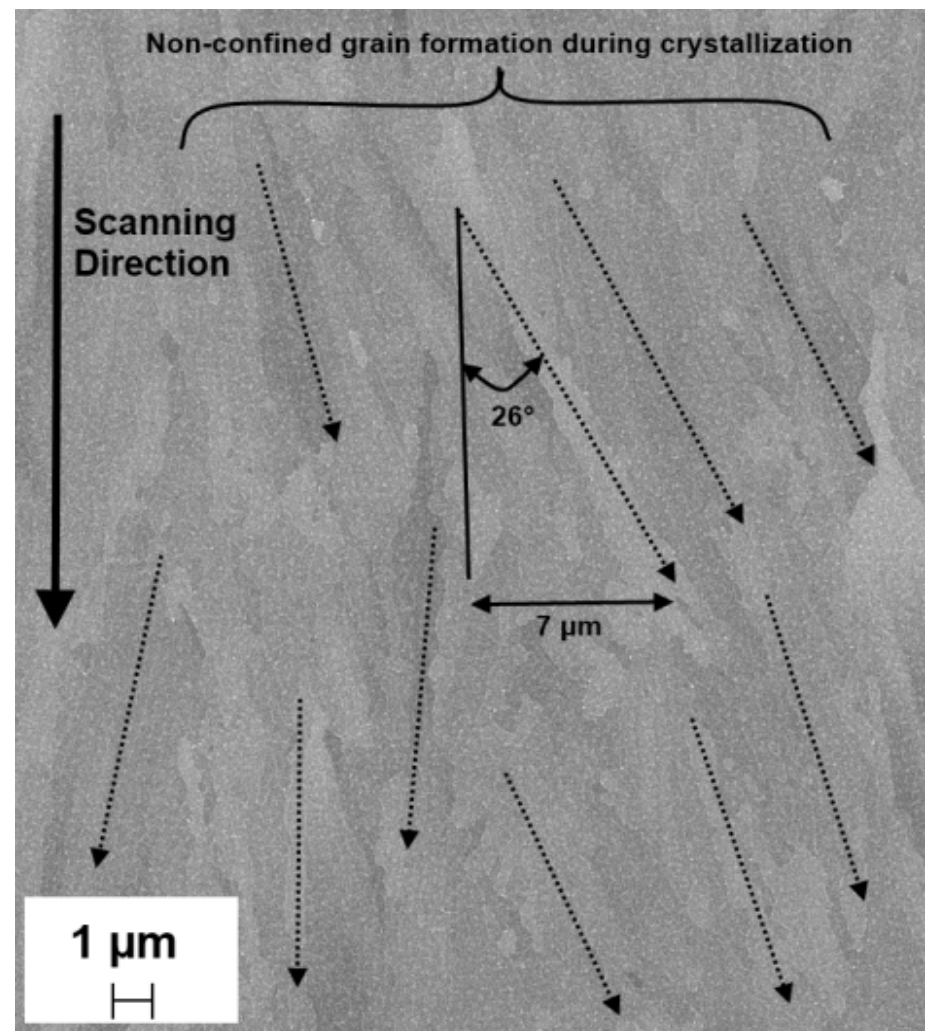

Figure 3.9: A SEM top view of LC GeSi film without preformed lines. The large grains are formed without any confinement leading to length axis rotations as high as $26^{\circ}$ with respect to the laser scanning direction. This highlights the importance of preformed lines in controlling the location of grain boundaries. The contrast between grains is most likely due to different crystal orientation as supported by the results from EBSD.

The samples were further compared to as-deposited poly$\mathrm{Ge}_{0.85} \mathrm{Si}_{0.15}$ films (poly-GeSi) of similar thickness. As visible in Fig. 3.10, the latter exhibit smaller-sized grains of approx. $200 \mathrm{~nm}$. Moreover, atomic force microscopy reveals a much higher surface 
roughness (RMS) of the as-deposited poly-GeSi film $(12.6 \mathrm{~nm})$ compared to the LC GeSi film $(2.5 \mathrm{~nm})$. This difference in surface roughness can be clearly visualized in Fig. 3.11 which shows the SEM cross-sectional view of both as-deposited and LC GeSi films.

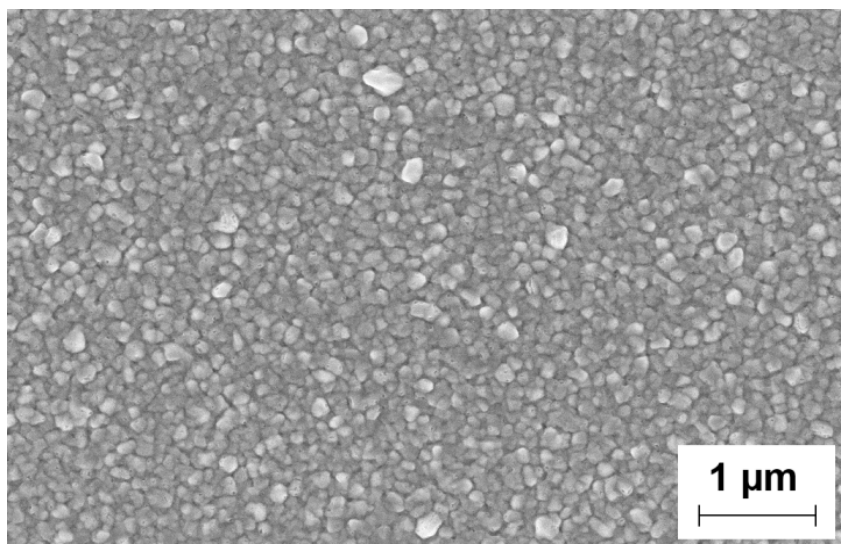

Figure 3.10: A SEM top view of as-deposited poly-GeSi film showing small grains with a typical size of $200 \mathrm{~nm}$.

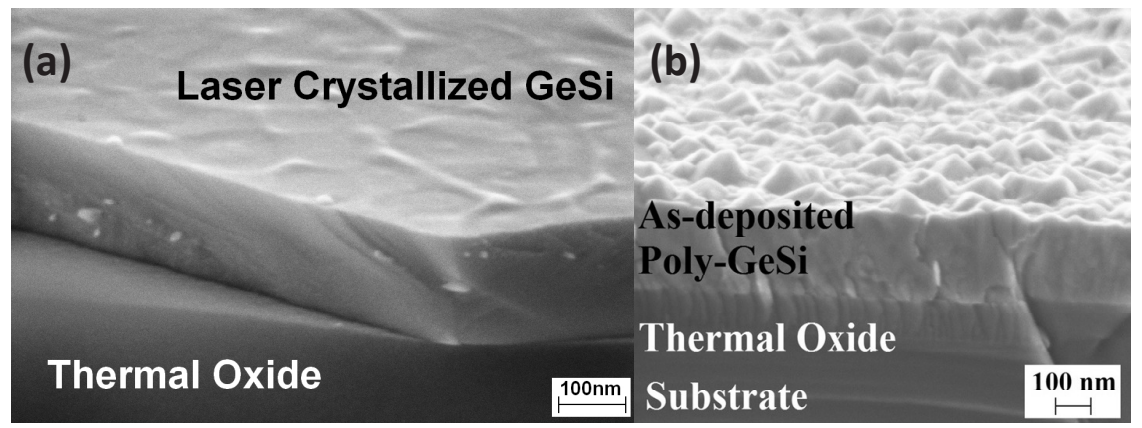

Figure 3.11: A SEM cross-sectional view of (a) LC GeSi and (b) as-deposited poly-GeSi films showing the big difference in surface roughness.

\subsubsection{Grain orientation and residual stress}

A standard X-ray diffraction (XRD) $\theta-2 \theta$ scan was performed on laser-crystallized a-GeSi and as-deposited poly-GeSi film. Both films exhibit the (111), (220) and (311) $2 \theta$ peaks. The XRD scan of a-GeSi film (without laser crystallization) confirmed its amorphous nature with no observable $2 \theta$ peaks. 
In order to gain further insight into these materials, grazing incidence angle XRD (GAXRD) scans were also performed using incidence angle $\omega$ ranging from $2.5^{\circ}$ to $4^{\circ}$. The low angle further limits the X-ray penetration into the substrate, so any angular dependence can be used to acquire depth information.

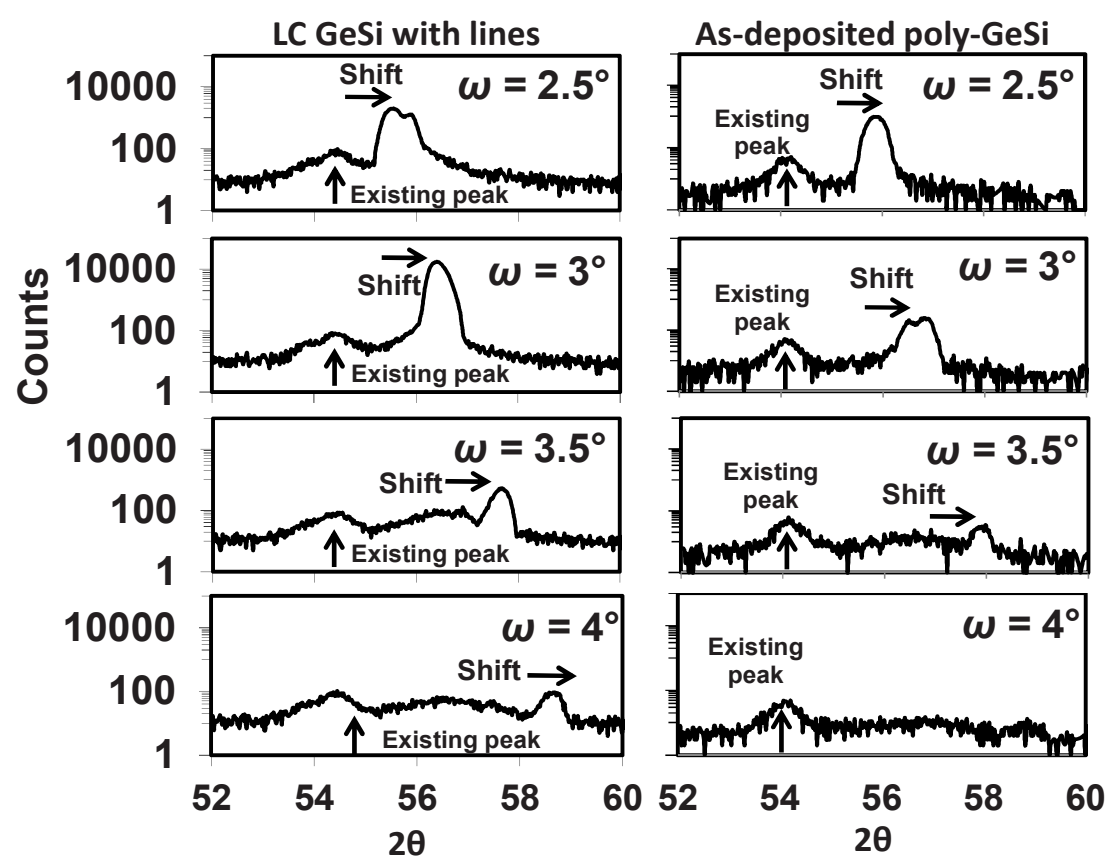

Figure 3.12: Shifted (311) $2 \theta$ peaks are shown in detail for LC GeSi film and as-deposited poly-GeSi film indicating a residual tensile stress. The shift increases for higher $\omega$ angles. For the LC GeSi films, the shifted (311) $2 \theta$ peak with the highest intensity counts (17733) appears at $\omega=3^{\circ}$, and for the asdeposited poly-GeSi film at $\omega=2.5^{\circ}$ (with a count of 933). The former exhibits a 19-times-more-intensive shifted (311) $2 \theta$ peak than the latter.

Fig. 3.12 shows the GAXRD results for LC GeSi film and asdeposited poly-GeSi film (under the same data acquisition conditions). One can see that: (i) shifted (311) $2 \theta$ peaks have emerged adjacent to the expected (311) $2 \theta$ peak position; and (ii) when the incidence angle $\omega$ moves from $2.5^{\circ}$ to $4^{\circ}$, the shift increases towards higher $2 \theta$ angles, for all the films. This shift represents a reduced lattice spacing $d$, indicating a tensile stress along the lateral 
direction (i.e. along the film surface), and is observed for both the LC and as-deposited GeSi films. Similarly, shifting of the $2 \theta$ peaks with respect to $\omega$ indicates a gradient in stress as a function of depth.

For different incidence angles ranging from $2.5^{\circ}$ to $4^{\circ}$, the calculated $\alpha$ (the angle between the crystal plane and the wafer surface, for details see section 2.3) for all the individual shifted (311) $2 \theta$ peaks is $25^{\circ}$, for all the films. This indicates that the diffraction peaks originate from the lattice planes all oriented at $25^{\circ}$ to the surface.

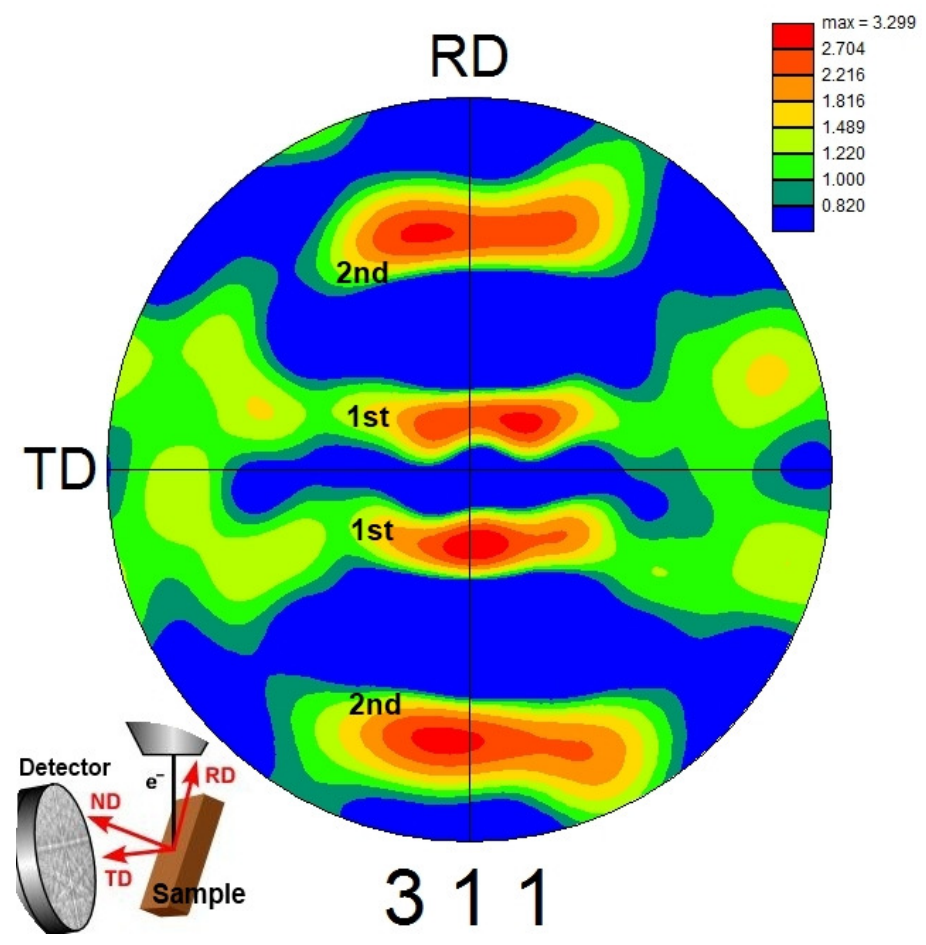

Figure 3.13: This pole figure is obtained using EBSD showing angular distributions (311) planes with respect to the film surface. RD-Rolling direction (which is along the film surface), TD-Transverse direction, ND-Normal direction. A large number of (311) planes occur at an angle of $25^{\circ}$ to the surface (first maximum) while the second maximum appears at around $65^{\circ}$.

Materials for Monolithic Integration of Optical Functions on CMOS 
\begin{tabular}{l|l} 
Chapter 3 - Green-Laser Crystallization and Dopant Activation of GeSi & $\mathbf{5 0}$
\end{tabular}

Alloys

The existence of such-oriented (311) planes is further confirmed through EBSD. The EBSD pole figure (see Fig. 3.13) shows the angular distribution of (311) lattice planes in the sample rolling direction (RD) i.e. with respect to the film surface. Two main orientations can be seen: a large number of (311) planes occur at an angle of $25^{\circ}$ to the surface (first maximum) while the second maximum appears at around $65^{\circ}$. From the statistical analysis we conclude that more than $60 \%$ of the grains begin their growth as (001) planes and finish as (311) planes. This indicates a preferential evolutionary selection [10] towards (311) planes.

Table 3.1: Strain calculation for LC GeSi film and as-deposited poly-GeSi film. All XRD spectra were obtained under the same acquisition conditions to facilitate comparisons.

\begin{tabular}{cccccccc}
\hline $\begin{array}{c}\text { Material } \\
\text { Type }\end{array}$ & $\omega$ & $\begin{array}{c}(311) 2 \theta \\
\text { normal } \\
\text { peak }\end{array}$ & $\begin{array}{c}(311) 2 \theta \\
\text { shifted } \\
\text { peak }\end{array}$ & $\begin{array}{c}(311) 2 \theta \\
\text { shifted } \\
\text { peak } \\
\text { intensity } \\
\text { counts }\end{array}$ & $\begin{array}{c}d_{0} \\
(\AA)\end{array}$ & $\begin{array}{c}d \\
(\AA)\end{array}$ & $\begin{array}{c}\Delta d / d_{0} \\
(\%)\end{array}$ \\
\hline $\begin{array}{c}\text { As-deposited } \\
\text { Poly } \\
\mathrm{Ge}_{0.85} \mathrm{Si}_{0.15}\end{array}$ & $2.5^{\circ}$ & $54.17^{\circ}$ & $55.81^{\circ}$ & 933 & 1.647 & 1.602 & 2.7 \\
\hline $\begin{array}{c}L C \\
G e_{0.85} \mathrm{Si}_{0.15}\end{array}$ & $3.0^{\circ}$ & $54.35^{\circ}$ & $56.41^{\circ}$ & 17733 & 1.642 & 1.586 & 3.4 \\
\hline
\end{tabular}

For the LC GeSi films, the shifted (311) $2 \theta$ peak with the highest intensity counts (17733) appears at $\omega=3^{\circ}$, and for the as-deposited poly-GeSi film at $\omega=2.5^{\circ}$ (with a count of 933). This indicates that the lattice planes with the corresponding $d$ have the highest prominence. Considering these two prominent peaks, the strain for both types of GeSi film is calculated as shown in Table 3.1. The LC GeSi film shows a strain $\left(\Delta d / d_{0}\right)$ of $3.4 \%$; for the asdeposited film the strain reaches $2.7 \%$. The former further exhibits a 19-times-more-intensive shifted (311) $2 \theta$ peak than the latter; apparently, a much higher number of strained (311) planes exists in the LC film compared to as-deposited poly-GeSi.

In order to further verify the existence of strain, Raman measurements were done using a $30-\mathrm{mW}, 532 \mathrm{~nm}$ laser beam at room temperature. For a relaxed $\mathrm{Ge}_{0.85} \mathrm{Si}_{0.15}$ film, the first-order $\mathrm{Ge}-\mathrm{Ge}$ 
peak should appear around $298 \mathrm{~cm}^{-1}$ [11]. It is considerably offset for both layers, as shown in Fig. 3.14. The left-hand shift compared to $298 \mathrm{~cm}^{-1}$ indicates that both layers have tensile stress, being the highest in the LC GeSi film. This is in line with the XRD results. It is important to note that no $\mathrm{Ge}-\mathrm{Si}$ and $\mathrm{Si}-\mathrm{Si}$ Raman peaks were observed in the spectrum due to the low concentration of these bonds [12] (as expected, given the high germanium fraction).

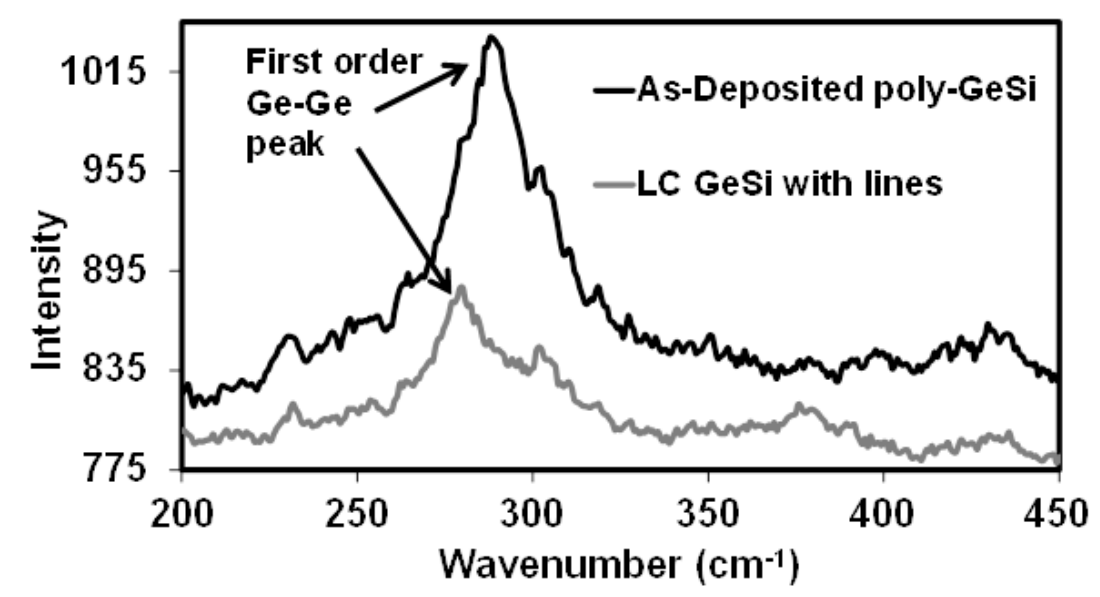

Figure 3.14: Raman Spectra of as-deposited poly-GeSi and LC GeSi with preformed lines. The left-hand shift of the Ge-Ge peak corroborates the results obtained from the XRD.

The residual tensile stress in the layer can be attributed to the different thermal expansion coefficients of the $\mathrm{Ge}_{0.85} \mathrm{Si}_{0.15}$ film $\left(5.2 \times 10^{-6}{ }^{\circ} \mathrm{C}^{-1}[13]\right)$ and the $\mathrm{SiO}_{2}$ layer beneath it $\left(0.5 \times 10^{-6}{ }^{\circ} \mathrm{C}^{-1}\right.$, both values at $300 \mathrm{~K}$ ). During the laser treatment, the GeSi film is melted. As it cools down and solidifies, its shrinking is obstructed by the underlying oxide layer. To be noted, the GeSi layer is cooled from a very high temperature (i.e. from its melting point) in comparison to the colder underlying oxide layer, magnifying the effect.

Fig. 3.15 shows the concentration of $\mathrm{Ge}$ and $\mathrm{Si}$ atoms along the film depth profile, as obtained by X-ray Photoelectron Spectroscopy (XPS). The a-GeSi film prior to crystallization and the LC GeSi film are compared. The atomic concentrations are constant along the depth of the a-GeSi film. Yet, the upper layer of the LC GeSi film is germanium-enriched. This segregation of Ge to the surface occurs in 
order to lower the surface energy of the crystallized film [14]. This is further enhanced by multiple melting due to the large pulse overlap. The vertical gradient in the material composition leads to a gradient in thermal expansion coefficient, and can also contribute to the residual stress in the LC GeSi films.

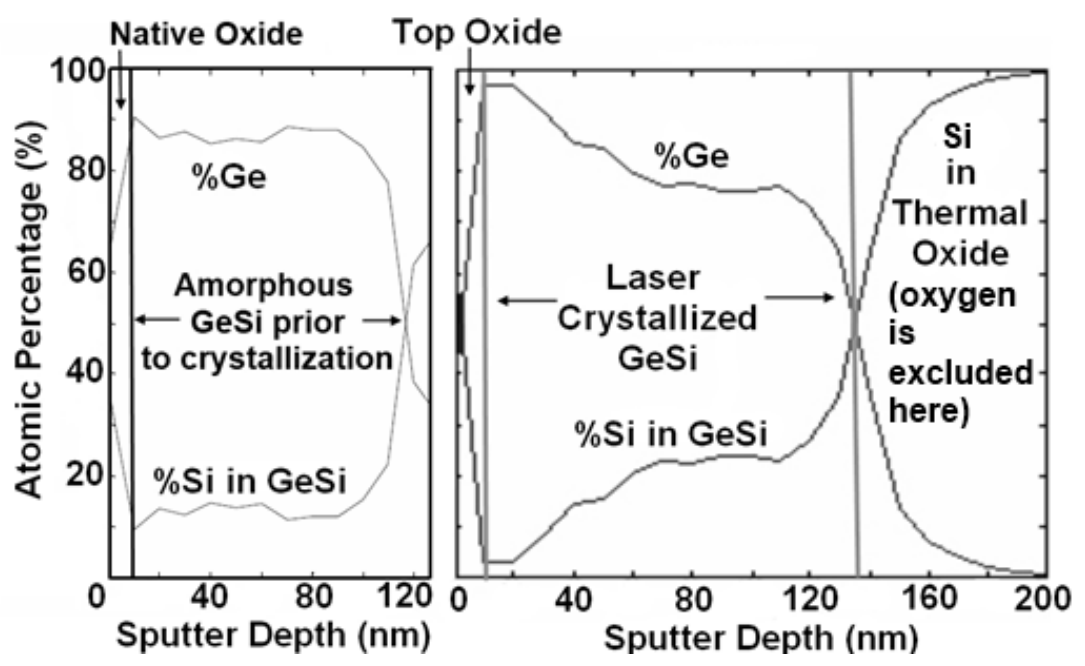

Figure 3.15: XPS depth profile detailing the composition of aGeSi films before and after the laser crystallization process. Ge enrichment can be observed at the top layer of the LC film.

\subsubsection{Optical properties}

Spectroscopic Ellipsometry (SE) was used to determine the refractive index $n$, extinction coefficient $k$ and the band gap of the $\mathrm{Ge}_{0.85} \mathrm{Si}_{0.15}$ films. These optical properties are highly relevant for GeSi application in optoelectronic devices such as photodiodes. The Tauc-Lorentz (TL) model (see section 2.7) was used to parameterize these films. To note, the TL model only takes into account inter-band absorption in the material and does not include defect absorption, intra-band absorption or Urbach tail absorption. For GeSi films in our study inter-band absorptions are of high relevance as they can effectively create electron-hole pairs contributing to the photo-current in detectors.

The obtained values of the four parameters: the Tauc gap or optical band gap $E_{g}$, the peak transition energy $E_{0}$, the broadening 
term $\mathrm{Br}$ and the transition-matrix-element related parameter Amp for a-GeSi film are shown in Table 3.2. Two TL dispersions (with coupled $E_{\mathrm{g}}$, i.e., using same $E_{\mathrm{g}}$ ) were used to describe the LC GeSi film and the as-deposited poly-GeSi film representing the two high energy inter-band peak transitions (also shown in Table 2). The values of $E_{0}$ for both materials can be related to those of pure Ge (4.4 $\mathrm{eV}$ and $2.3 \mathrm{eV})$ and $\mathrm{Si}(4.4 \mathrm{eV}$ and $3.4 \mathrm{eV})$ [15] supporting the choice TL model for fitting.

Table 3.2. Tauc-Lorentz dispersion parameters as obtained for a-GeSi film, as-deposited poly-GeSi film and LC GeSi film through fitting.

\begin{tabular}{cccccc}
\hline Material & $\begin{array}{c}\text { No. of } \\
\text { TL Osc. }\end{array}$ & $\begin{array}{c}\boldsymbol{E}_{\boldsymbol{g}} \\
(\mathbf{e V})\end{array}$ & $\begin{array}{c}\boldsymbol{E}_{\boldsymbol{0}} \\
(\mathbf{e V})\end{array}$ & $\begin{array}{c}\boldsymbol{B r} \\
(\mathbf{e V})\end{array}$ & $\begin{array}{c}\boldsymbol{A m p} \\
(\mathbf{e V})\end{array}$ \\
\hline $\mathrm{a}-\mathrm{Ge}_{0.85} \mathrm{Si}_{0.15}$ & TL1 & $0.96 \pm 0.005$ & $3.0 \pm 0.01$ & $3.0 \pm 0.03$ & $178.5 \pm 1.7$ \\
\hline $\mathrm{LC} \mathrm{Ge}_{0.85} \mathrm{Si}_{0.15}$ & TL1 & $0.34 \pm 0.02$ & $2.4 \pm 0.006$ & $0.3 \pm 0.02$ & $13.2 \pm 0.4$ \\
\hline & TL2 & $\begin{array}{c}\text { Coupled to } \\
\text { TL1 } \boldsymbol{E}_{\boldsymbol{g}}\end{array}$ & $3.9 \pm 0.02$ & $1.3 \pm 0.05$ & $64.9 \pm 1.8$ \\
\hline $\begin{array}{c}\text { As-deposited } \\
\text { Poly-Ge }{ }_{0.85} \mathrm{Si}_{0.15}\end{array}$ & TL1 & $0.83 \pm 0.01$ & $2.6 \pm 0.01$ & $0.9 \pm 0.03$ & $32.4 \pm 1.3$ \\
\hline & TL2 & $\begin{array}{c}\text { Coupled } \\
\text { to TL1 } \boldsymbol{E}_{\boldsymbol{g}}\end{array}$ & $3.9 \pm 0.01$ & $1.5 \pm 0.05$ & $70.6 \pm 1.6$ \\
\hline
\end{tabular}

The $n$ and $k$ for the GeSi films with respect to the photon energy are shown in Figs. 3.16a and 3.16b.

The first $E_{0}$-peak for the LC GeSi appears at $2.4 \mathrm{eV}$, lower than $2.6 \mathrm{eV}$ of as-deposited poly-GeSi film. Increase in Ge fraction causes shift in the first $E_{0}$-peak to lower photon energy levels. For example first $E_{0}$-peak for pure Si appears at $3.4 \mathrm{eV}$ while for pure $\mathrm{Ge}$ it is at $2.3 \mathrm{eV}$ [15]. This indicates a higher Ge fraction in the LC film compared to the as-deposited poly-GeSi film. Given the high sensitivity of SE to the uppermost layers for light absorbing films, this observation is consistent with the Ge-enrichment observation by XPS (see Fig. 3.15).

Relaxed mono-crystalline $\mathrm{Ge}_{0.85} \mathrm{Si}_{0.15}$ has a band gap of $0.84 \mathrm{eV}$ [16]. Using the TL model fit, the as-deposited poly-GeSi indeed exhibits a $0.83 \mathrm{eV}$ optical band gap. The a-GeSi film shows a wider 
band gap of $0.96 \mathrm{eV}$. Such band gap widening is commonly seen in a-Si films compared to crystalline Si.
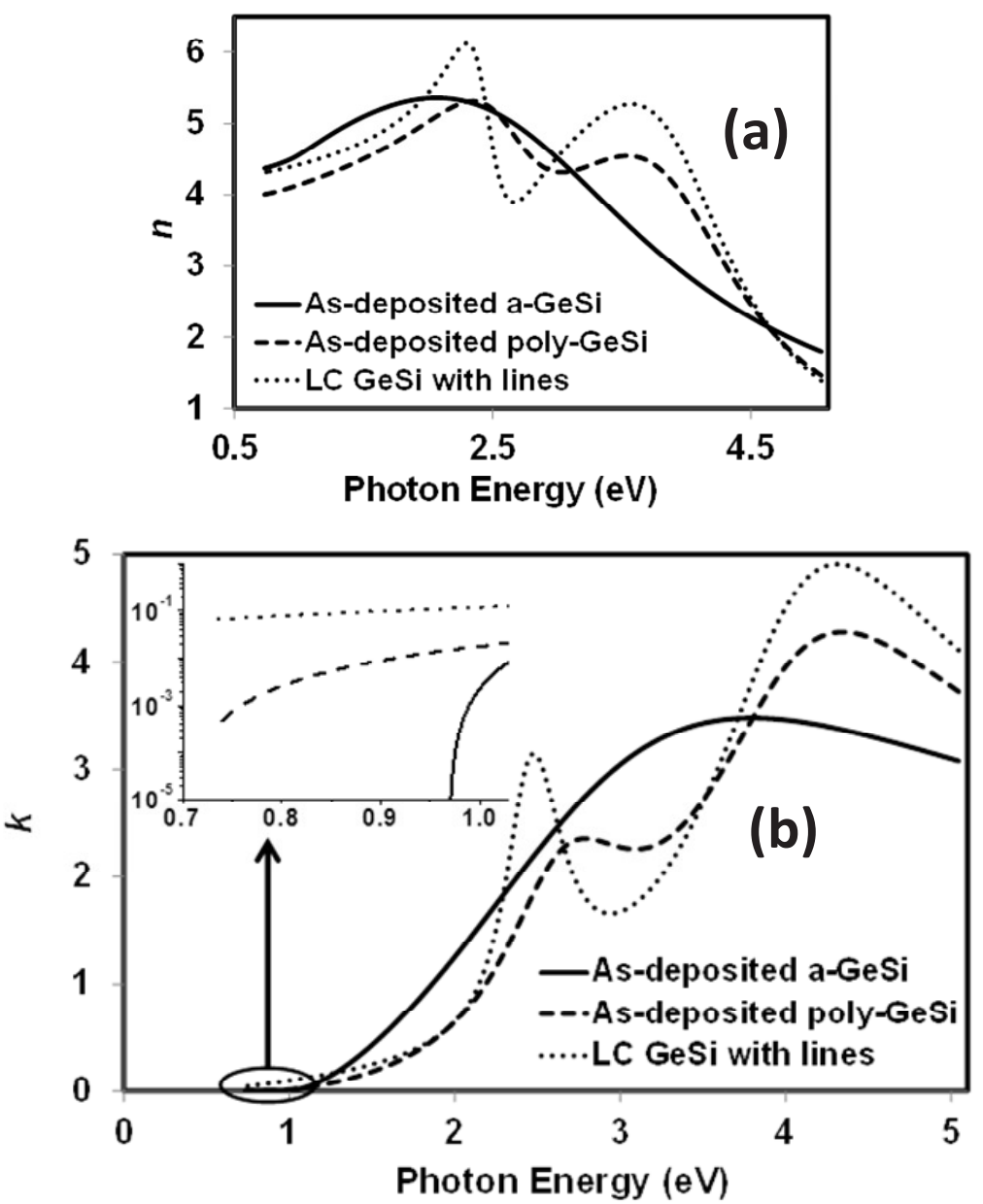

Figure 3.16: The (a) refractive index $n$ and (b) extinction coefficient $k$ of the a-GeSi film, as-deposited poly-GeSi film and LC GeSi film. The inset shows a zoomed-in view of $k$ indicating the absorption near the edge.

The band gap of the LC GeSi film as determined using TL model is as small as $0.34 \mathrm{eV}$. To note, the accuracy of extracting this particular value can be low because it falls outside the spectral range detectable by our SE. Nevertheless, we can expect narrowing of the band gap caused by a significant tensile strain $[17,18]$.

Materials for Monolithic Integration of Optical Functions on CMOS 
To note, as-deposited poly-GeSi exhibits an extracted band gap very close to the value of unstrained mono-crystalline material. The XRD results (Fig. 3.11) show a 19-times lower intensity of the shifted (311) $2 \theta$ peak for the as-deposited poly-GeSi layer compared to the LC GeSi layer (see also Table 3.1). This points to a lower number of strained (311) planes and, therefore indicates a smaller impact on the band gap.

Fig 3.17 shows the Raman $\mathrm{Si}$ peak originating from the substrate for LC and as-deposited poly-GeSi samples as well as for a sample with a plain oxide layer on Si only. It can be seen that the intensity of this $\mathrm{Si}$ peak for $\mathrm{LC} \mathrm{GeSi}$ is the lowest, more than 2 times lower than as-deposited poly-GeSi sample. This could likely be caused by a higher absorption of the $532 \mathrm{~nm}$ laser light (or the scattered light) by the LC GeSi leading to less light penetrating to the Si substrate (or absorbing more Raman-scattered light having a very similar wavelength) thereby resulting in the lower Si peak intensity. This further confirms the enhanced absorption in the LC GeSi layer and indirectly supports its apparently small band gap.

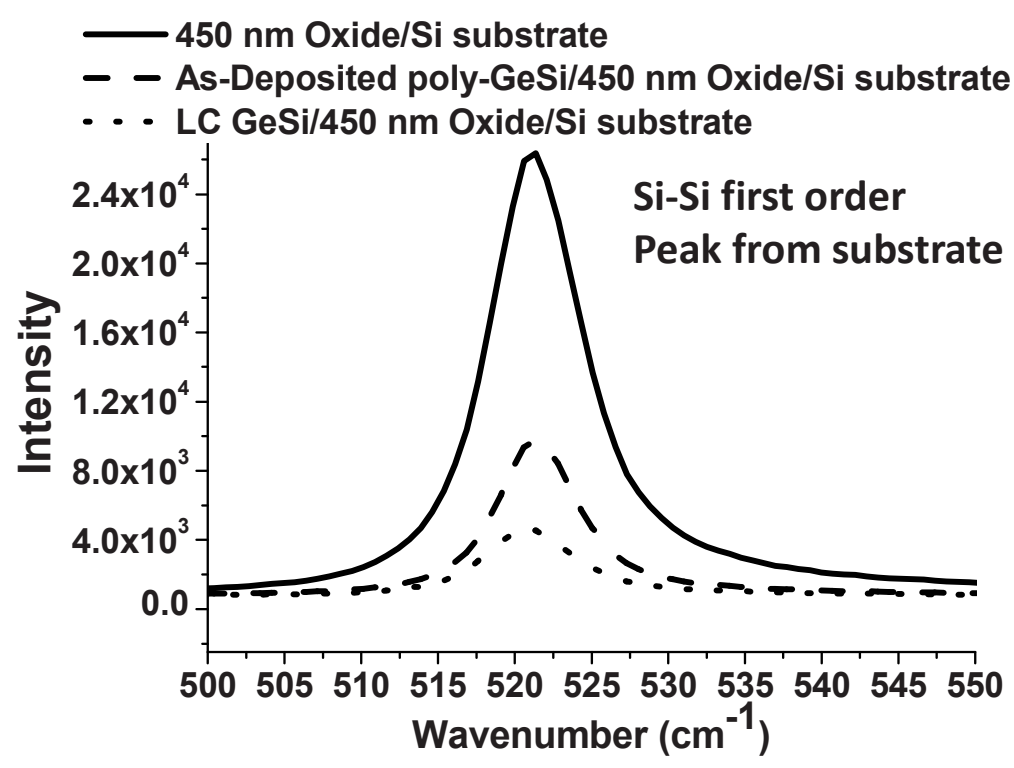

Figure 3.17: Raman peak originating from Si substrate with different layers (see legend) on it. 
This probable band gap narrowing, resulting from laser crystallization is an interesting effect. It may widen the application range of GeSi in optoelectronics. For example, one might be able to use LC GeSi films to realize infrared photodetectors for wavelengths between 1 and $5 \mu \mathrm{m}$. Hence further analysis is required (such as photoluminescence spectroscopy) to confirm the extracted band gap value.

\subsection{Activation of ion-implanted dopants}

For the fabrication of devices such as p-i-n photodetectors, formation of highly doped regions is of utmost importance. In order to enable post-processing on top of a CMOS chip, where the substrate temperature should not exceed $450{ }^{\circ} \mathrm{C}$, ion-implantation and laser activation of dopants is being studied.

$\mathrm{BF}_{2}^{+}, \mathrm{As}^{+}$and $\mathrm{P}^{+}$were implanted at a dose of $10^{15} \mathrm{~cm}^{-2}$ into as-deposited poly- $\mathrm{Ge}_{0.85} \mathrm{Si}_{0.15}$ and a- $\mathrm{Ge}_{0.85} \mathrm{Si}_{0.15}$ films (100 nm thick). $\mathrm{BF}_{2}^{+}$was implanted at $30 \mathrm{keV}$, arsenic and phosphorous at $40 \mathrm{keV}$. Furnace annealing, rapid thermal annealing and laser annealing were compared for dopant activation in the poly- $\mathrm{Ge}_{0.85} \mathrm{Si}_{0.15}$ film. We also carried out laser crystallization of ion-implanted a- $\mathrm{Ge}_{0.85} \mathrm{Si}_{0.15}$ films, combining crystallization and dopant activation in a single process step.

The activation of dopants was inferred from the sheet resistance value of the film obtained using the four-point probe method. (In case the sheet resistance did not change upon anneal, the activation was considered unsuccessful.) By multiplying the sheet resistance with the film thickness (measured using SE), the resistivity was obtained. Resistivity values below $20 \mathrm{~m} \Omega-\mathrm{cm}$, corresponding to an active dopant concentration above $10^{19} \mathrm{~cm}^{-3}$ (for mono-crystalline $\mathrm{Ge}$, see [19]), were considered desirable.

Furnace annealing (FA) and rapid thermal annealing (RTA) were performed with various combinations of annealing time and temperature. FA resulted in successful activation of boron dopants but neither As nor P got activated. RTA led to comparable results, see Table 3.3. The n-type dopants (As and P) have high diffusivity in pure Ge, and are reported to out-diffuse [20]. As a result, given sufficient thermal budget, these impurities will move out of the Ge. A similar problem can be expected in poly- $\mathrm{Ge}_{0.85} \mathrm{Si}_{0.15}$ films, which 
explains the lack of As and P activation by FA and RTA.

On the other hand, green laser annealing (LA) activated all three dopant types (see Table 3.3). The laser energy density per pulse was lowered and chosen to activate the dopants without melting the film. This successful activation of n-type dopants could be attributed to the sub- $\mu$ s-long laser pulses, limiting the diffusion of the dopants.

$\mathrm{BF}_{2}^{+}, \mathrm{As}^{+}$and $\mathrm{P}^{+}$were also implanted in a plain a- $\mathrm{Ge}_{0.85} \mathrm{Si}_{0.15}$ film which was subsequently laser crystallized using the green laser. This involved melting and re-crystallization of the implanted a- $\mathrm{Ge}_{0.85} \mathrm{Si}_{0.15}$ films. A significant reduction in the resistivity values of As- and P-doped films was observed (Table 3.3). In opposite, the resistivity of B-doped GeSi has increased. The single-step treatment was however not optimized for sequential super-lateral growth; the grain size was in the range of $200 \mathrm{~nm}$, i.e., similar to that of as-deposited poly-GeSi.

Table 3.3. Comparison of different dopant activation methods, used for ion-implanted poly-Ge ${ }_{0.85} S_{i} i_{0.15}$ and a-Ge $e_{0.85} S_{0.15}$ films (see text for details). The thickness of all films is $100 \mathrm{~nm}$.

\begin{tabular}{|c|c|c|c|c|c|}
\hline \multirow[b]{2}{*}{ Method } & \multirow[b]{2}{*}{ Material } & \multirow[b]{2}{*}{ Process Parameters } & \multicolumn{3}{|c|}{ Resistivity (m $\Omega$-cm) } \\
\hline & & & Boron & As & $\mathbf{P}$ \\
\hline FA & $\begin{array}{c}\text { poly- } \\
\mathrm{Ge}_{0.85} \mathrm{Si}_{0.15}\end{array}$ & $\begin{array}{l}600-800{ }^{\circ} \mathrm{C} ; \\
15-30 \text { minutes }\end{array}$ & $6.7-7.8$ & $>200$ & $>200$ \\
\hline$\overline{\mathrm{RTA}}$ & & $\begin{array}{l}700-900{ }^{\circ} \mathrm{C} ; \\
5-60 \text { seconds }\end{array}$ & $5.0-5.5$ & $>200$ & $>200$ \\
\hline RTA & & $\begin{array}{c}500^{\circ} \mathrm{C} ; \\
5 \mathrm{~s} \text { to } 5 \mathrm{mins}\end{array}$ & $5.0-5.5$ & $>200$ & $>200$ \\
\hline $\mathrm{LA}$ & & $\begin{array}{l}\text { 95\% overlapping; } \\
0.4 \mathrm{Jcm}^{-2} \\
\text { FWHM: } 40 \mu \mathrm{m}\end{array}$ & 10 & 6.9 & 31.2 \\
\hline $\begin{array}{l}\text { LC with } \\
\text { implanted } \\
\text { dopants }\end{array}$ & $\begin{array}{c}\mathrm{a}- \\
\mathrm{Ge}_{0.85} \mathrm{Si}_{0.15}\end{array}$ & $\begin{array}{c}\text { 99.75\% overlapping; } \\
0.6 \mathrm{Jcm}^{-2} \\
\text { FWHM: } 40 \mu \mathrm{m}\end{array}$ & 90.6 & 2.7 & 17.6 \\
\hline
\end{tabular}

\subsection{Conclusions}

In this chapter, crystallization of a- $\mathrm{Ge}_{0.85} \mathrm{Si}_{0.15}$ films using a green laser was investigated, for the purpose of semiconductor device 
fabrication at low substrate temperature. For the films with preformed lines, a fine-tuned laser crystallization recipe resulted in the formation of polycrystalline material with large crystal grains. Of the overall surface area, $64 \%$ has grains longer than $2 \mu \mathrm{m}$, some of them being considerably longer: $30 \%$ of the area shows a grain length in the range of $10-25 \mu \mathrm{m}, 5 \%$ up to $35 \mu \mathrm{m}$ and $2 \%$ up to $50 \mu \mathrm{m}$.

The grains were confined between the preformed lines (i.e. within a width of $3 \mu \mathrm{m}$ ) thereby facilitating the fabrication of semiconductor devices in a subsequent fabrication process. This would likely enhance the electrical device characteristics compared to devices on thin polycrystalline films with random grain boundaries. Films without preformed lined exhibited more random positioning of grain boundaries with a large angle of deviation in the crystal's length axis.

The laser crystallization led to a strain of $3.4 \%$ due to the occurrence of residual tensile stress. The possibility of significant band gap narrowing was observed in the laser crystallized films, which can widen the application range of $\mathrm{GeSi}$ in infrared photodetectors. The simulation using Silvaco-Atlas code in chapter 1 should perhaps be repeated with strain included.

We finally studied activation of implanted p-type $\left(\mathrm{BF}_{2}{ }^{+}\right)$and ntype $\left(\mathrm{As}^{+}, \mathrm{P}^{+}\right)$dopants in $\mathrm{Ge}_{0.85} \mathrm{Si}_{0.15}$ films. Green laser annealing was able to successfully activate both $\mathrm{p}$ - and n-type dopants. On the other hand, both furnace annealing and rapid thermal annealing failed in activating the n-type dopants. The one-step laser treatment (crystallization and annealing combined together) of n-type implanted a- $\mathrm{Ge}_{0.85} \mathrm{Si}_{0.15}$ films resulted in their reduced resistivity compared to the two-step laser treatment. The one-step laser treatment of the ptype samples provided however a 9-times higher resistivity compared to the two-step treatment.

\section{References}

1. J. Holleman, A. E. T. Kuiper and J. F. Verweij, J. Electrochem. Soc. 140, 1717 (1993).

2. J. S. Im, H. J. Kim, and M. O. Thompson, Appl. Phys. Lett. 63, 1969 (1993).

3. M. Lee, S. Moon, M. Hatano, K. Suzuki and C. P. 
Grigoropoulos, J. Appl. Phys. 88, 4994 (2000).

4. R.S. Sposili and J.S. Im, Appl. Phys. Lett. 69, 2864 (1996).

5. K. Murakami, O. Eryu, K. Takita, and K. Masuda, Phys. Rev. Lett. 59, 2203 (1987).

6. I. Brunets, J. Holleman, A. Y. Kovalgin, A. Boogaard and J. Schmitz, IEEE Trans. Electron Devices 56, 1637 (2009).

7. H. J. Kim and J. S. Im, Appl. Phys. Lett. 68, 1513 (1996).

8. C. Eisele, M. Berger, M. Nerding, H.P. Strunk, C.E. Nebel and M. Stutzmann, Thin Solid Films 427, 176 (2003).

9. K. Suzuki, M. Takahashi and M. Saitoh, Appl. Phys. A 69, S263 (1999).

10. E. Vallat-Sauvain, U. Kroll, J. Meier, A. Shah, and J. Pohl, J. Appl. Phys. 87, 3137 (2000).

11. H. H. Burke and I. P. Herman, Phys. Rev. B 48, 15016 (1993).

12. F. Pezzoli, Lucio Martinelli, E. Grilli, M. Guzzi et al, Mater. Sci. Eng. B 124-125, 127(2005).

13. M.E. Levinshtein, S.L. Rumyantsev, M.S. Shur, Properties of Advanced Semiconductor Materials GaN, AlN, InN, BN, SiC, SiGe, p. 149-188, John Wiley \& Sons, New York (2001).

14. P. C. Weakliem and E.A. Carter, Phys. Rev. B 45, 13458 (1992).

15. J. R. Chelikowsky and M. L. Cohen, Phys. Rev. B 14, 556 (1976).

16. R. Braunstein, A.R. Moore, F. Herman, Phys. Rev. 109, 695 (1958).

17. M. E. Kurdi, G. Fishman, S. Sauvage, and P. Boucaud, J. Appl. Phys. 107, 013710 (2010).

18. J. Michel, J. Liu and L. C. Kimerling, Nat. Photonics 4, 527 (2010).

19. D. B. Cuttris, Bell System Technical Journal 40, 509 (1961).

20. A. Axmann, M. Schulz and C. R. Fritzsche, Appl. Phys. 12, 173 (1977). 


\section{Chapter 4}

\section{Low Loss Silicon Oxynitride: Deposition and Properties}

In this chapter a detailed analysis is presented of the deposition and properties of silicon oxynitride $\left(\mathrm{SiO}_{x} N_{y}\right)$ films aiming towards low-temperature fabrication at $150{ }^{\circ} \mathrm{C}$ with low optical losses in the visible and near-infrared range. The influence of the deposition parameters such as $\mathrm{SiH}_{4}$ fraction, deposition pressure and $\mathrm{Ar} / \mathrm{N}_{2}$ ratio on the film properties was experimentally investigated using spectroscopic ellipsometry, X-ray photoelectron spectroscopy and Fourier transform infrared spectroscopy. These findings were consistent with the chemical modelling of gas-phase composition of the plasma thereby leading to better understanding of the deposition process. The propagation losses were determined using the prism coupling technique for various IR wavelengths ranging between $1300 \mathrm{~nm}$ and $1600 \mathrm{~nm}$. Propagation losses as low as $0.5 \pm 0.05 \mathrm{~dB} / \mathrm{cm}$ at $1300 \mathrm{~nm}$ wavelength are measured, a very significant outcome for a low temperature deposited waveguide material.

This work was published in:

- B. Rangarajan, A.Y. Kovalgin, K. Wörhoff and J. Schmitz, Opt. Lett. 38, 941 (2013).

- B. Rangarajan, A.Y. Kovalgin, and J. Schmitz, Surf. Coat. Tech. 230, 46 (2013). and presented at:

- 19th EuroCVD meeting 2013, Varna, Bulgaria (Oral presentation).

Materials for Monolithic Integration of Optical Functions on CMOS 


\subsection{Deposition system}

The custom-built remote inductively coupled PECVD (ICPECVD) system (shown in Fig. 4.1) was used to deposit silicon oxynitride films. The system has a base pressure of $10^{-7}$ mbar. The deposition chamber is connected to an external load lock via a motorized arm for loading and unloading 4-inch wafers. The ICP source is directly located on top of the deposition chamber and is supplied by Alcatel Micro Machining system (13.56 MHz with $2 \mathrm{~kW}$ as the maximum electric power). The height of the wafer in the chamber can be adjusted with respect to the plasma generation region. The chamber has two glass windows for performing spectroscopic ellipsometry in in-situ configuration. Between the chuck and wafer, Ar gas is circulated and maintained at 10 mbar pressure to control the wafer temperature.

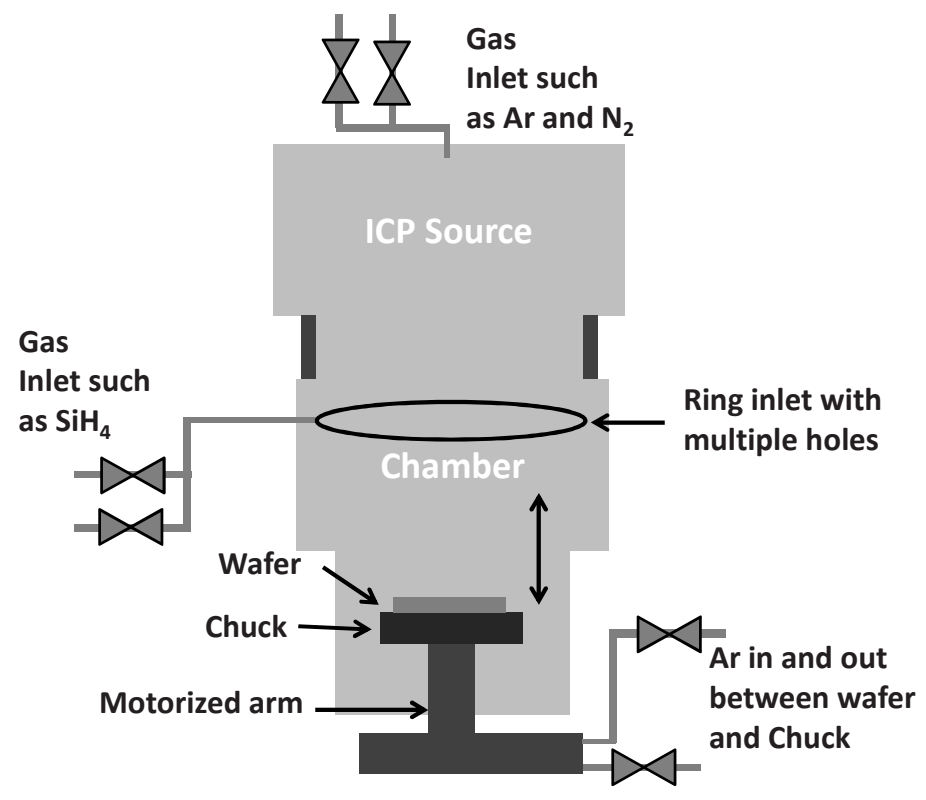

Fig 4.1: A schematic sketch showing the ICPECVD reactor used for SiON deposition.

\subsection{Precursor gases}

The precursor gases were $2 \% \mathrm{SiH}_{4}$-in-Ar and $\mathrm{N}_{2}$ diluted with Ar. The $\mathrm{N}_{2}$ purity was $99.999 \%$ with $\mathrm{O}_{2} \leq 1 \mathrm{ppm}$ and $\mathrm{H}_{2} \mathrm{O} \leq 3 \mathrm{ppm}$ as 
per the provider's specifications. However the $\mathrm{N}_{2}$ line is rather long and shared by other systems in the cleanroom; this could possibly lead to higher $\mathrm{O}_{2}$ and $\mathrm{H}_{2} \mathrm{O}$ levels than specified. In practice the deposited films always contained a certain amount of oxygen depending on process conditions.

\subsection{Experimental}
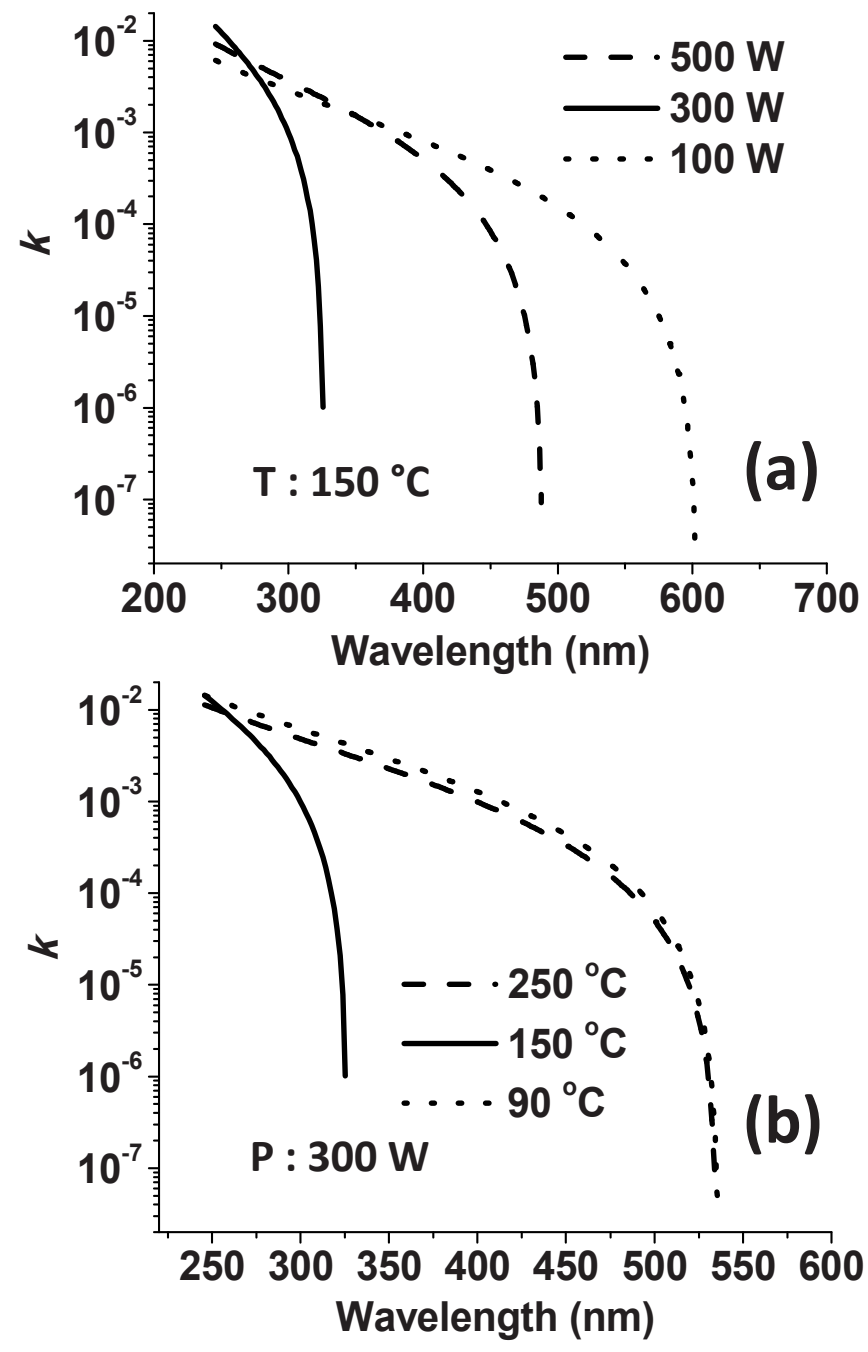

Fig 4.2: The extinction coefficient $k$ as function of wavelength for different (a) plasma power and (b) substrate temperature. 
As a first step in this study, the plasma power and substrate temperature were varied. Figs. $4.2 \mathrm{a}$ and $4.2 \mathrm{~b}$ depict the resulting extinction coefficients $(k)$ as a function of wavelength. The lowest extinction coefficient was obtained with a plasma power of $300 \mathrm{~W}$ at $150{ }^{\circ} \mathrm{C}$; the remainder of this study was carried out using those settings.

This was followed by a study on the influence of the deposition pressure set at 0.01 mbar and 0.06 mbar along with two different $2 \%$ $\mathrm{SiH}_{4}$-in-Ar flows of 10 and $100 \mathrm{sccm}$, which amounted to $0.08 \%$ and $0.8 \%$ of $\mathrm{SiH}_{4}$ (volume) fraction in the reaction chamber, respectively. In addition, the influence of the $\mathrm{Ar} / \mathrm{N}_{2}$ flow ratio on the properties of the deposited films was analyzed. The $\mathrm{Ar} / \mathrm{N}_{2}$ ratio was varied between 2 and 16 while the total $\mathrm{Ar}+\mathrm{N}_{2}$ flow was kept constant at $235 \mathrm{sccm}$. To be noted, the $0.01 \mathrm{mbar}$ pressure setting hardly yielded a stable pressure reading; the latter could vary between 0.01 and 0.018 mbar.

\subsection{Chemical modeling of plasma composition}

The chemical composition of the plasma largely determines the elemental composition of the deposited films and therewith their optical properties. We chemically modeled the reactions in the plasma to understand the influence of the deposition parameters such as pressure and $\mathrm{SiH}_{4}$ fraction on the plasma composition. The approach was to first look at the film properties using spectroscopic ellipsometry (SE), X-ray photoelectron spectroscopy (XPS) and Fourier transform infrared spectroscopy (FTIR) and then to relate these to the results obtained using chemical modelling.

It is widely known that the plasma chemistry largely depends on the electron energy distribution function (EEDF). EEDFs for different plasma reactors can be different based on their design and type of excitation source. Therefore the use of EEDFs based on the common Maxwell-Boltzmann or Druyvesteyn distributions in the model can lead to significant deviations in the results and misinterpretation of the relation between the modeled plasma composition and the actual film properties. A detailed view on this is provided in $[1,2]$.

Therefore, for this model, the EEDFs were experimentally determined (under different process conditions) using a Langmuir 
probe for non-depositing plasmas such as pure Ar and $\mathrm{N}_{2}$ plasma as well as for $\mathrm{Ar}-\mathrm{N}_{2}$ plasma. Using optical emission spectroscopy these measured EEDFs were further verified for the depositing plasmas by adding small amounts of $\mathrm{SiH}_{4}(\leq 0.8 \%$ of the volume fraction) $[1,2]$. It was shown in $[1,2]$ that the EEDFs measured using a Langmuir probe resembled the EEDFs measured using small additions of $\mathrm{SiH}_{4}$ (as long as the total pressure was below 0.08 mbar). The rate constants for individual electron-impact reactions were determined using the measured EEDFs and the reaction cross-sections (obtained from literature) $[1,2]$. On the other hand the rate constants for the homogenous reactions were directly obtained from literature.

The $\mathrm{Ar}-\mathrm{SiH}_{4}-\mathrm{N}_{2}-\mathrm{O}_{2}$ plasma is modeled with 173 reactions and using this model we compute the concentrations of important chemically-reactive species such as $\mathrm{SiH}_{\mathrm{y}}(y=0$ to 3$), \mathrm{H}, \mathrm{N}, \mathrm{O}, \mathrm{O}\left({ }^{1} \mathrm{D}\right)$, and synthesized $\mathrm{H}_{2} \mathrm{O}$ in the plasma.

The 173 reactions used in this model can be categorized as follows:

- Electron impact reactions

- Dissociative excitation of $\mathrm{SiH}_{\mathrm{y}}(y=1$ to 4$)$ : 10 reactions.

- Dissociative ionization of $\mathrm{SiH}_{\mathrm{y}}(y=1$ to 4$): 19$ reactions.

- Dissociative excitation of $\mathrm{SiH}_{\mathrm{y}}{ }^{+}(y=1$ to 3$)$ ions: 10 reactions.

- Dissociative recombination of $\mathrm{SiH}_{\mathrm{y}}{ }^{+}(y=1$ to 3$)$ ions: 8 reactions.

- Dissociation of $\mathrm{Si}_{2} \mathrm{H}_{6}: 2$ reactions.

- Dissociation of $\mathrm{Si}_{3} \mathrm{H}_{8}: 1$ reaction.

- Dissociation of $\mathrm{Si}_{2} \mathrm{H}_{5}$ and $\mathrm{Si}_{2} \mathrm{H}_{4}: 2$ reactions.

- Radiative recombination with $\mathrm{H}^{+}$and $\mathrm{Si}^{+}: 2$ reactions.

- Dissociative excitation of $\mathrm{N}_{2} \mathrm{O}: 2$ reactions.

- Dissociative excitation of $\mathrm{N}_{2}: 1$ reaction.

- Dissociative excitation of $\mathrm{O}_{2}: 3$ reactions.

- Collisions with hydrogen: 6 reactions.

- Charge exchange between proton $\left(\mathrm{H}^{+}\right)$and $\mathrm{SiH}_{\mathrm{y}}(y=1$ to 4$)$ for thermal energy range not exceeding $0.1 \mathrm{eV}: 8$ reactions.

- $\mathrm{Si}_{\mathrm{x}} \mathrm{H}_{\mathrm{y}}$ based secondary homogeneous reactions: 47 reactions.

- Homogeneous reaction in $\mathrm{H}_{2}-\mathrm{O}_{2}-\mathrm{N}_{2}$ plasma: 17 reactions.

- $\mathrm{SiH}_{\mathrm{x}}-$ Nitrogen based gas-phase reactions: 7 reactions.

- $\mathrm{SiH}_{\mathrm{x}}$-Oxygen based gas-phase reactions: 21 reactions.

- Ar based reactions: 7 reactions. 
Hydrogen is not directly fed into the reactor but is generated in the plasma through dissociation of $\mathrm{SiH}_{4}$. Similarly $\mathrm{H}_{2} \mathrm{O}$ is also synthesized (apart from what comes from the $\mathrm{N}_{2}$ supply line, if any) in the plasma via gas-phase reactions between oxygen- and hydrogencontaining radicals.

The result of this modeling is plotted as concentration (in terms of density) of the resultant products from the above reactions as a function of reaction time. This is done by solving a system of nonlinear differential equations.

From the above results the relative concentration of $\mathrm{N}$ with respect to $\mathrm{H}_{2} \mathrm{O}$ (synthesized), $\mathrm{O}$ and $\mathrm{O}\left({ }^{1} \mathrm{D}\right)$ in the plasma is plotted. $\mathrm{H}_{2} \mathrm{O}$ (synthesized), $\mathrm{O}$ and $\mathrm{O}\left({ }^{1} \mathrm{D}\right)$ are the three major oxidizing agents in the plasma.

The ratios of $\mathrm{N} / \mathrm{H}_{2} \mathrm{O}, \mathrm{N} / \mathrm{O}$ and $\mathrm{N} / \mathrm{O}\left({ }^{1} \mathrm{D}\right)$ in the plasma were derived for each individual set of deposition parameters. The changes in these ratios in the gas phase can shift the equilibrium between heterogeneous nitridation and oxidation reactions (thereby controlling the surface nitridation and oxidation of the depositing films). This can heavily influence the N-to-O ratio in the deposited films. These ratios are compared to the prior experimental results from SE, XPS and FTIR as mentioned earlier. For a detailed description of the chemical modeling approach we refer to [1].

\subsection{Understanding the influence of process parameters on $\mathrm{SiO}_{\mathrm{x}} \mathrm{N}_{\mathrm{y}}$ properties}

For $\mathrm{SiO}_{\mathrm{x}} \mathrm{N}_{\mathrm{y}}$ to be suitable as a waveguide material it should first of all be uniform, homogeneous and flat, which can be achieved using CVD deposition. Further it should have the right composition, material density and chemical bonding. For this class of materials it is known that excess silicon leads to high absorption mainly at visible wavelengths. In the infrared spectral range, $\mathrm{Si}-\mathrm{H}$ and N-H bonds lead to absorption due to bond vibrations around $1500 \mathrm{~nm}$ [3].

In the following subsections, we analyze $\mathrm{SiO}_{\mathrm{x}} \mathrm{N}_{\mathrm{y}}$ films deposited under varying $\mathrm{SiH}_{4}$ fraction, deposition pressure, and $\mathrm{Ar} / \mathrm{N}_{2}$ ratio. We deduce the composition of these films from the SE (TaucLorentz model), XPS and FTIR measurements and relate this to the gas phase composition as calculated with our chemical model. 


\subsubsection{Influence of $\mathrm{SiH}_{4}$ fraction}
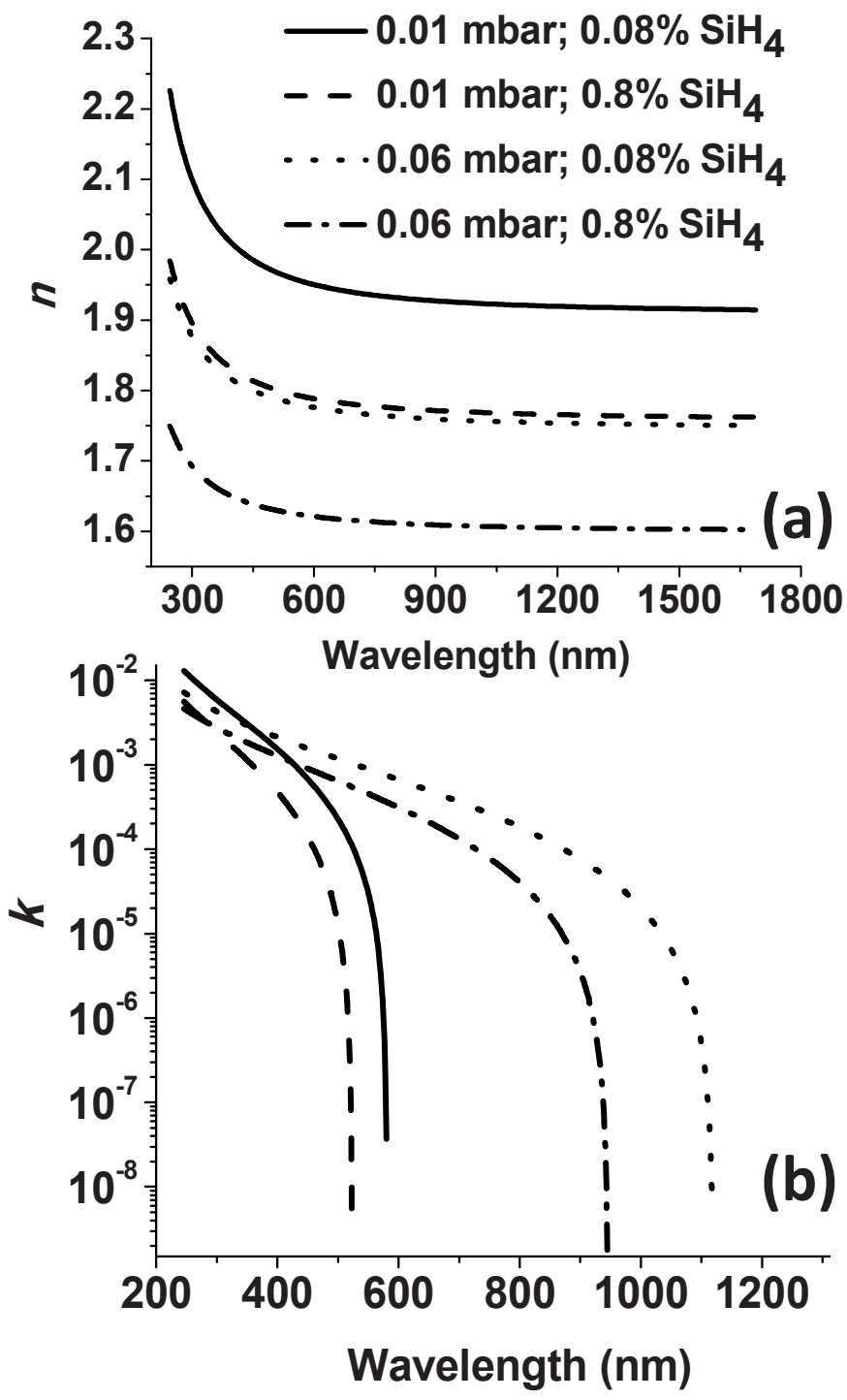

Fig 4.3: (a) The refractive index $n$ and (b) extinction coefficient $k$ as function of wavelength for two different deposition pressures and $\mathrm{SiH}_{4}$ fractions. The plasma power is $300 \mathrm{~W}$, the $\mathrm{Ar} / \mathrm{N}_{2}$ ratio is 4 , and the substrate temperature is $150{ }^{\circ} \mathrm{C}$. 
Figures $4.3 \mathrm{a}$ and $4.3 \mathrm{~b}$ illustrate that increasing the $\mathrm{SiH}_{4}$ fraction from $0.08 \%$ to $0.8 \%$ leads to a decrease in the refractive index $(n)$ and shift of $k$ towards lower wavelengths. The XPS analysis shows that this is unexpectedly accompanied by an increase in the film's oxygen concentration from $5 \%$ to $26 \%$ at $0.01 \mathrm{mbar}$ and $26 \%$ to $50 \%$ at 0.06 mbar. For reference, the atomic concentration of $\mathrm{N}, \mathrm{Si}$ and $\mathrm{O}$ versus the film thickness for a $\mathrm{SiO}_{\mathrm{x}} \mathrm{N}_{\mathrm{y}}$ film with $5 \%$ (average value) of oxygen is shown in Fig. 4.4.

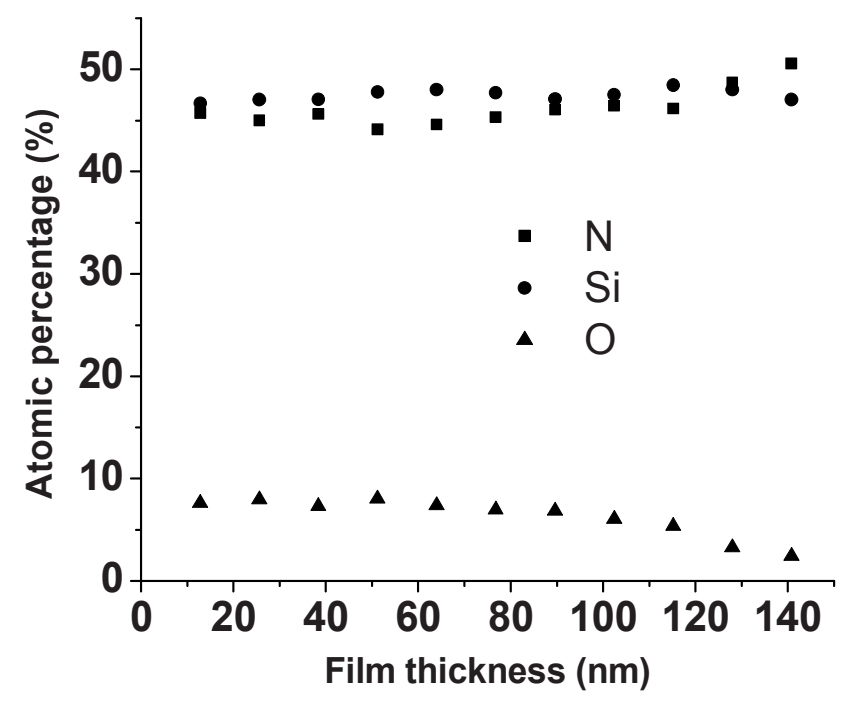

Fig 4.4: The atomic concentration of $N$, Si and $O$ versus the film thickness for $\mathrm{SiO}_{x} \mathrm{~N}_{y}$ film with 5\% (average value) of oxygen.

For $\mathrm{SiO}_{\mathrm{x}} \mathrm{N}_{\mathrm{y}}$ films the refractive index can vary between 1.48 $\left(\mathrm{SiO}_{2}\right)$ and $2.02\left(\mathrm{Si}_{3} \mathrm{~N}_{4}\right)$ depending on the composition of the material. An increase in the oxygen content can therefore result in a decrease of the refractive index as indicated in Fig. 4.3a. FTIR results as shown in Fig. 4.5 point to the growing prominence of both $\mathrm{Si}-\mathrm{O}-\mathrm{Si}$ stretching and bending vibrations with absorption peaks at around $1090 \mathrm{~cm}^{-1}$ and $800 \mathrm{~cm}^{-1}$ respectively. In addition, the Si-N peak shifts from $850 \mathrm{~cm}^{-1}$ to $940 \mathrm{~cm}^{-1}$ with decreasing intensity for films deposited at higher $\mathrm{SiH}_{4}$ fractions. This is caused by an increase of the oxygen content in the films corroborating the XPS results. 


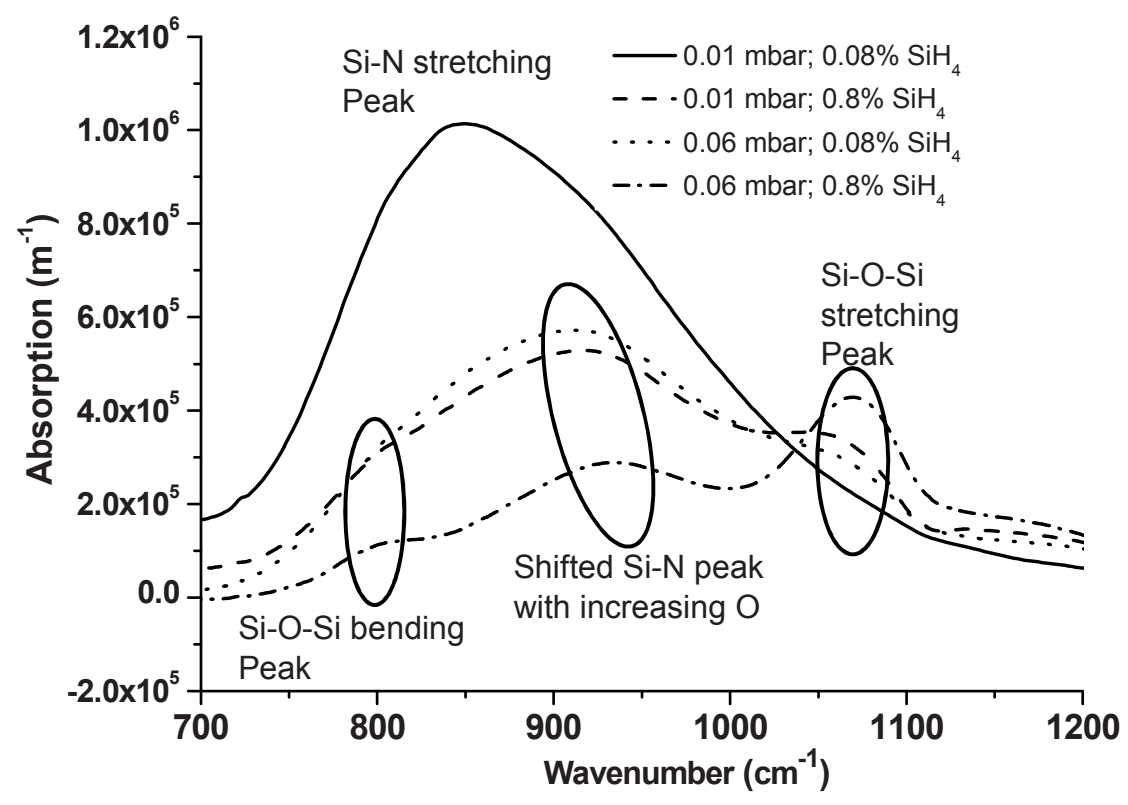

Fig 4.5: FTIR spectra showing shift of Si-N peak from $850 \mathrm{~cm}^{-1}$ to $940 \mathrm{~cm}^{-1}$ as well as growing prominence of Si-O-Si stretching and bending peaks at around $1090 \mathrm{~cm}^{-1}$ and 800 $\mathrm{cm}^{-1}$, respectively, due to either increase in the $\mathrm{SiH}_{4}$ fraction or deposition pressure.

Both increase of the $\mathrm{SiH}_{4}$ fraction and total gas pressure lead to a higher partial pressure of $\mathrm{SiH}_{4}$. The relation between the partial pressure and oxygen concentration in the films is however not obvious. This relation can be further clarified using the results obtained from chemical modeling. Fig. 4.6 shows the calculated change in the ratios of $\mathrm{N} / \mathrm{H}_{2} \mathrm{O}, \mathrm{N} / \mathrm{O}$ and $\mathrm{N} / \mathrm{O}\left({ }^{1} \mathrm{D}\right)$ in the plamsa during the change in the $\mathrm{SiH}_{4}$ fraction at a deposition pressure of $0.01,0.013,0.018$ (the additional two values were also considered due to the variation in the actual pressure as mentioned in section 4.1) and 0.06 mbar. It can be observed that there is a dramatic decrease in the ratio of $\mathrm{N} / \mathrm{H}_{2} \mathrm{O}$ for an increase in the $\mathrm{SiH}_{4}$ fraction in all cases. This supersedes the small changes observed in the N/O (a decrease) and $\mathrm{N} / \mathrm{O}\left({ }^{1} \mathrm{D}\right)$ (an increase) ratios. The absolute concentrations of $\mathrm{H}_{2} \mathrm{O}, \mathrm{O}$ and $\mathrm{O}\left({ }^{1} \mathrm{D}\right)$ for varying $\mathrm{SiH}_{4}$ fractions are shown in Fig. 4.7. It can be observed that at both deposition pressures $(0.01$ and 0.06 mbar), the concentration of $\mathrm{H}_{2} \mathrm{O}$ increases by almost 100 times with increasing $2 \% \mathrm{SiH}_{4}$-in-Ar flow from 10 to $100 \mathrm{sccm}$. Its level almost 
reaches the concentration levels of atomic oxygen.
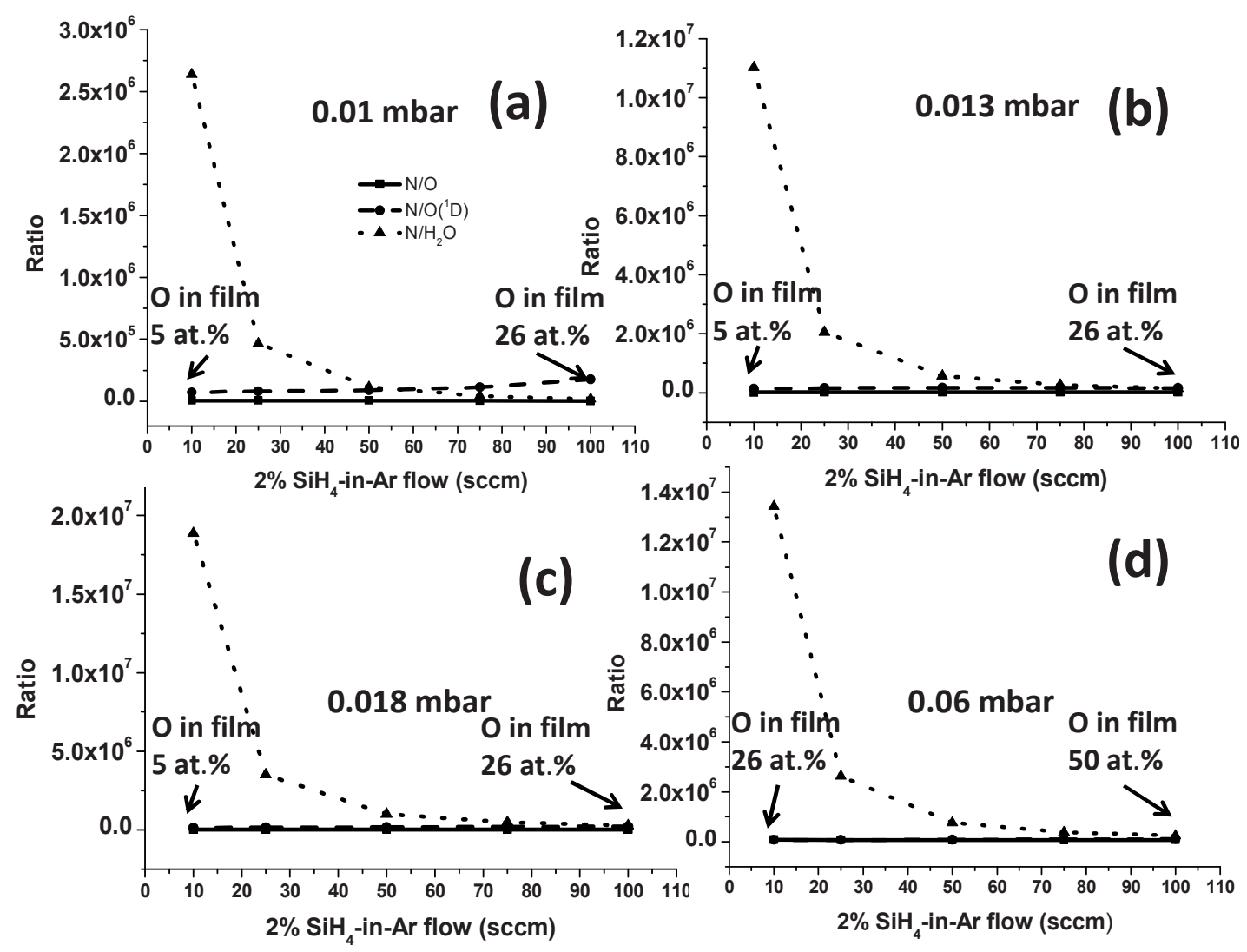

Fig 4.6: Calculated change in the ratios of $\mathrm{N} / \mathrm{H}_{2} \mathrm{O}, \mathrm{N} / \mathrm{O}$ and $N / O\left({ }^{1} D\right)$ in the plasma during the change in the $\mathrm{SiH}_{4}$ fraction for deposition pressures of (a) 0.01, (b) 0.013 mbar, (c) 0.018 and (d) 0.06 mbar using chemical modeling.

To note, the calculated water concentration is not the vapor supplied by the low-quality nitrogen source. As stated earlier in section 4.3 it is a product synthesized in the plasma by the secondary gas-phase reactions between oxygen- and hydrogen-containing radicals. In other words, the absolute increase of $\mathrm{H}_{2} \mathrm{O}$ concentration can be related to a higher concentration of one of these radicals or both. The relative increase, expressed in terms of lowering the $\mathrm{N} / \mathrm{H}_{2} \mathrm{O}$ ratio, can also be explained by a suppression of $\mathrm{N}_{2}$ dissociation as well as binding the active atomic nitrogen to other less-active 
complexes.
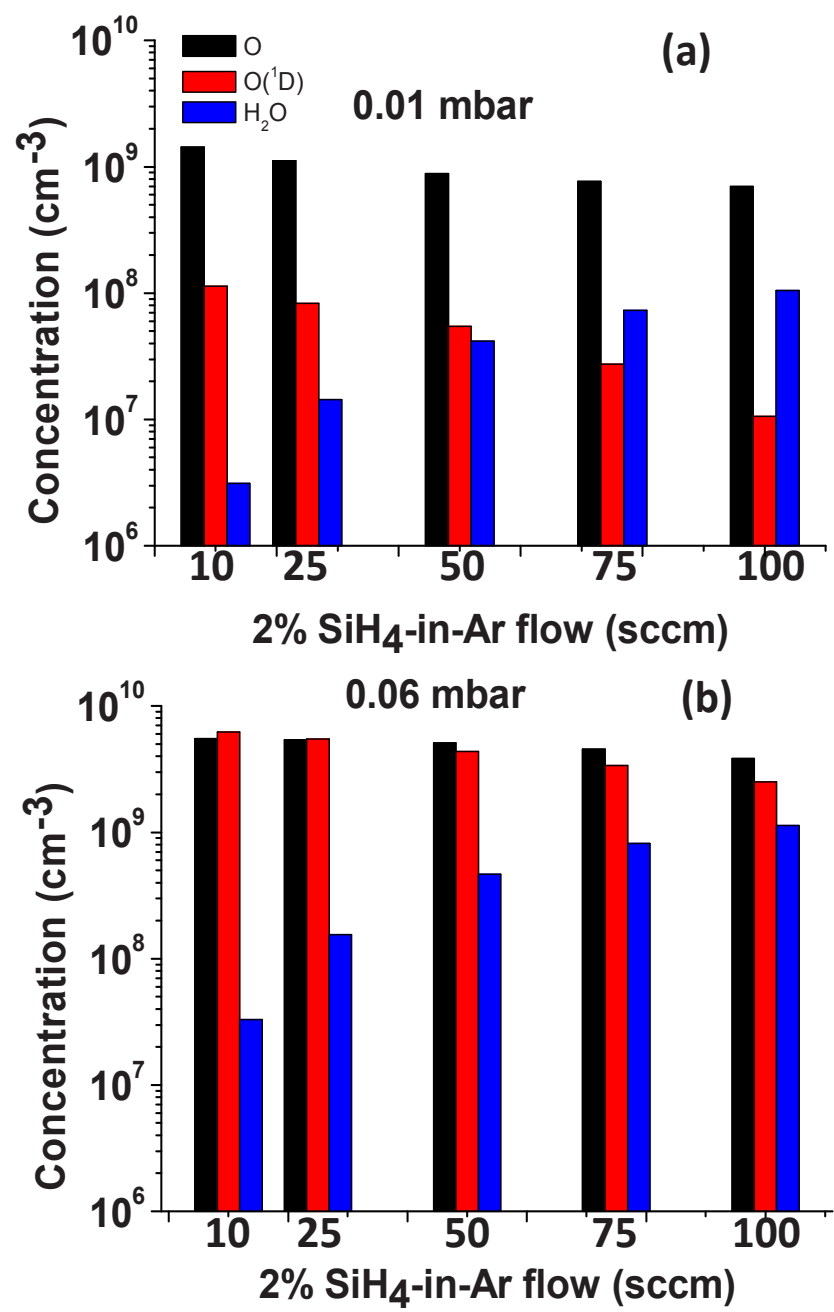

Fig 4.7: Calculated changes in the $\mathrm{H}_{2} \mathrm{O}, \mathrm{O}$ and $\mathrm{O}\left({ }^{1} \mathrm{D}\right)$ absolute concentration in the plasma during the change in the $\mathrm{SiH}_{4}$ fraction for deposition pressures of (a) 0.01 and (b) $0.06 \mathrm{mbar}$ using chemical modeling.

Nevertheless, according to the modeling, the increase in the $\mathrm{SiH}_{4}$ partial pressure leads to the formation of more molecular and atomic hydrogen, as a result of $\mathrm{SiH}_{4}$ dissociation. It is safe to assume that the amount of $\mathrm{O}_{2}$ supplied to the reactor remains the same as the 
$\mathrm{N}_{2}$ flow is fixed and much higher than the $\mathrm{SiH}_{4}$ flow. The result is the enhanced formation of $\mathrm{OH}$ and finally $\mathrm{H}_{2} \mathrm{O}$ in comparison to atomic nitrogen. The lowering $\mathrm{N} / \mathrm{H}_{2} \mathrm{O}$ ratio (and also N/all-O where all-O is the sum of all oxygen containing radicals) in the gas phase can eventually shift the equilibrium between heterogeneous nitridation and oxidation reactions towards surface oxidation. This will finally result in a higher incorporation of oxygen. The result highlights the possible influence of in-situ synthesized precursors initially not provided by the supply.

The improved film transparency (shift of $k$ towards lower wavelengths) at higher $\mathrm{SiH}_{4}$ fractions can occur also due to the increased oxygen incorporation. This is in line with the fact that pure $\mathrm{SiO}_{2}$ is more transparent than pure $\mathrm{Si}_{3} \mathrm{~N}_{4}$.

\subsubsection{Influence of deposition pressure}

From Figs. $4.3 \mathrm{a}$ and $4.3 \mathrm{~b}$ it can also be seen that the change in the deposition pressure from 0.01 mbar to 0.06 mbar results in a decrease of $n$ and a shift of $k$ towards higher wavelengths. This trend is noticeable for both fractions of $\mathrm{SiH}_{4}$ studied. The XPS analysis have shown that the pressure increase also causes more oxygen in the films: it rises from $5 \%$ to $26 \%$ at $0.08 \%$ of $\mathrm{SiH}_{4}$ and $26 \%$ to $50 \%$ at $0.8 \%$ of $\mathrm{SiH}_{4}$. This is directly seen in the SE results showing lower $n$ values for films deposited at the higher pressure (Fig. 4.3a). Accordingly, FTIR spectra in Fig 4.5 reveal the growing prominence of both Si-O-Si stretching and bending absorption peaks at $1090 \mathrm{~cm}^{-1}$ and $800 \mathrm{~cm}^{-1}$, respectively. Importantly, there is no clear appearance of the stretching peak for films deposited at $0.08 \%$ of $\mathrm{SiH}_{4}$ and 0.01 mbar having the lowest oxygen concentration of 5\%; although the broad and asymmetrical peak at $\sim 850 \mathrm{~cm}^{-1}$ can still point to the existence of Si-O bonds.

Results of the chemical modeling are shown in Fig. 4.8. Here it can be observed that the $\mathrm{N} / \mathrm{H}_{2} \mathrm{O}$ and $\mathrm{N} / \mathrm{O}\left({ }^{1} \mathrm{D}\right)$ ratios initially show an increasing trend to higher values in the range from 0.01 to 0.018 mbar followed by a gradual decreasing trend. To bear in mind, the pressure setting of 0.01 mbar hardly yielded a constant pressure reading as the latter varied between 0.01 and 0.018 mbar (section 4.1). Taking this effect into account the overall trend in $\mathrm{N} / \mathrm{H}_{2} \mathrm{O}$ and $\mathrm{N} / \mathrm{O}\left({ }^{1} \mathrm{D}\right)$ ratios can be considered to be decreasing. This supported the experimentally observed increase of oxygen content in the films. 
From Fig. 4.9 it can be observed at $0.08 \% \mathrm{SiH}_{4}$ fraction both the absolute concentrations of $\mathrm{H}_{2} \mathrm{O}$ and $\mathrm{O}^{1} \mathrm{D}$ increase by more than 10 times with increase in pressure from 0.01 to 0.06 mbar. Meanwhile at $0.8 \% \mathrm{SiH}_{4}$ fraction such a change in pressure causes the absolute concentration of $\mathrm{O}^{1} \mathrm{D}$ to increase by more than 100 times. The pressure set at 0.06 mbar and the $\mathrm{SiH}_{4}$ fraction at $0.8 \%$ leads to a comparable level of $\mathrm{H}_{2} \mathrm{O}, \mathrm{O}^{1} \mathrm{D}$ and $\mathrm{O}$ concentrations in the plasma. Films deposited under these conditions contain the highest oxygen atomic percentage of $50 \%$.

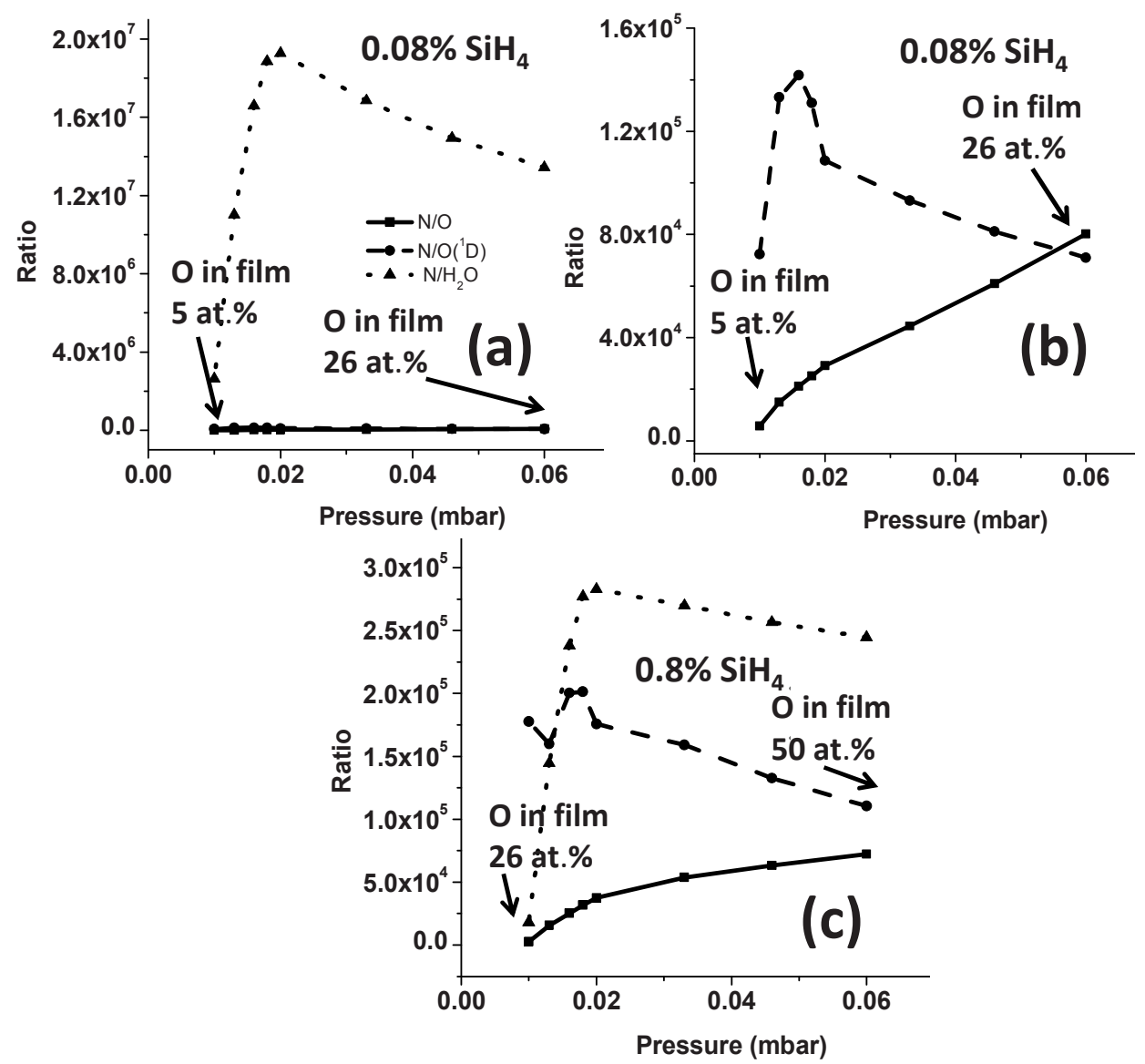

Fig 4.8: Calculated change in the ratios of $\mathrm{N} / \mathrm{H}_{2} \mathrm{O}, \mathrm{N} / \mathrm{O}$ and $N / O\left({ }^{1} D\right)$ as a function of the pressure in the plasma for a $\mathrm{SiH}_{4}$ fraction of (a) $0.08 \%$ (b) $0.08 \%$ with the focus on $N / O$ and $N / O\left({ }^{1} D\right)$ and (c) $0.8 \%$ using chemical modeling. 

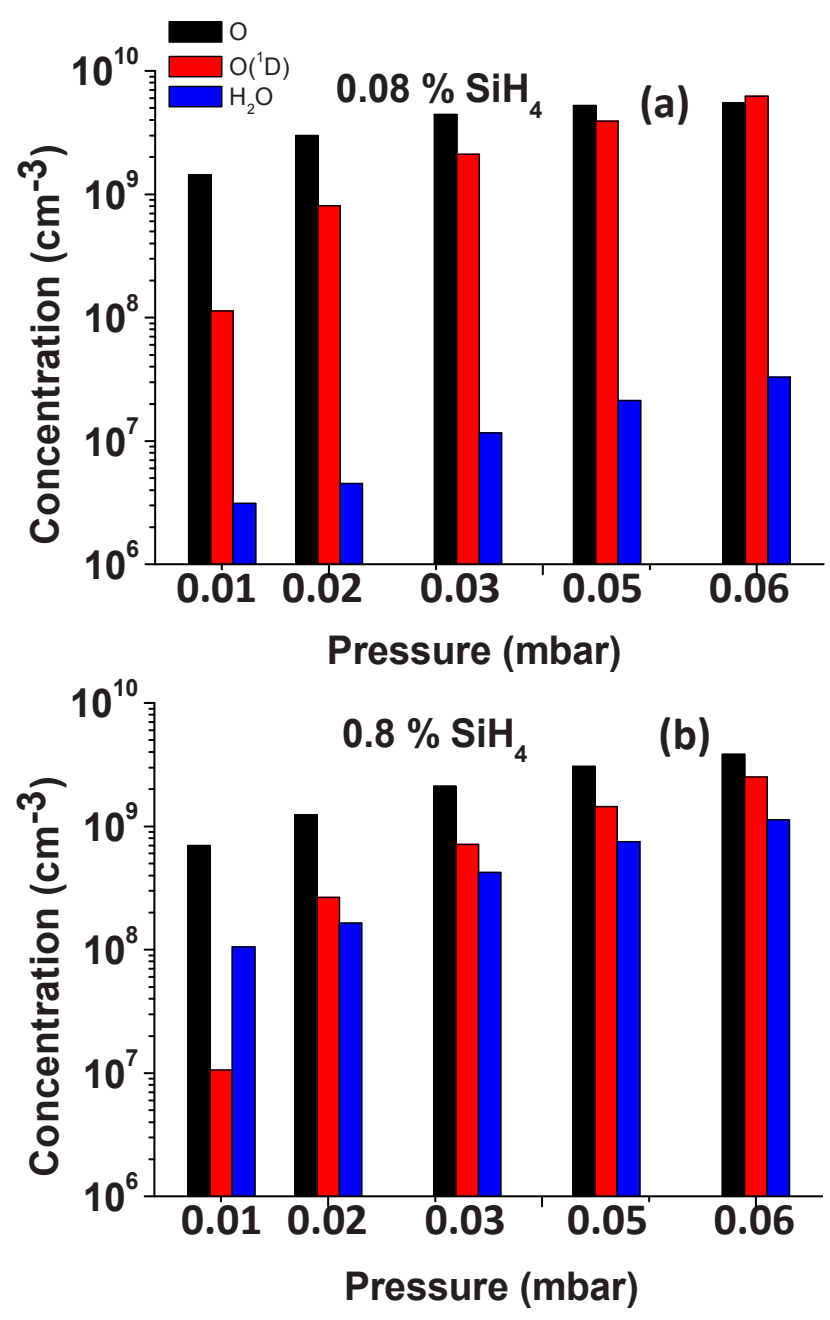

Fig 4.9: Calculated changes in the H2O, $O$ and $O\left({ }^{1} D\right)$ absolute concentrations in the plasma as function of the pressure for a $\mathrm{SiH}_{4}$ fraction of (a) $0.08 \%$ and (b) $0.8 \%$ using chemical modeling.

One should bear in mind that influence of the deposition pressure at a constant $\mathrm{SiH}_{4}$ fraction is different compared to varying the $\mathrm{SiH}_{4}$ fraction at a constant deposition pressure, as the pressure strongly influences the EEDF in the system studied. Namely, with increasing the pressure, the electron energy can significantly decrease. This shift of EEDF towards lower energies was measured 
experimentally in our ICPECVD reactor [4]. On the other hand, only changing (in a certain range) the $\mathrm{SiH}_{4}$ fraction, the EEDF can remain constant at constant pressure. As demonstrated by the modeling, increasing the pressure results in a lower excitation and dissociation of all plasma components (see ref [4] for further details including the effect of pressure on EEDF), with a higher impact on those requiring higher electron energies such as $\mathrm{Ar}$ and $\mathrm{N}_{2}$. To note, excitation of argon to its ${ }^{3} \mathrm{P}_{2}$ metastable state requires at least $11.55 \mathrm{eV}$ [5]. Although direct electron-impact dissociation of $\mathrm{N}_{2}$ and $\mathrm{O}_{2}$ is included in the model, dissociation by metastable argon is excluded due to the uncertainty of rate constants. This can eliminate the possible route to generate atomic $\mathrm{N}$ and $\mathrm{O}$ in the plasma, affecting the calculated ratio of the species.

The shift of $k$ towards higher wavelengths at higher deposition pressures demonstrated in Fig 4.2b (even with increasing oxygen content) can indicate the presence of excess $\mathrm{Si}$ in the deposited films. The latter agrees with the previous considerations: the dissociation of $\mathrm{SiH}_{4}$ (compared to $\mathrm{N}_{2}$ ) is less-suppressed by lowering the EEDF with increasing the pressure as the formation of $\mathrm{SiH}_{\mathrm{x}}$ radicals requires lower electron energies [4].

\subsubsection{Influence of Ar-to- $\mathrm{N}_{2}$ ratio}

Figs $4.10 \mathrm{a}$ and $4.10 \mathrm{~b}$ show the influence of the $\mathrm{Ar} / \mathrm{N}_{2}$ ratio on the values of $n$ and $k$. The total pressure and the $\mathrm{SiH}_{4}$ fraction remain fixed at $0.01 \mathrm{mbar}$ and $0.08 \%$, respectively. The total $\mathrm{Ar}+\mathrm{N}_{2}$ flow was maintained at $235 \mathrm{sccm}$ in all cases. The fixed parameters enable low oxygen incorporation $(\sim 5 \%)$ into the films and an appropriate value of $n$ above 1.95 at $632 \mathrm{~nm}$. The higher $n$ provides a larger refractive index contrast between the $\mathrm{SiO}_{\mathrm{x}} \mathrm{N}_{\mathrm{y}}$ core and its cladding layer, needed for the waveguide application. 

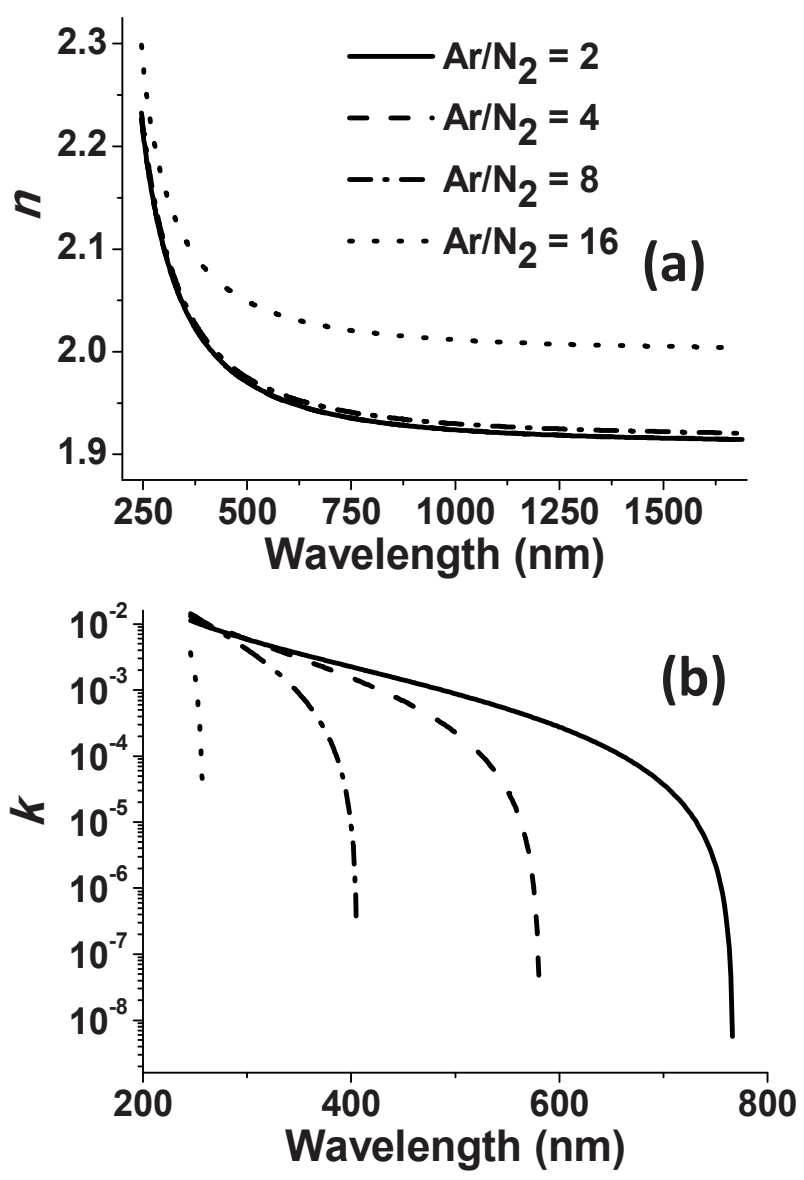

Fig 4.10: (a) The refractive index $n$ and (b) extinction coefficient $k$ as function of wavelength for different $\mathrm{Ar} / \mathrm{N}_{2}$

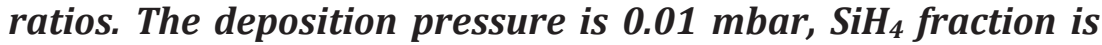
$0.08 \%$ and plasma power is $300 \mathrm{~W}$.

A gradual shift of the transparency edge (sharp decrease of $k$ in Fig 4.10b) towards lower wavelengths is observed with an increase of the $\mathrm{Ar} / \mathrm{N}_{2}$ ratio from 2 to 16 . This indicates a reduction of excess $\mathrm{Si}$ in the films. The mechanism behind it is the increased dissociation of $\mathrm{N}_{2}$ (via the pre-dissociation route) caused by inelastic collisions between excited metastable argon and ground-state nitrogen. An increase of the $\mathrm{Ar} / \mathrm{N}_{2}$ ratio leads to a higher relative concentration of the metastable argon (and therefore increased energy transfer), which enhances the pre-dissociation route. As demonstrated in [6], this high-efficiency dissociation mechanism can increase the amount of 
atomic nitrogen in the plasma even at a low concentration of the initial $\mathrm{N}_{2}$. The enhanced dissociation increases the $\mathrm{N} / \mathrm{SiH}_{\mathrm{x}}$ ratio in plasma, thereby shifting the N/Si ratio in the deposited films towards the stoichiometric value, i.e. giving less excess Si. However a small silicon excess still remains (which falls outside the detectable range of the spectroscopic ellipsometer) as indicated by the limited propagation length of $4 \mathrm{~cm}$ by $632 \mathrm{~nm}$ laser. Stoichiometric films could probably be obtained by further increasing the $\mathrm{Ar} / \mathrm{N}_{2}$ ratio; this was however practically hindered by the available mass flow controllers.

For $\mathrm{Ar} / \mathrm{N}_{2}$ ratios of 2,4 and 8 the $n$ remains unchanged. However, a clear increase of $n$ is observed for an $\mathrm{Ar} / \mathrm{N}_{2}$ ratio of 16 (Fig. 4.10a), accompanied by the strong reduction of $k$ in Fig 4.10b. The trend in $n$ indicates to an increased density of the films at the highest $\mathrm{Ar} / \mathrm{N}_{2}$ ratio. This conclusion is confirmed by the XPS results showing no change of the elemental film composition $\left(\mathrm{Si}_{0.45} \mathrm{O}_{0.05} \mathrm{~N}_{0.50}\right)$ while increasing the $\mathrm{Ar} / \mathrm{N}_{2}$ ratio from 4 to 16 . FTIR results additionally show no dependence of either Si-O-Si stretching or Si-O-Si bending absorption-peak intensities on the $\mathrm{Ar} / \mathrm{N}_{2}$ ratio.

\subsection{Measurement of propagation losses}

For determining the propagation losses in the infrared wavelength range, $\mathrm{SiO}_{\mathrm{x}} \mathrm{N}_{\mathrm{y}}$ films with a thickness of $400 \mathrm{~nm}$ are deposited onto a $100-\mathrm{mm}$ Si wafer with $8 \mu \mathrm{m}$ thermal oxide thereby creating a slab waveguide. Transverse-electric (TE) polarized light either from a 1300-nm laser diode or a tunable laser (1450-1600 nm) is coupled into the waveguide by a prism. The scattered light of the propagating fundamental TE mode is captured by a digital infrared camera across the diameter of the $100-\mathrm{mm}$ wafer. The losses are determined from the captured images. The prism coupling methodology is explained in section 2.9. 

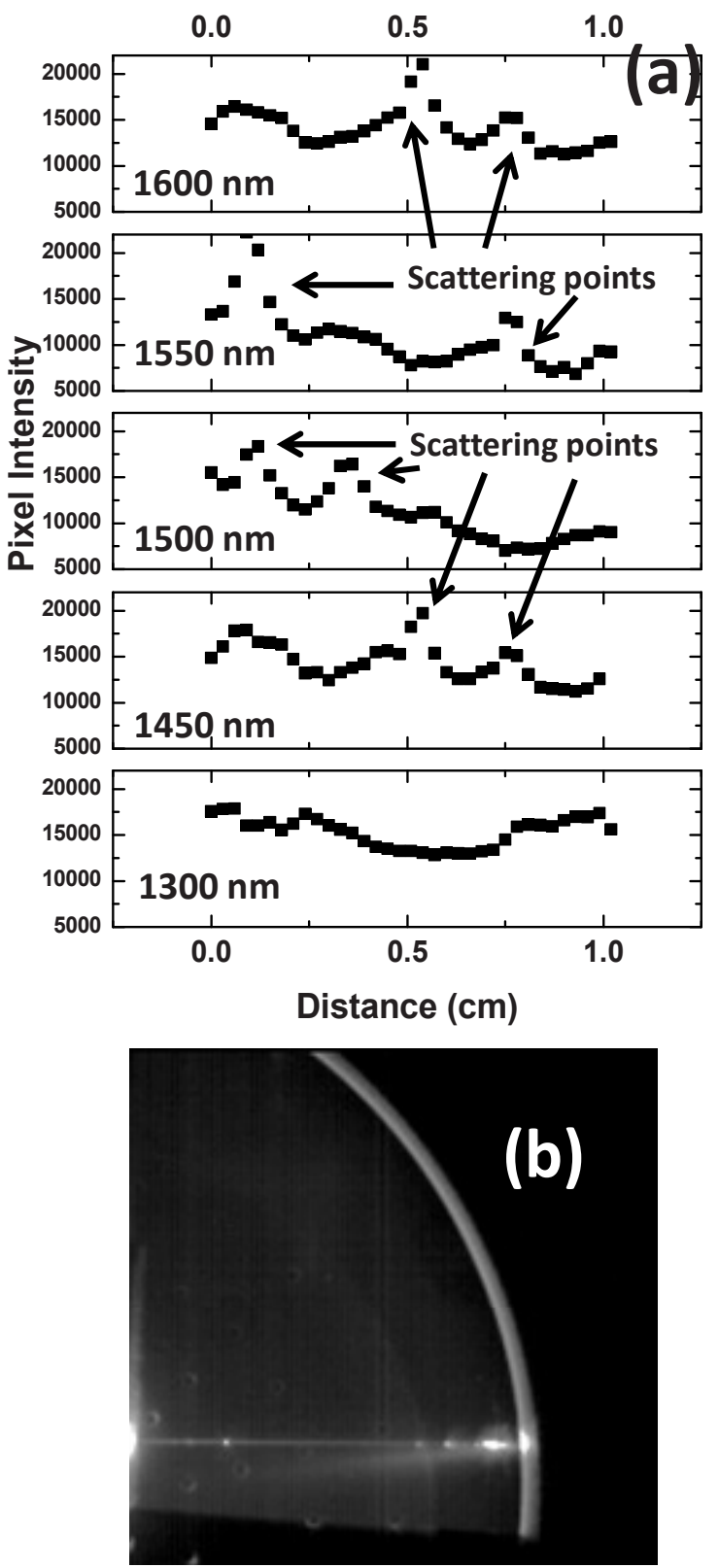

Fig 4.11: (a) The propagation of light measured in terms of pixel intensities over $1 \mathrm{~cm}$ distance; (b) An example of an image captured using the prism coupling set up with infrared camera (see section 2.9 for details on prism coupling). 
Table 4.1. Propagation losses of the optimized $\mathrm{Si}_{0.45} \mathrm{O}_{0.05} \mathrm{~N}_{0.50}$ film, compared to the loss values of non-annealed PECVD waveguide materials reported in the literature.

\begin{tabular}{cccccc}
\hline Type of Film & Process & $\begin{array}{c}\text { Process } \\
\text { Temperature }\left({ }^{\circ} \mathbf{C}\right)\end{array}$ & $\boldsymbol{\lambda}(\mathbf{n m})$ & $\begin{array}{c}\text { Propagation } \\
\text { loss }(\mathbf{d B} / \mathbf{c m})\end{array}$ & Ref \\
\hline $\mathrm{SiON}$ & PECVD & Not mentioned & 1510 & 30 & {$[6]$} \\
& & & 1550 & $>2.5$ & \\
$\mathrm{SiN}$ & PECVD & 350 & 1550 & $2.1 \pm 0.2$ & {$[7]$} \\
$\mathrm{a}-\mathrm{Si}$ & PECVD & 400 & 1520 & 4.4 & {$[8]$} \\
& & & 1550 & $3.2 \pm 0.2$ & \\
& & & 1620 & 1.9 & \\
$\mathrm{a}-\mathrm{Si}$ & PECVD & 220 & 1300 & 1.8 & {$[9]$} \\
$\mathrm{Si}_{0.45} \mathrm{O}_{0.05} \mathrm{~N}_{0.50}$ & ICPECVD & 150 & 1300 & $0.5 \pm 0.05$ & - \\
$($ this work) & & & 1450 & $0.7 \pm 0.07$ & \\
& & & 1500 & $2.4 \pm 0.20$ & \\
& & & 1550 & $1.6 \pm 0.20$ & \\
\hline
\end{tabular}

The waveguide material with the lowest $k$ and oxygen content obtained using 0.01 mbar pressure, $10 \mathrm{sccm}$ of $2 \% \mathrm{SiH}_{4}$-in-Ar flow with an ICP source power of $300 \mathrm{~W}$ and an $\mathrm{Ar} / \mathrm{N}_{2}$ ratio of 16 was used for measuring the propagation losses. The extracted value of $n$ for the film was $2.02 \pm 0.02$ at $\lambda=632 \mathrm{~nm}$ with an optical band gap of $4.8 \mathrm{eV}$. At $1300 \mathrm{~nm}$, we extracted $n$ of 1.99 and at 1550 and $1600 \mathrm{~nm} n$ of 1.98. By XPS the composition of the film was determined as $\mathrm{Si}_{0.45} \mathrm{O}_{0.05} \mathrm{~N}_{0.50}$, with the $\mathrm{Si} 2 \mathrm{p}$ peak appearing at $101.6 \mathrm{eV}$.

Figure 4.11 shows the propagation of light over a distance of $1 \mathrm{~cm}$ for different wavelengths accompanied by a sample of one of the captured images. From these graphs losses as low as $0.5 \pm 0.05 \mathrm{~dB} / \mathrm{cm}, 1.6 \pm 0.2 \mathrm{~dB} / \mathrm{cm}$ and $0.6 \pm 0.05 \mathrm{~dB} / \mathrm{cm}$ are measured at $1300 \mathrm{~nm}, 1550 \mathrm{~nm}$ and $1600 \mathrm{~nm}$ wavelength, respectively.

These results are compared with earlier works in Table 4.1 and Fig 4.12. Our films are deposited at the lowest temperature but still show the lowest propagation losses (without any additional annealing) at various IR wavelengths in comparison to similar studies.

The comparison is however complicated by the fact that some 
results are obtained from slab waveguides (this work and ref. [7]), and some from patterned waveguides (refs. [8]-[10]). To be precise, in ref. [8], there were no details regarding sidewall roughness. The authors mainly relate the losses due to absorption. From ref [9], the losses were taken for a channel waveguide which was $500 \mathrm{~nm}$ wide. The losses are considered mostly due to the absorption in a-Si core (as the TE polarized light is mainly confined within the a-Si core). The sidewall roughness therefore plays a less crucial role in this case. Authors have also shown that as the channel width is decreased, the losses increase due to pronounced scattering of light at the sidewalls caused by the expansion of the light mode. In ref [10], the authors note that the losses obtained were mainly due to absorption and radiation.

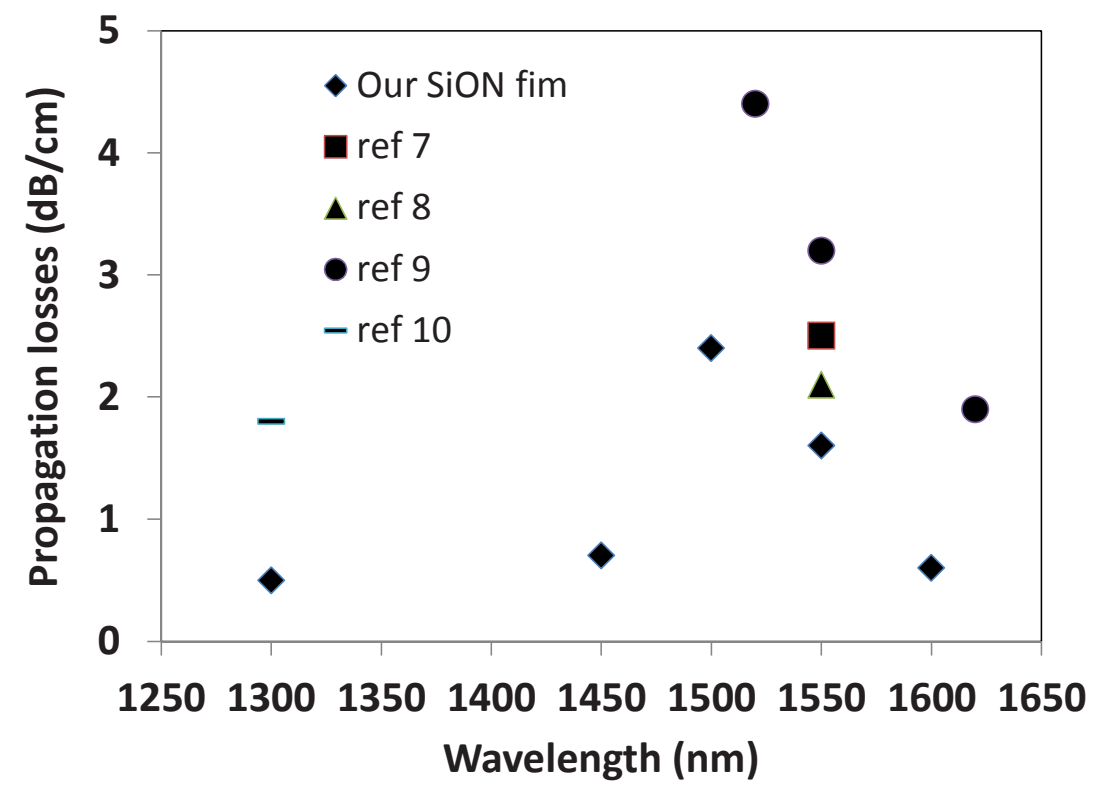

Fig 4.12: Comparison of the propagation losses between our SiON film and the literature data as mentioned in Table 4.1.

\subsection{FTIR analysis on $\mathrm{Si}-\mathrm{H}$ and $\mathrm{N}-\mathrm{H}$ bonds}

$\mathrm{Si}-\mathrm{H}$ and $\mathrm{N}-\mathrm{H}$ bonds, resulting in a broad absorption peak at about $1500 \mathrm{~nm}$ and extending to $1550 \mathrm{~nm}$, can cause high optical losses in this widely used range for optical telecommunication [3]. To enable the material application as a waveguide, it is imperative to 
control the concentration of these bonds.

In our study, none of the deposited films show any presence of $\mathrm{Si}-\mathrm{H}$ absorption peak at around $2200 \mathrm{~cm}^{-1}$ which indicates a very low concentration of the bonds (Fig 4.13). However, the broad absorption peak in the range of $3150-3500 \mathrm{~cm}^{-1}$ with the maximum at $3300 \mathrm{~cm}^{-1}$, which is widely attributed to N-H stretching vibrations, needs further analysis. This is due to the fact that the (stretching) O-H absorption peak can also appear in the same range and has similar shape [11].

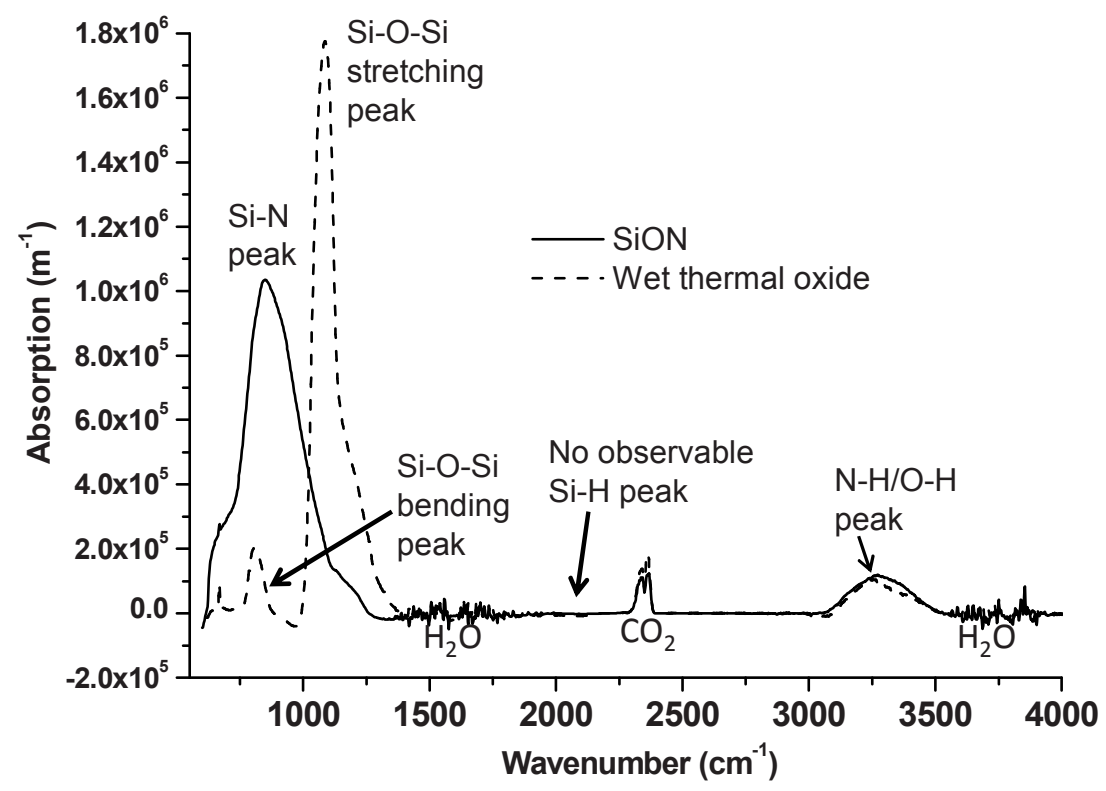

Fig 4.13: Comparison of FTIR spectra of our $\mathrm{Si}_{0.45} \mathrm{O}_{0.05} \mathrm{~N}_{0.50}$ film with $\mathrm{SiO}_{2}$ thermally grown at $1150{ }^{\circ} \mathrm{C}$ in wet ambient wet thermal oxide.

In our case we attribute the peak at $3300 \mathrm{~cm}^{-1}$ mainly to $\mathrm{O}-\mathrm{H}$ bonds. This is based on the following considerations/analysis. First, for the best-quality $\mathrm{Si}_{0.45} \mathrm{O}_{0.05} \mathrm{~N}_{0.50}$ films, the losses measured were $2.6 \mathrm{~dB} / \mathrm{cm}$ and $1.6 \mathrm{~dB} / \mathrm{cm}$ at $1500 \mathrm{~nm}$ and $1550 \mathrm{~nm}$, respectively. If we entirely assign the peak at $3300 \mathrm{~cm}^{-1}$ to $\mathrm{N}-\mathrm{H}$ bonds and calculate the concentration of bonded hydrogen atoms based on the Lanford and Rand method [12], the value will exceed $9.05 \times 10^{22}$ atoms $/ \mathrm{cm}^{3}$. Such a high concentration should induce very high losses [13], which is not the case for our films. Second, a comparison between our ICPECVD $\mathrm{Si}_{0.45} \mathrm{O}_{0.05} \mathrm{~N}_{0.50}$ and a wet-thermal $\mathrm{SiO}_{2}$ is shown in Fig 
4.10. One can see the similarity of the two peak shapes at $3300 \mathrm{~cm}^{-1}$. Both O-H (in Si-O-H) and N-H (in Si-N-H) bond vibrations tend to produce nearly-identical absorption peaks. Third, annealing our samples at $800{ }^{\circ} \mathrm{C}$ and further at $1100{ }^{\circ} \mathrm{C}$ did not result in any significant change in the absorption peak at $3300 \mathrm{~cm}^{-1}$. As the $\mathrm{N}-\mathrm{H}$ bonds are broken at these high temperatures $[13,14]$ this should have affected the peak. This analysis indirectly suggests that the peak appearing at $3300 \mathrm{~cm}^{-1}$ mainly corresponds to $\mathrm{O}-\mathrm{H}$ bonds.

We therefore have successfully realized the deposition of $\mathrm{SiO}_{\mathrm{x}} \mathrm{N}_{\mathrm{y}}$ films in plasma with non-measurable concentrations of Si-H and $\mathrm{N}-\mathrm{H}$ bonds. The dangling bonds of silicon are in this case terminated by $\mathrm{O}-\mathrm{H}$ groups, which do not interfere with the 1500 $1550 \mathrm{~nm}$ range important for the telecommunication. It is to be noted that $\mathrm{O}-\mathrm{H}$ bonds do cause optical losses at around $1400 \mathrm{~nm}$ [15]; this wavelength is however sparsely used for optical applications.

\subsection{Testing CMOS compatibility on Timepix chips}

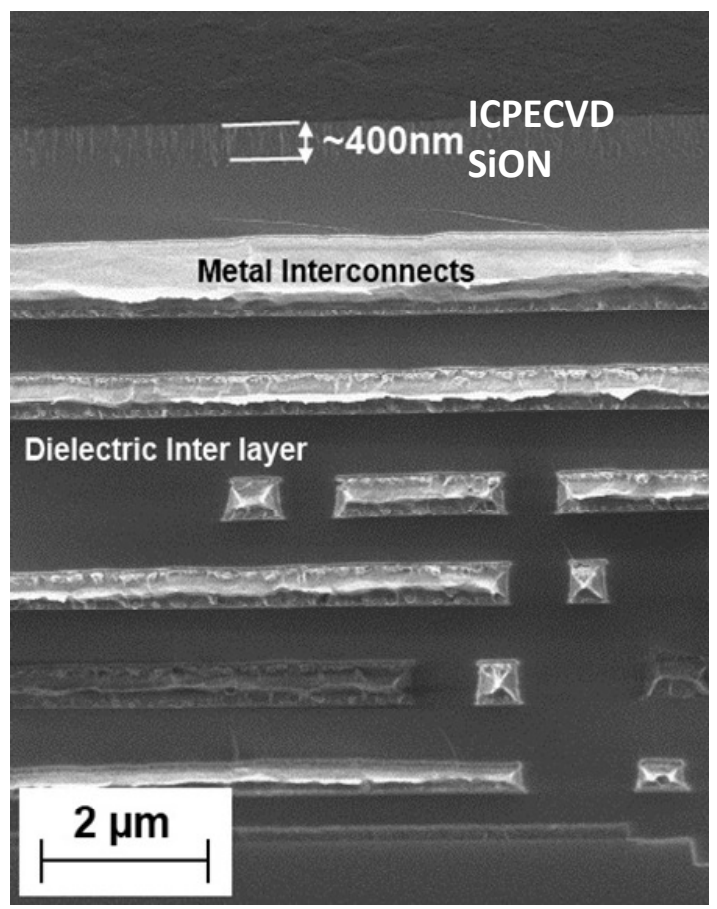

Fig 4.14. Cross-sectional SEM image of the functional CMOS chip with the deposited $\mathrm{SiO}_{x} \mathrm{~N}_{y}$ layer on top.

Materials for Monolithic Integration of Optical Functions on CMOS 
To test CMOS compatibility, optimized $\mathrm{Si}_{0.45} \mathrm{O}_{0.05} \mathrm{~N}_{0.50}$ films with a thickness of $400 \mathrm{~nm}$ are deposited on the front side of Timepix [16] chips (mixed-signal chips made in a commercial $0.25-\mu \mathrm{m}$ CMOS technology). A $2.2 \mathrm{~cm}^{2}$ Timepix chip, with its analog and digital test modes, is well suited to investigate any possible functionality loss [17]. The most probable causes for chip failure would be the temperature-stress, mechanical stress and plasma damage [18].

A scanning electron microscope (SEM) image with a crosssection of the chip is shown in Fig 4.14. Digital and analog functionality tests [16], performed prior to and after the deposition process by using an automated probe station, were identical: the chip (containing 550 transistors) remained fully functional.

\subsection{Conclusions}

$\mathrm{SiO}_{\mathrm{x}} \mathrm{N}_{\mathrm{y}}$ waveguide materials were deposited using remote plasma ICPECVD at $150{ }^{\circ} \mathrm{C}$ in a low-quality nitrogen environment which had traces of $\mathrm{O}_{2}$ and $\mathrm{H}_{2} \mathrm{O}$ in it. We have investigated the influence of $\mathrm{SiH}_{4}$ fraction, deposition pressure and $\mathrm{Ar} / \mathrm{N}_{2}$ flow-ratio on the properties of the deposited films. Increasing the $\mathrm{SiH}_{4}$ fraction as well as the deposition pressure enhanced the incorporation of oxygen into the films. A higher $\mathrm{SiH}_{4}$ fraction led to an increased formation of $\mathrm{H}_{2} \mathrm{O}$ and $\mathrm{OH}$ species in the plasma whereas a higher deposition pressure led to lowering the electron energy distribution function thereby suppressing the dissociation of $\mathrm{N}_{2}$ (which requires higher electron energies) in comparison with $\mathrm{O}_{2}$. An increase of the $\mathrm{Ar} / \mathrm{N}_{2}$ flow-ratio reduced the extinction coefficient $k$ of the films due to the enhanced formation of atomic nitrogen in the plasma. This decreased the amount of excess $\mathrm{Si}$ in the films by shifting the N/Si ratio towards the stoichiometric value.

Propagation losses as low as $0.5 \pm 0.05 \mathrm{~dB} / \mathrm{cm}$ at $1300 \mathrm{~nm}$ wavelength are measured, improving the current state of the art in silicon-based waveguide fabrication by a factor of three. The films contain non-measurable concentrations of $\mathrm{Si}-\mathrm{H}$ and $\mathrm{N}-\mathrm{H}$ groups as the potential dangling bonds of silicon are terminated by O-H groups. The latter is beneficial because these groups do not cause an absorption in the telecommunication range of 1500-1550 nm.

Furthermore, CMOS compatibility of the $\mathrm{SiO}_{\mathrm{x}} \mathrm{N}_{\mathrm{y}}$ fabrication 
process is shown by functional testing of a $0.25-\mu \mathrm{m}$-technology chip. We conclude that the ICPECVD technique enables the threedimensional integration of photonic waveguides with microelectronics.

\section{References}

1. A.Y. Kovalgin, A. Boogaard, R.A.M. Wolters, ECS Trans. 25, 429 (2009).

2. A.Y. Kovalgin, A. Boogaard, I. Brunets, J. Holleman, J. Schmitz, Surf. Coat. Technol. 201, 8849 (2007).

3. J. Aarnio, P. Heimala, M. Del Giudice, and F. Bruno, Electron. Lett. 27, 2317 (1991).

4. A. Boogaard, A.Y. Kovalgin, A.A.I. Aarnink, J. Holleman, R.A.M. Wolters, I. Brunets, and J. Schmitz, ECS Trans. 2, 181 (2007).

5. T. Makabe, Z. Petrovic, Plasma Electronics: Applications in microelectronic device fabrication (CRC Press Taylor \& Francis Group, 2006), pp. 78-79 and 94-96.

6. S. E. Alexandrov and A. Y. Kovalgin, Advanced Mater. Opt. Electr. 8, 13 (1998).

7. M. Fadel, M. Bülters, M. Niemand, E. Voges, and P. M. Krummrich, J. Lightwave Technol. 27, 698 (2009).

8. S. C. Mao, S. H. Tao, Y. L. Xu, X. W. Sun, M. B. Yu, G. Q. Lo and D. L. Kwong, Opt. Express 16, 20809 (2008).

9. S. Zhu, G. Q. Lo, and D. L. Kwong, Opt. Express 18, 25283 (2010).

10. G. Cocorullo, F. G. Della Corte, I. Rendina, C. Minarini, A. Rubino, and E. Terzini, Opt. Lett. 21, 2002 (1996).

11. P. Larkin, Infrared and Raman Spectroscopy; Principles and Spectral Interpretation (Elsevier, 2011), pp. 117-134.

12. W. Lanford and M. Rand, J. Appl. Phys. 49, 2473 (1978).

13. R. Germann, H. W. M. Salemink, R. Beyeler, G. L. Bona, F. Horst, I. Massarek, and B. J. Offrein, J. Electrochem. Soc. 147, 2237 (2000).

14. C. M. M. Denisse, K. Z. Troost, F. H. P. M. Habraken, W. F. van der Weg and M. Hendriks, J. Appl. Phys. 60, 2543 (1986).

15. N. Uchida and N. Uesugi, J. Lightwave Technol. 4, 1132 (1986).

16. X. Llopart, R. Ballabriga, M. Campbell, L. Tlustos, W. Wong, 
Nucl. Instr. Meth. A 581, 485 (2007).

17. J. Lu, A.Y. Kovalgin, K.H.M. van der Werf, R.E.I. Schropp,

J. Schmitz, IEEE Trans. Electron Devices 58, 2014 (2011).

18. J. Schmitz, Nucl. Instr. Meth. A 576, 142 (2007). 


\section{Chapter 5}

\section{Conclusions and Recommendations}

\subsection{Conclusions}

In this thesis we have carried out process and materials studies to enable the fabrication of high quality germanium-silicon and silicon oxynitride films with the aim to realize high-performance optical waveguides and photodetectors. The process temperatures were well below $450{ }^{\circ} \mathrm{C}$ (at the substrate level). This low temperature makes the realization of optical interconnects on CMOS possible.

\subsubsection{Germanium-Silicon (GeSi)}

In this work amorphous- $\mathrm{Ge}_{0.85} \mathrm{Si}_{0.15}$ films, deposited using LPCVD at $430{ }^{\circ} \mathrm{C}$, were crystallized using a pulsed green laser (a $\mathrm{Yb}$ :YAG thin disk laser with $\lambda=515 \mathrm{~nm}$ ). Preformed amorphous$\mathrm{Ge}_{0.85} \mathrm{Si}_{0.15}$ lines in the film with a pitch of $3 \mu \mathrm{m}$ were used to steer the grain growth. Laser process conditions were chosen to obtain so called sequential super-lateral growth during crystallization.

Electron backscatter diffraction results showed that a substantial part of the surface area was covered by grains longer than $2 \mu \mathrm{m}$. To be precise, grains with length in the range of $10-25 \mu \mathrm{m}$ covered $30 \%$ of the surface area. The range further extended to $35 \mu \mathrm{m}(5 \%)$ and up to $50 \mu \mathrm{m}(2 \%)$ with a total of $64 \%$ longer than $2 \mu \mathrm{m}$. In comparison, crystal grains of up to approx. $2 \mu \mathrm{m}$ in length were reported in high- $x$ $\mathrm{Ge}_{x} \mathrm{Si}_{1-x}$ films so far using pulsed green laser crystallization. 
The preformed lines helped in steering the formation of the large elongated grains within a $3 \mu \mathrm{m}$ wide space (i.e. constraining the grain growth only between the lines). When $\mathrm{p}$-i-n photodetectors are fabricated in good alignment with the preformed lines, a current path free of grain boundaries can be created between the $\mathrm{p}+$ and $\mathrm{n}+$ regions. This can improve the efficiency of the photodetection by avoiding grain boundaries which act as recombination centers.

In the absence of the preformed lines the deviation in the grain's length axis was as high as $26^{\circ}$ resulting in unfavorable positioning of grain boundaries.

The crystallization process also led to a substantial strain of $3.4 \%$ due to the occurrence of residual tensile stress in the resultant films, in particular at the surface. Possibly band gap narrowing was observed through spectroscopic ellipsometry analysis, likely the result of strain in the layer. This phenomenon (if confirmed true by other techniques such as photoluminescence spectroscopy) can enhance the usability of $\mathrm{GeSi}$ in near- and mid-infrared photodetection.

In addition laser annealing led to successful electrical activation of both p-type (boron) and n-type (As and P) ion-implanted dopants in poly- $\mathrm{Ge}_{0.85} \mathrm{Si}_{0.15}$ films which otherwise failed using furnace and rapid thermal annealing. The laser dopant activation again allows low temperature to be maintained at the substrate level enabling fabrication of a complete $\mathrm{p}-\mathrm{i}-\mathrm{n}$ photodetector on CMOS.

\subsubsection{Silicon Oxynitride (SiON)}

Inductively coupled PECVD was used for depositing silicon oxynitride waveguide material using $\mathrm{SiH}_{4}$ and $\left(99.999 \%\right.$ pure) $\mathrm{N}_{2}$ diluted with $\mathrm{Ar}$ at a low substrate temperature of $150{ }^{\circ} \mathrm{C}$. The resultant films $\left(\mathrm{Si}_{0.45} \mathrm{O}_{0.05} \mathrm{~N}_{0.50}\right)$ showed propagation losses as low as $0.5 \pm 0.05 \mathrm{~dB} / \mathrm{cm}, 1.6 \pm 0.2 \mathrm{~dB} / \mathrm{cm}$ and $0.6 \pm 0.05 \mathrm{~dB} / \mathrm{cm}$ at $1300 \mathrm{~nm}$, $1550 \mathrm{~nm}$ and $1600 \mathrm{~nm}$ wavelength, respectively as obtained using the prism coupling technique. This improved the current state of the art in silicon-based waveguide fabrication for $1300 \mathrm{~nm}$ wavelength by a factor of three.

To demonstrate the CMOS post-process compatibility, $\mathrm{Si}_{0.45} \mathrm{O}_{0.05} \mathrm{~N}_{0.50}$ films were deposited on top of a $0.25 \mu \mathrm{m}$ technology 
chip resulting in no deterioration in the chip's functionality. This shows that $\mathrm{Si}_{0.45} \mathrm{O}_{0.05} \mathrm{~N}_{0.50}$ films deposited at a low substrate temperature of $150{ }^{\circ} \mathrm{C}$ also likely to have low mechanical stress. This successful experiment shows the possibility of integrating photonic waveguides with photodetectors on CMOS.

The low losses at $1550 \mathrm{~nm}$ wavelength are attributed to the low (non-measurable) concentrations of Si-H and N-H bonds in the film. It is demonstrated that there is a likelihood of the potential dangling bonds of silicon being terminated by $\mathrm{O}-\mathrm{H}$ groups. This is beneficial as the overtones of $\mathrm{O}-\mathrm{H}$ vibrations do not interfere in the telecommunication range of $1500-1550 \mathrm{~nm}$.

Additionally films deposited at higher $\mathrm{Ar} / \mathrm{N}_{2}$ flow-ratio contained less excess Si. This opens the possibility of using this material also for visible wavelengths, for instance in labs-on-chip.

\subsection{Recommendations}

\subsubsection{Germanium-Silicon (GeSi)}

Three recommendations are provided as following:

(a) Reducing the laser beam width.

It has been shown in literature and also pointed out in this thesis that the width of the laser beam strongly influences the super lateral growth. Smaller laser widths are known to suppress the spontaneous nucleation at the center of the irradiated region thereby allowing the elongation of the lateral grains. The minimum width used in this thesis was $15 \mu \mathrm{m}$ (limited due to the constraints of the laser equipment). If the width can be reduced to sub-10 $\mu \mathrm{m}$, this might help in further elongating the lateral grains.

(b) Photoluminescence spectroscopy.

In this thesis we have reported a tensile strain of $3.4 \%$ in laser crystallized $\mathrm{Ge}_{0.85} \mathrm{Si}_{0.15}$. Possibly band-gap narrowing occurs as a result of this strain in the layer (observed via spectroscopic ellipsometry). Although this phenomenon is widely reported in literature, it would be nicer to prove this effect conclusively in our case using photoluminescence spectroscopy.

Materials for Monolithic Integration of Optical Functions on CMOS 
(c) Testing on CMOS.

Laser processing is already used for manufacturing TFTdisplays and thin-film solar panels on glass showcasing its ability to keep the substrate at a lower temperature. However for practical demonstration, laser crystallization of GeSi films should be performed on a CMOS chip. This may however require additional optimization of laser parameters.

\subsubsection{Silicon Oxynitride (SiON)}

Two recommendations are provided as following:

(a) Further increase in $\mathrm{Ar} / \mathrm{N}_{2}$ ratio.

A high $\mathrm{Ar} / \mathrm{N}_{2}$ ratio during deposition reduces the excess silicon in the resultant films. A higher ratio above 16 (considering that there is sufficient $\mathrm{N}_{2}$ flow to the system for deposition) could likely result in a perfectly stoichiometric silicon oxynitride film (i.e. film with no excess silicon) but was practically hindered by the available mass flow controllers. It would be interesting to know if such a process window exists.

(b) Analysis of $\mathrm{N}_{2}$ supply-line using mass spectrometry.

The source of oxygen in the films is related to the contamination in the long $\mathrm{N}_{2}$ supply line of the clean-room. It would be interesting to know the actual concentrations of the contaminants in the $\mathrm{N}_{2}$ line $\left(\mathrm{O}_{2}\right.$ or $\mathrm{H}_{2} \mathrm{O}$ or both) entering the deposition system. This may further help in verifying the modeling results. Better would be to supply uncontaminated $\mathrm{N}_{2}$ and separately control the concentration of oxygen-containing gases.

\subsubsection{Further integration}

(a) Fabrication of photodetectors.

Using electron backscatter diffraction we have provided the evidence of the existence of large elongated grains with controlled location and density of grain boundaries in the laser crystallized films. The next step would be to fabricate photodetectors on these films and compare their electrical performance to those fabricated on crystallized films without preformed lines as well as as-deposited poly-GeSi

Materials for Monolithic Integration of Optical Functions on CMOS 
films. This would help to quantitatively measure the improvements obtained as a result of controlled grain formation.

(b) Fabrication of waveguide structures.

Using the prism-coupling technique we have shown low propagation losses in $\mathrm{Si}_{0.45} \mathrm{O}_{0.05} \mathrm{~N}_{0.50}$ slab waveguides. However for practical applications the losses in channel/strip or rib waveguide structures should be quantified.

(c) Integration of photodetectors and waveguides on CMOS.

After the separate optimization of photodetectors and waveguides (steps (a) and (b)), the next step would be their integration on a flat silicon wafer and measurement and optimization of the combined waveguide-detector performance. A possible scenario has been shown in section 3.1. If successful this can further be replicated on CMOS. 


\section{Summary}

Miniaturization in microelectronics has tremendously brought down the cost per function apart from bringing other benefits such as increased processing power. However this miniaturization in complementary metal oxide semiconductor (CMOS) is predicted to end by the year 2018, as forecast by the International Technology Roadmap for Semiconductors. Therefore it becomes necessary to look for other technologies and methodologies to further advance microelectronics. To this end many researchers are developing novel devices such as tunnel field effect transistors as well as exploring new channel materials such as molybdenite $\left(\mathrm{MoS}_{2}\right)$.

Besides the search for better channel materials and devices, one can further improve a CMOS chip by integrating new functionalities to it (prior to packaging). Examples of such functionalities include sensing and actuating (both physical and chemical), energy harvesting or optical data processing and communication.

There are many techniques available to realize the integration of new functionalities. One among them is CMOS post-processing. Here the new components are monolithically fabricated on top of CMOS. This technique does not require additional lateral space as it is done in the third dimension (i.e. vertical stacking).

However post-processing a CMOS chip should be done at temperatures below $450{ }^{\circ} \mathrm{C}$ to avoid metal interconnect damage. This limits the choice of processing techniques that can be used for depositing materials. The quality of the materials is also usually compromised as the deposition temperature is brought down.

This thesis, under the program called MEMPHIS (Merging Electronics and Micro \& Nano Photonics in Integrated Systems http://www.smartmix-memphis.nl/), focusses on the selection and optimization of materials and low temperature processes to realize waveguides and photodetectors on top of CMOS.

Waveguides and photodetectors are important components of an optical interconnect used for digital data transfer. Optical 
interconnects provide faster communication in comparison to their electrical counterparts.

For both waveguides and photodetectors we considered materials that can promise good properties in a wide spectrum of wavelengths ranging from visible to $1800 \mathrm{~nm}$. This was done to broaden the range of possible applications for the studied materials.

Germanium-silicon was chosen as the material for photodetector. By varying the $\mathrm{Ge}$ to $\mathrm{Si}$ ratio one can cover a wide spectral range from visible to $1800 \mathrm{~nm}$ which satisfies our broader interests. We used $\mathrm{Ge}_{0.85} \mathrm{Si}_{0.15}$ as our starting point for the specific case of $1150 \mathrm{~nm}$ light detection under the program MEMPHIS.

Mono-crystalline and amorphous germanium-silicon was not considered for this work. The former requires high deposition temperature while the latter exhibits considerable non-idealities (such as an ill-defined band gap).

A better alternative was polycrystalline germanium-silicon. It can be readily deposited at low temperature using techniques such as low pressure chemical vapor deposition. However the uncontrolled formation of grain boundaries in as-deposited polycrystalline germanium-silicon can deteriorate the performance of photodetectors (such as p-i-n photo-diodes) that are fabricated on it. For instance by hindering carrier transport and providing recombination centers. Therefore controlling the location and density of grain boundaries can provide an effective way of improving device performance.

To this purpose, pulsed-laser crystallization was chosen to crystallize amorphous $\mathrm{Ge}_{0.85} \mathrm{Si}_{0.15}$ (deposited using low pressure chemical vapor deposition at $430{ }^{\circ} \mathrm{C}$ ) for producing polycrystalline films. A short (green) laser pulse with relatively long repetition time was used. Preformed lines were applied to help steer the grain growth during crystallization thereby controlling the location of grain boundaries. This process allowed maintaining the substrate at a low temperature.

Using laser crystallization we managed to produce polycrystalline $\mathrm{Ge}_{0.85} \mathrm{Si}_{0.15}$ which has $64 \%$ of the surface area covered by grains longer than $2 \mu \mathrm{m}$ and reaching up to $50 \mu \mathrm{m}$ at predetermined locations. Photodetectors fabricated in good alignment 
with the preformed lines are likely to have better performance as current paths free of grain boundaries can be created.

Additionally we showed the successful activation of p- and ntype dopants in germanium-silicon using laser annealing. This process enables complete fabrication of photodetectors under low substrate temperature.

On the other hand silicon oxynitride was chosen as the material for waveguides. It has (a) a wide transparency range from visible to infrared wavelengths (b) low mechanical stress (which reduces the probability of damaging the CMOS chip) and (c) tunable refractive index (which can be tuned to a value closer to silicon nitride to reach better light confinement).

Silicon oxynitride can be deposited using low temperature techniques such as plasma enhanced chemical vapor deposition. However plasma-deposited films have high hydrogen content in the form of Si-H and N-H bonds. These bonds cause high optical losses at wavelengths around 1500-1550 nm. Usually post deposition annealing $\left(>1000^{\circ} \mathrm{C}\right)$ is required to remove hydrogen from the films.

In this work, we used inductively-coupled plasma enhanced chemical vapor deposition to deposit $\mathrm{Si}_{0.45} \mathrm{O}_{0.05} \mathrm{~N}_{0.50}$ films at $150{ }^{\circ} \mathrm{C}$. This deposition technique (with suitably configured permanent magnets) produces high density plasma which is known to provide better quality films compared to conventional plasma depositions. The resultant films showed propagation losses as low as $0.5 \pm 0.05 \mathrm{~dB} / \mathrm{cm}, 1.6 \pm 0.2 \mathrm{~dB} / \mathrm{cm}$ and $0.6 \pm 0.05 \mathrm{~dB} / \mathrm{cm}$ at $1300 \mathrm{~nm}$, $1550 \mathrm{~nm}$ and $1600 \mathrm{~nm}$ wavelength, respectively.

Further we demonstrated the CMOS post-process compatibility by depositing $\mathrm{Si}_{0.45} \mathrm{O}_{0.05} \mathrm{~N}_{0.50}$ films on top of a $0.25 \mu \mathrm{m}$ technology chip, resulting in no deterioration in the chip's functionality.

To quickly summarize, this thesis consists of five chapters. In chapter 1 we motivate our choice of materials and processing techniques. Chapter 2 presents the basic principles behind several material characterization techniques used in this thesis. Chapter 3 and 4 provides a detailed process and material study of germaniumsilicon and silicon oxynitride films respectively followed by conclusions and recommendations in chapter 5. 


\section{Samenvatting}

Geometrische schaling van micro-elektronische componenten heeft voor een indrukwekkende daling van de prijs per functie gezorgd, voornamelijk bij de gangbare CMOS technologie. Deze miniaturisering zal echter eens ophouden. De International Technology Roadmap for Semiconductors voorspelt dat dit punt al in 2018 wordt bereikt. Daarna zijn andere materialen en andere technologieën nodig voor verdere ontwikkeling van de microelektronica. Om dit mogelijk te maken wordt nu al veel onderzoek gedaan aan nieuwe componenten zoals transistoren gebaseerd op tunneling transport (Tunnel FETs) en nieuwe materialen zoals molybdenite $\left(\mathrm{MoS}_{2}\right)$ voor geleidende kanalen.

Een andere manier om micro-elektronica verder te ontwikkelen is het toevoegen van nieuwe functionaliteit aan bestaande CMOS componenten en schakelingen. Er kunnen allerlei nieuwe elementen worden toegevoegd zoals sensoren en actuatoren (zowel fysisch als chemisch), energieopwekking en -opslag of optische data verwerking en communicatie.

De nieuwe mogelijkheden kunnen op uiteenlopende wijzen aan het systeem worden toegevoegd. In dit werk richten we ons op methoden waarbij de nieuwe elementen direct aan de chip zelf toegevoegd worden door middel van nabewerkingstappen. De onderdelen vormen één geheel met het silicium substraat en de CMOS componenten, we spreken van monolithische CMOS nabewerking. Dit gebeurt voorafgaand aan het verzagen en ommantelen van de afzonderlijke chips. Dit proces vereist geen extra ruimte op de substraten, er wordt gestapeld in de derde dimensie.

Bij alle nabewerkingstappen van een CMOS substraat mag de temperatuur niet boven de $450{ }^{\circ} \mathrm{C}$ uitkomen om schade te voorkomen aan metalen onderdelen van de chip. Dit zorgt voor een drastische beperking in het palet aan processtappen dat gebruikt kan worden, vooral voor depositie van materialen. De kwaliteit van gedeponeerde lagen wordt door de bank genomen lager als de procestemperatuur omlaag gebracht wordt. 
Dit proefschrift is gebaseerd op onderzoek dat is uitgevoerd in het MEMPHIS programma (Merging Electronics and Micro \& Nano Photonics in Integrated Systems - http://www.smartmixmemphis.nl/). Het onderzoek richt zich op de keuze voor en optimalisering van materialen en lage-temperatuur bewerkingen voor het maken van golfgeleiders en fotodetectoren bovenop CMOS.

Golfgeleiders (waveguides) en fotodetectoren zijn essentiële onderdelen voor optische schakelingen voor digitaal data transport. Een optisch systeem zal een hogere overdrachtssnelheid kunnen toestaan dan de gebruikelijke elektrische verbindingen.

Voor zowel de golfgeleiders als de fotodetectoren kijken we naar materialen die werkzaam zijn in een breed spectrum met golflengtes van zichtbaar licht tot $1800 \mathrm{~nm}$. Hierdoor wordt het toepassingsgebied zo groot mogelijk.

Voor fotodetectie is gekozen voor germanium-silicium. Door de $\mathrm{Ge} / \mathrm{Si}$ verhouding aan te passen kan de gevoeligheid worden ingesteld over een breed golflengtebereik. In het MEMPHIS programma is specifiek naar detectoren voor licht van $1150 \mathrm{~nm}$ gekeken, hiervoor wordt $\mathrm{Ge}_{0.85} \mathrm{Si}_{0.15}$ gebruikt.

Monokristallijn en amorf germanium-silicium zijn buiten beschouwing gelaten. In het eerste geval vanwege de hoge depositietemperatuur, in het tweede geval vanwege een ongewenste verdeling van het energiebandenspectrum.

Polykristallijn germanium-silicium is een beter alternatief. Het kan gemakkelijk worden aangebracht bij lage temperatuur met lagedruk chemische opdamptechnieken (LP-CVD). De vorm en grootte van kristallieten is moeilijk te beheersen. Dit kan nadelig zijn voor de werking van fotodetectoren zoals $\mathrm{p}$-i-n fotodiodes. De overgangen tussen de kristallieten hinderen het ladingstransport en dragen bij aan verhoogde recombinatie van ladingsdragers. De oplossing voor dit probleem is het vooraf opleggen van de morfologie van de gekristalliseerde laag.

Dit wordt gedaan door het kristalliseren van amorfe $\mathrm{Ge}_{0.85} \mathrm{Si}_{0.15}$ lagen met behulp van gepulsde laser stralen. Het gaat om korte pulsen van een groene laser die na relatief lange tijd worden herhaald. De Ge-Si lagen worden gedeponeerd met LP-CVD bij een temperatuur van $430{ }^{\circ} \mathrm{C}$. Van te voren is een lijnstructuur aangebracht in de $\mathrm{Ge}-\mathrm{Si}$ 
laag om de vorming van kristallieten in een bepaalde richting te duwen. Het volledige proces kan bij een lage temperatuur worden uitgevoerd.

Met laser-kristallisatie kan een polykristallijne laag gevormd worden van $\mathrm{Ge}_{0.85} \mathrm{Si}_{0.15}$ waarbij $64 \%$ van het oppervlak wordt ingenomen door kristallieten van minstens $2 \mu \mathrm{m}$ tot $50 \mu \mathrm{m}$ op vooraf gekozen plaatsen. Als in die gebieden fotodetectoren worden gemaakt die zijn uitgericht op de aan de kristalstructuur opgelegde voorkeursrichting zullen deze componenten een veel betere werking hebben doordat de stroom niet gehinderd wordt door kristalovergangen.

Daarnaast hebben we aangetoond dat met zogeheten laser annealing, het kortstondig en zeer lokaal uitgloeien, zowel p- als ntype dotering kan worden geactiveerd in germanium-silicium.

Met deze twee processen kan de volledige vervaardiging van fotodectoren gedaan worden op een lage temperatuur.

Voor de golfgeleiders is silicium-oxynitride gebruikt. Dit materiaal heeft een goede transparantie over een breed golflengtebereik van zichtbaar licht tot infrarood, een lage mechanische spanning zodat de lagen het substraat niet zullen beschadigen en een brekingsindex die kan worden gevarieerd zodat deze die van silicium-nitride kan benaderen, wat tot minder verlies van licht leidt.

Silicium-oxynitride kan worden aangebracht met behulp van plasma ondersteunde chemisch opdampen (PE-CVD). Zulke plasmagedeponeerde lagen hebben echter vaak een hoog waterstof gehalte door de vele Si-H en N-H bindingen. Deze bindingen leiden tot grote optische verliezen voor golflengtes van $1500-1550 \mathrm{~nm}$. De waterstof atomen kunnen worden verwijderd door uitgloeien bij hoge temperatuur $\left(>1000^{\circ} \mathrm{C}\right)$.

In dit onderzoek gebruiken we chemische opdamptechnieken ondersteund met inductief gekoppeld plasma (IC-CVD) om lagen van $\mathrm{Si}_{0.45} \mathrm{O}_{0.05} \mathrm{~N}_{0.50}$ te deponeren bij een temperatuur van niet meer dan $150{ }^{\circ} \mathrm{C}$. Deze techniek maakt gebruik van permanente magneten, hiermee wordt een hoge plasma dichtheid bereikt. Dit zorgt voor betere kwaliteit van de gedeponeerde lagen dan conventionele plasmaopwekking. De verkregen lagen hebben een 
uitdovingcoëfficiënt van $0.5 \pm 0.05 \mathrm{~dB} / \mathrm{cm}, 1.6 \pm 0.2 \mathrm{~dB} / \mathrm{cm}$ en $0.6 \pm 0.05 \mathrm{~dB} / \mathrm{cm}$ bij een golflengte van respectievelijk $1300 \mathrm{~nm}$, $1550 \mathrm{~nm}$ en $1600 \mathrm{~nm}$.

Daarnaast laten we zien dat deze $\mathrm{Si}_{0.45} \mathrm{O}_{0.05} \mathrm{~N}_{0.50}$ lagen direct op CMOS substraten kunnen worden aangebracht. De nabewerking heeft geen enkele nadelige invloed op de werking van de $0.25 \mu \mathrm{m}$ CMOS circuits.

Dit proefschrift bevat vijf hoofdstukken. In het eerste hoofdstuk staat de motivatie voor de keuzes die gemaakt zijn aangaande de gebruikte materialen en processtappen. Het tweede hoofdstuk gaat over de werking van een aantal karakterisatietechnieken die in het proefschrift worden gebruikt. Het derde en het vierde hoofdstuk beschrijft een gedetailleerd onderzoek aan respectievelijk germanium-silicium en silicium-oxynitride lagen. In het laatste hoofdstuk volgen conclusies en aanbevelingen. 


\section{Acknowledgements}

I dedicate the following pages to the people who have greatly influenced my life during the course of my PhD.

First I would like to thank my promotor Jurriaan Schmitz for offering me a position in his group. This opportunity provided me with great experiences, both personal and professional. I really appreciate and thank him for all the time and effort that he has put in reviewing this thesis. His encouragement and kind support helped me in completing this thesis in a relatively short period.

I also thank my assistant promotor Alexey Kovalgin for his motivation and kind support. As my daily supervisor I really liked his approach to solving problems and interpreting data from experiments which is unique and inspiring. I also appreciate and thank him for all the encouragement that he provided during the course of writing this thesis.

I would also like to thank my other committee members for taking time and reading this thesis. I really appreciate and thank them for their feedback which greatly helped in refining this thesis.

The work presented here has benefitted from very strong external collaborations. I thank Peter Oesterlin from INNOVAVENT $\mathrm{GmbH}$ for the work on laser crystallization. Although he had an extremely busy schedule for most part of the year he always managed to accommodate us for our experiments, which has formed a major part of this thesis. I also thank René de Kloe from EDAX for providing us with electron backscatter diffraction. This technique played a major role in the analysis of laser crystallized films. Thanks to Kerstin Wörhoff and Sergio Vázquez-Córdova from IOMS group for helping us with the characterization of waveguides using prism coupling. Finally thanks to Spee Diederick from Utrecht University for helping us with Fourier transform infrared spectroscopy.

I would also like to thank Tom Aarnink from our research group for the introduction to the cluster deposition system, Robert 
Wijn from Nanolab (MESA+) for his help in the cleanroom and my ex-colleague Ihor Brunets for the introduction to laser crystallization. Further I would also like to thank Lan Anh Tran for atomic force microscopy, Gerard Kip for X-ray photoelectron spectroscopy and Mark Smithers for scanning electron microscopy, all from MESA+ Institute for Nanotechnology.

Apart from work, I made very good friends during my stay in Enschede. One among them is Annemiek. I am extremely grateful for her kindness and benevolence. Her optimism and cheerfulness brought smile on my face even on the toughest day. She is definitely the sweetest person that I have met until now.

I must also thank my paranymphs Joost and Giulia who are also my dearest friends. Both of them have been very kind and considerate towards me since the beginning of my stay in the Netherlands. Any time I needed help both of them came forward instantly. I have had wonderful moments with them and thank them wholeheartedly for supporting me with the preparations of my defense. I must also thank Pietro especially for making me one of his paranymphs. I thoroughly enjoyed those moments. I should also thank him for single-handedly helping me move to my new apartment at Enschede. It is by no surprise that I like Giovanni (son of Pietro and Giulia) very much.

I thank Victor and Shuo who are also my dearest friends and have supported me at all times. I thoroughly enjoyed the innumerous Chinese dinners that I got invited to. I also thank them for introducing me to different genres of movies.

I must also thank Buket for all her encouragement and support and especially for her delicious cheese cake. I should also thank my other two friends Jiwu and Wei Cheng for their wonderful support.

I also appreciate and thank my friend Alessandro for all his help during my move to 's-Hertogenbosch and hosting me in Eindhoven for a couple of weeks during my initial training at Philips. I should also thank Marcin and Weronika for all the coffees, cakes and sweets that I am often getting invited to.

I also thank my ex-colleagues (listed here in no particular order) Bijoy, Sumy, Vidhu, Naveed, Boni, Natalie, Alfons, JanLaurens, Sander, Tom, Ray, Cora, Remke, Jiahui, Hao, Harish, Erik, 
Rob, Arjen, Deepu, Anubha, Miquel and Dirk for all their kind support and encouragement during my stay at the university. Special thanks to Bijoy and Sumy for all the additional help and support.

My sincere thanks to Ronald Dekker from Philips for introducing me to SRON and thanks to Giulia for introducing me to Ronald Dekker. I must also thank my group leader Henk Hoevers, my supervisor Marcel Bruijn and my colleagues Marcel Ridder, Tonny Coppens, Jennifer Serkei and Ton van der Linden at SRON for their kind support and for being extremely considerate and flexible throughout the course of writing my thesis.

Special thanks to Dipen and Ruta from Leiden for hosting me numerous times at their place and offering me wonderful Indian food. I thoroughly enjoyed their company and especially the group holiday trip to Barcelona.

I am extremely indebted to my parents (Mr. Rangarajan Seshadri and Mrs. Janaki Rangarajan) and my sister Shashi for their love and wonderful support. My sister has always been a source of inspiration to me and has always been there for me at difficult times. Their consistent encouragement has helped me a lot in completing this thesis. I would also like to thank God for everything that I have in my life.

Lastly I would like to thank all the readers of this thesis for showing interest in this work. Please kindly accept my apologies in case I have missed someone in this acknowledgment.

Balaji Rangarajan

's-Hertogenbosch, 2013 


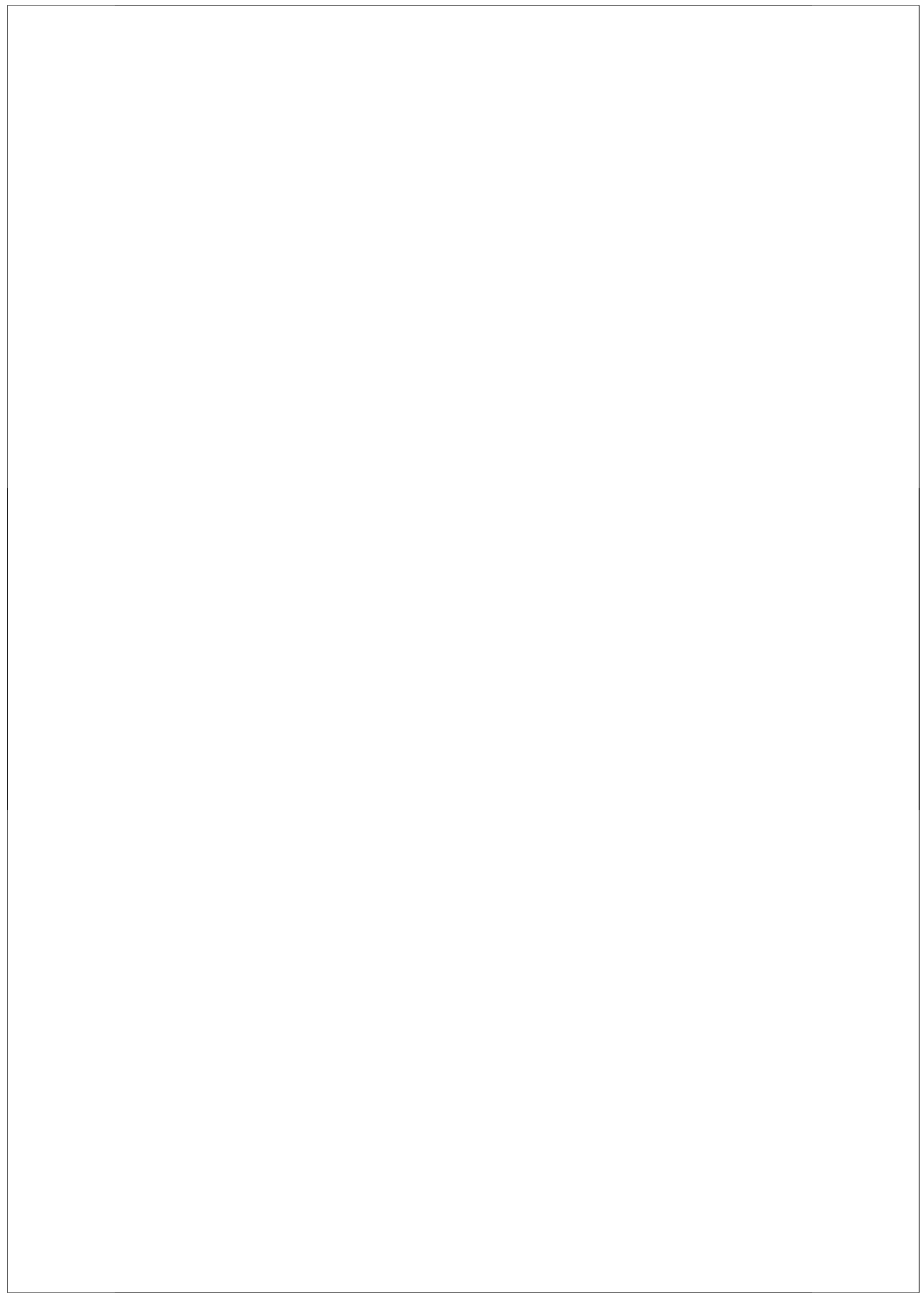


